\title{
Outdooraktivitäten und damit zusammenhängende Einrichtungen im Sommer und in den Übergangszeiten
}

\author{
Coordinating Lead Authors (CLAs) \\ Ulrike Pröbstl-Haider \\ Lead Authors (LAs) \\ Ulrike Pröbstl-Haider, Claudia Hödl, Kathrin Ginner
}

Contributing Authors (CAs)

Martin Falk, Florian Borgwardt, Herbert Formayer, Marc Olefs, Kai Illing

\subsection{Allgemeine Entwicklung und Trends}

Der Sommertourismus in Österreich trägt wesentlich zu der großen Bedeutung des Tourismus insgesamt bei. So hat die Zahl der Nächtigungen in den Sommermonaten in Österreich 2018 erneut einen Höchstwert erreicht. Mit bisher 68,67 Mio. Nächtigungen liegt die Sommersaison 2018 (Mai bis September) um 2,2 \% über dem Vorjahresniveau. Auch die Zahl der Ankünfte stieg in der vergangenen Sommersaison um 2,9\% auf 21,70 Mio. (Statistik Austria 2018). Mehr Nächtigungen wurden auch im September 2018, also außerhalb der eigentlichen Sommersaison festgestellt. Im September 2018 nahm die Zahl der Gäste um 2,0 \% auf 3,86 Mio. zu, Gästenächtigungen stiegen um 1,4 \% auf 11,24 Mio. Zu diesem Ergebnis trugen die ausländischen Herkunftsmärkte mit einem Plus von 1,6\% auf 7,86 Mio. bei. Die Nächtigungszahlen wichtiger Herkunftsländer, wie Deutschland $(+1,2 \%)$, Schweiz und Liechtenstein $(+3,5 \%)$ sowie der Niederlande $(+2,1 \%)$, erhöhten sich weiter. Die Zahl der inländischen Gästenächtigungen stieg ebenfalls um $0,9 \%$ auf 3,38 Mio. (Statistik Austria 2018).

Bei dieser sogenannten Renaissance der Sommerfrische geht es - wie sozialpsychologische Arbeiten hervorheben weniger um eine Präferenz für ländliche Räume und attraktivere Kulturlandschaften, sondern vielmehr um authentische oder authentisch empfundene Räume für Selbstreflexion, Erlebnisse, neue Erkenntnisse und kreative Gestaltung als touristische Gegenwelt zu einem „entfremdeten, anonymen, ökonomisierten und ungesunden Alltag" (Lippmann 2016, S. 206; May 2017). Unterstützt werden diese sozialpsychologischen Motive aber auch durch attraktive Angebote im Sommer und politisch instabile Verhältnisse in bisherigen Urlaubsländern wie Tunesien, Türkei und anderen Ländern im Nahen Osten. Hitzestress im Sommer in städtischen Räumen kommt als weiteres wichtiges Motiv hinzu (Weber et al. 2018).
Diese Trend kann man auch in aktuellen Studien zu den Reisemotiven inländischer Urlauberinnen und Urlauber verfolgen. Eine Studie zu aktuellen Reisemotiven der österreichischen Bevölkerung zeigt, dass für rund zwei Drittel der Befragten „Natur und Ruhe“ ein besonders wichtiges Motiv sind, ebenso viele Urlauberinnen und Urlauber interessieren sich für „Wellness und Entspannung“. Weniger attraktiv erscheinen Urlaube mit dem Schwerpunkt „Kunst und Kultur". Nur jeder Vierte würde diese Rubrik zum Motto des Urlaubs machen. Noch dahinter liegen „Action und Sport“ (rund $21 \%$ ) und „Bildung und Wissen“ mit rund $18 \%$. Die Österreicherinnen und Österreicher setzten im Urlaub also vor allem auf Erholung. Darunter verstehen die Befragten gute frische Luft $(73,4 \%)$, Ruhe $(72,7 \%)$ und schöne Natur (70,1 \%; Nationalparks Austria 2016) ${ }^{1}$.

Weiterhin bestätigen sich aktuell Hinweise der Trendforschung, wonach sich die Urlaubswünsche und Aktivitäten weiter diversifizieren (Zukunftsinstitut 2011). In der Folge entwickelt sich ein stark fragmentierter Angebotsmarkt mit starkem Fokus auf einen persönlichen, flexibel zugänglichen Komfort. Beispiele für eine starke Diversifizierung zeigen sich insbesondere im Angebot für das Segment Radfahren und Wandern. Der wachsende Radtourismus in Österreich zeigt, dass entschleunigtes Reisen an Bedeutung gewinnt. Bei Flusskreuzfahrten auf der Donau oder mehrtätigen Bike- und Wandertouren wird der Weg zum Ziel (Österreich Werbung 2018a).

Eine weitere wichtige Entwicklung ist die Positionierung von Sommerdestinationen im Zusammenhang mit „Experience Design“. Dieser Begriff beschreibt die Praxis der Ge-

\footnotetext{
${ }^{1}$ Insgesamt wurden im Rahmen der zitierten Studie 1514 Österreicherinnen und Österreicher zwischen 14 und 69 Jahren befragt. Genaue Informationen zur Altersverteilung der befragten Personen sind nicht verfügbar. Eine (mögliche) Altersabhängigkeit der Motive lässt sich daher nicht belegen.
} 
staltung von Produkten, Prozessen, Dienstleistungen, Ereignissen und Umgebungen mit einem Fokus auf die Qualität der Benutzererfahrung (Tussyadiah 2013). Es geht darum, Erlebnisse zu schaffen, die den Gästen in Erinnerung bleiben und weitererzählt werden. Diesem Trend zu Design und Themenbergen folgen zahlreiche Bergbahnen in Österreich. Seit 2001 setzen die inzwischen 79 Themenberge überaus erfolgreich darauf, den Bergsommer mit einzigartigen Attraktionen besonders anziehend zu gestalten. Teil der sog. besten österreichischen Sommerbergbahnen sind unter anderem die bekanntesten mit Seilbahnen erschlossenen Berge Österreichs, wie z. B. Dachstein, Zugspitze, Kitzsteinhorn und Wilder Kaiser (Seilbahnen Österreich o.J.).

\subsection{Relevante Entwicklungen in den wichtigsten Herkunftsländern}

Neben einem starken Inlandsmarkt stellen wie bisher Deutschland, die Niederlande und Schweiz/Liechtenstein wichtige Herkunftsmärkte dar (Abb. 1.5 in Kap. 1; Statistik Austria 2019). Das Interesse erwies sich in den vergangenen Jahren als gleichbleibend hoch und tendenziell ansteigend. Bei ausgezeichneten und stabilen Wetterbedingungen lässt sich auch eine Zunahme durch spontane Buchungen in den umliegenden europäischen Nachbarstaaten erkennen. Dies zeigte sich 2018 u. a. durch eine deutliche Zunahme an deutschen sowie polnischen Urlauberinnen und Urlaubern (Österreich Werbung 2018b).

Befragungen von deutschen Gästen zeigten, dass sich die Urlaubsmotive vier Gruppen zuordnen lassen (Pröbstl-Haider et al. 2014). Dazu zählen das Erlebnis von Natur und regionalen Besonderheiten, das soziale Erlebnis (Familie/Gruppenerlebnis), Erholung mit Well-being (Erholungsurlaub) sowie Aktivitäten und Sporterlebnis (aktiver Urlaub/Sporturlaub). Weiterhin ist eine Zunahme italienischer Gäste aufgrund der Hitze in italienischen Städten in den Sommermonaten und gezielter Werbung für österreichische Natur und Kultur wahrscheinlich (Cai et al. 2011; Österreich Werbung 2011, 2018c). Generell trägt auch der Aspekt der Sicherheit zu einer Zunahme der Reisen nach Österreich bei, weil viele alternative Urlaubsregionen, wie zum Beispiel Tunesien, Ägypten, aber auch die Türkei und andere Reiseziele im Nahen Osten, diesbezüglich an Attraktivität verloren haben. Von dieser Entwicklung profitiert vor allem der Sommertourismus in Österreich (vgl. Kap. 1). Als vorteilhaft für deutsche Urlauberinnen und Urlauber wird auch die Tatsache empfunden, dass es keine Sprachbarriere gibt.

Das Nachfragepotenzial bei deutschen Gästen erscheint bei Weitem nicht ausgeschöpft, da vielfach der Sommerurlaub in den Bergen noch mit Anstrengung und Planungsaufwand verbunden wird (Österreich Werbung und Fachverband Seilbahnen WKO 2018). In einer repräsentativen Befragung in Deutschland geben nur $10 \%$ an, gar nicht an einem Urlaub im Alpenraum interessiert zu sein (Pröbstl et al. 2012; Pröbstl-Haider und Haider 2014). Diese Ergebnisse sowie die Daten der Österreich Werbung und der WKO legen eine weitere Zunahme deutscher Sommerurlaubender in den österreichischen Alpen nahe (Pröbstl et al. 2012).

Neben dem Wanderurlaub, der stark nachgefragt wird, ist auch der Radtourismus ein wachsendes Segment. Insgesamt ist nach Pechlaner et al. (2015) von 18,6 Mio. Mountainbikern in Europa und rund 40,4 Mio. Trekkingbike-Benutzern auszugehen, die jeweils ein wichtiges touristisches Potenzial darstellen. Bereits heute werden den Mountainbikenden in Österreich 26.400 Kilometer Radrouten zur Verfügung gestellt. Die Verkaufszahlen in Deutschland unterstreichen auch die zunehmende Bedeutung des E-Mountainbikes (Pechlaner et al. 2015). Von dieser Entwicklung wird auch ein starker Einfluss auf die Nachfrage und Produktentwicklung in Österreich erwartet, weil mit dem E-Bike für ein Bergerlebnis weniger Kondition und Kraft erforderlich ist (Hatje 2016; Pröbstl-Haider et al. 2017a). Insgesamt zeigt sich eine starke Diversifizierung, die von verschiedenen E-Bikes, über Fat-, Trekking-, Offroad-, Mountain- und Citybikes bis zu den klassischen Rennrädern reicht.

Trotz der quantitativen Zunahme der sommertouristischen Nachfrage ist zu beachten, dass die Wertschöpfung in Sommer und Winter sehr unterschiedlich ist (siehe Tab. 7.1). So beliefen sich die durchschnittlichen Tagesausgaben der Urlauberinnen und Urlauber im Winter 2018/2019 auf $185 €$, jene im Sommer 2018 hingegen nur auf $160 €$ (Österreich Werbung 2018d, 2019). Dabei ist aber zu beachten, dass die Unterschiede v. a. bei den Kategorien Unterkunft sowie Seilbahnen und Lifte liegen, wo die Kosten im Winter deutlich höher sind (Österreich Werbung 2018d, 2019). In der Schweiz ist die größere ökonomische Bedeutung des Wintertourismus gegenüber dem Sommertourismus ebenfalls nachgewiesen (Backhaus et al. 2013).

Tab. 7.1 Ausgaben eines durchschnittlichen Urlaubsgastes in der Wintersaison 2018/2019 und Sommersaison 2018. (Gerundete Werte, gemäß Österreich Werbung 2018d, 2019)

\begin{tabular}{|l|l|l|}
\hline & $\begin{array}{l}\text { Ausgaben im } \\
\text { Winter (pro Person/ } \\
\text { Tag) in } €\end{array}$ & $\begin{array}{l}\text { Ausgaben im } \\
\text { Sommer (pro Per- } \\
\text { son/Tag) in } €\end{array}$ \\
\hline Unterkunft & 91 & 78 \\
\hline $\begin{array}{l}\text { Mobilität vor Ort } \\
\begin{array}{l}\text { Essen und } \\
\text { Getränke }\end{array}\end{array}$ & 28 & 15 \\
\hline $\begin{array}{l}\text { Sonstige Aus- } \\
\text { gaben }\end{array}$ & 39 & 23 \\
\hline $\begin{array}{l}\text { Gesamtausgaben } \\
\text { ohne An- und } \\
\text { Rückreise) }\end{array}$ & 185 & 43 \\
\hline
\end{tabular}


Weiterhin ist auch die unterschiedliche Wertschöpfung zwischen den Urlaubsformen und Aktivitäten zu beachten, die zum Beispiel bei Radtourismus oder Seentourismus deutlich voneinander abweichen (Abb. 1.4 in Kap. 1).

\subsection{Einfluss des Klimawandels bzw. Einfluss auf den Klimawandel}

\subsubsection{Allgemeiner Einfluss des Klimawandels auf Outdooraktivitäten im Urlaub}

\section{Einfluss von Temperatur, Sonnenscheindauer und Niederschlägen}

Die Analyse der relevanten Literatur zeigt zunächst, dass es eine Herausforderung darstellt, einzelne meteorologische Messgrößen wie die Temperatur und ihre Bedeutung für den Tourismus mit ausreichender Genauigkeit so zu definieren, dass es möglich ist, zukünftige Szenarien bewerten zu können. Zum Beispiel definieren Matzarakis und Amelung (2008) den physiologisch angenehmen Temperaturbereich zwischen 18 und $23{ }^{\circ} \mathrm{C}$ und argumentieren, dass die Wärmebelastung bei einer physiologischen Äquivalenttemperatur von $35^{\circ} \mathrm{C}$ beginnt. Für Großbritannien zeigt Maddison (2001), dass die im Idealfall höchste Temperatur pro Tag $30{ }^{\circ} \mathrm{C}$ nicht überschreiten sollte. Lise und Tol (2002) geben an, dass die optimale Mitteltemperatur über einen Zeitraum von 24 Stunden global bei $21^{\circ} \mathrm{C}$ liegen sollte. Für die deutschen Tourismusdestinationen hat Hamilton (2004) eine optimale Temperatur von $24{ }^{\circ} \mathrm{C}$ genannt. Angesichts dieser divergierenden Angaben, welche Temperaturen aus touristischer Sicht als angenehm einzustufen sind, ist es schwierig, die Auswirkungen des Klimawandels zu diskutieren, und eine Modellierung, die sich auf einen Teilaspekt oder eine Methode bezieht, ist problematisch. Daher schlagen einige Autorinnen und Autoren vor, sich nur auf den Temperaturbereich zu beziehen, der negative Auswirkungen auf die öffentliche Gesundheit hat (z. B. tropische Nächte; APCC 2014; vgl. auch Kap. 2, Tab. 2.1).

Aus der Sicht der sportwissenschaftlichen Forschung, die vor allem die thermophysiologische Empfindlichkeit bei Aktivitäten wie Radfahren, Klettern oder Bergwandern betrachtet, wird der multidisziplinär entwickelte Universal Thermal Climate Index (UTCI) bevorzugt (Jendritzky und de Dear 2009; Brocherie et al. 2015), der valide in unterschiedlichen klimatischen Verhältnissen, saisonalen Bedingungen für eine Vielzahl von unterschiedlich anstrengenden Aktivitäten eingesetzt werden kann. Auch Effekte durch Bekleidung lassen sich durch den UTCI modellieren und geben den jeweiligen thermischen Stress durch Hitze oder Kälte wieder. Verschiedene Autorinnen und Autoren erwarten deshalb, dass die touristische Ausrichtung auf Gesundheit und Well-being dazu führen wird, dass dieser Index weite Verbreitung finden wird und idealerweise zusammen mit Wetterinformationen angegeben werden sollte (Piskuta et al. 2012; Brocherie et al. 2015).

Aus physiologischer und sportmedizinischer Sicht stellen weiterhin Hitzewellen (d. h. längere Perioden mit extrem hohen Temperaturen) eine substanzielle Belastung für die menschliche Gesundheit dar, die vor allem ältere Menschen und Kinder bei erholungsbezogenen oder sportlichen Aktivitäten trifft (Brocherie et al. 2015). Die Effekte, die durch Hitze ausgelöst werden, können von Hitzewallungen, einem Kreislaufkollaps (Synkope), Krämpfen über Erschöpfungszustände bis zu Desorientierung reichen. Muskuläre Beanspruchung, Dehydrierung und starker Elektrolytverlust wirken hier zusammen und können durch weitere Faktoren wie Fettleibigkeit, geringe Fitness, unzureichende Akklimatisation sowie andere Belastungen wie Sonnenbrand verstärkt werden (Kerle und Nishimura 1996; Holtzhausen und Noakes 1997; Lorenzo et al. 2010; Ross et al. 2013).

Rudel et al. (2007) untersuchten unter Beachtung wichtiger tourismusrelevanter, bioklimatischer Parameter (insbesondere PET, physiologisch äquivalente Temperatur) die Bedingungen für den alpinen Sommertourismus unter Aspekten des Klimawandels. Zu den zentralen Schlussfolgerungen gehören (siehe auch Kap. 2 in diesem Bericht), unter anderem bezogen auf die touristischen Aktivitäten, folgende Aspekte:

- Die Anzahl der Tage mit Hitzestress nimmt zwar zu (Kap. 2), allerdings sind die bergtouristisch interessanten Lagen über 1000-1200 m nicht davon betroffen.

- Positiv wirkt sich auch die Tatsache aus, dass die Anzahl der Tage, in denen thermisch komfortable Bedingungen vorherrschen, sich insgesamt um ca. 10 Tage erhöhen und so zu einer Verlängerung thermisch geeigneter Bedingungen für Freizeit und Erholung führen. Davon können viele Outdooraktivitäten profitieren.

- Die Anzahl der Sonnentage erhöht sich danach ebenfalls, jedoch nur in höheren Lagen.

- Weiterhin wird von einem Trend hin zu Starkniederschlagsereignissen ausgegangen.

Aus touristischer Sicht positiv ist die erwartete Zunahme von Tagen mit wenig und keinem Niederschlag sowie der erwartete Rückgang der Anzahl an Nebeltagen. Rudel et al. (2007) gehen daher davon aus, dass der Seentourismus von diesen Veränderungen am meisten profitieren dürfte.

Für die Aktivitäten am Urlaubsort ist auch entscheidend, dass im mediterraneren Bereich die Verhältnisse in den Sommermonaten ungünstiger werden als in den zentralen und nördlichen Teilen Europas (Perry 2000; Lise und Tol 2002; Hamilton 2004; Zebisch et al. 2005; Amelung und Viner 2006; Bigano et al. 2006). Weitere Arbeiten heben die zu erwartenden Auswirkungen im Hinblick auf die saisonale Attraktivität hervor und erwarten andere Verteilungsmuster und Verschiebungen vom Sommer zu Frühling und Herbst 
(Scott und McBoyle 2001; Scott et al. 2004; Hamilton et al. 2005; Amelung und Viner 2006). Starke Erwärmungen in den Städten und urbanen Räumen - d. h. Sommertage mit $25^{\circ} \mathrm{C}$ und mehr sowie Hitzetage mit $30^{\circ} \mathrm{C}$ und mehr treten häufiger auf - könnten darüber hinaus die Attraktivität der Berggebiete weiter steigern (Zebisch et al. 2005; Allex et al. 2013; Weber et al. 2018).

Juschten et al. (2019) untersuchten am Beispiel von Wien eine mögliche Verhaltensänderung der urbanen Bevölkerung durch eine Reise in die „Sommerfrische“. Der Anteil von $46 \%$, die angaben, dass sie bereits Hitzestress erlebt haben und eine Reise antreten wollen, ist doppelt so hoch wie bei denjenigen Befragten, die sich bislang nicht durch Hitzestress belastet fühlen (23\%). Die Ergebnisse der Studie weisen insgesamt darauf hin, dass um die urbanen Räume die hitzebedingten Reisetätigkeiten zunehmen.

Falk (2014) betrachtet die Auswirkungen von Klimaschwankungen (gemessen als Durchschnittstemperaturen, Sonnenscheindauer und Niederschläge) auf die touristische Nachfrage in Österreich während der Sommerferienhochsaison (Juli und August). Dabei wird zwischen in- und ausländischen Besucherinnen und Besuchern unterschieden und ein langer Zeitraum analysiert (1960-2012 für inländische und 1967-2012 für ausländische Besucherinnen und Besucher). Ausgehend von statischen und dynamischen Tourismusnachfragemodellen zeigt sich, dass die Sonnenscheindauer - und in geringerem Maße auch die Temperaturen - einen starken und statistisch verlässlichen Einfluss auf die Zahl der in- und ausländischen Übernachtungen in der Sommersaison in Österreich hat. Für die inländischen Gäste zeigen die Ergebnisse, dass sich höhere Temperaturen und mehr Sonnenscheinstunden in der laufenden Sommersaison positiv auf die Übernachtungen in den gleichen Monaten auswirken. Bei ausländischen Übernachtungen zeigt sich dagegen, dass die Wetterverhältnisse im Juli und August die Besuchernächte erst mit einer einjährigen Verzögerung beeinflussen und vor allem Besucherinnen und Besucher aus dem benachbarten Ausland betreffen. Insgesamt sind die kurzfristigen Auswirkungen höherer Temperaturen und Sonnenscheinstunden auf die touristische Nachfrage jedoch nicht sehr groß. Ein einmaliger Temperaturanstieg im Juli und August (entspricht $1{ }^{\circ} \mathrm{C}$ ) wird die Zahl der inländischen Übernachtungen kurzfristig nur um 1,3\% erhöhen. Ein Anstieg der Sonnenscheindauer um $30 \%$ (entspricht dem Anstieg im Hitzesommer 2013 in Österreich) wird dazu führen, dass die Zahl der inländischen Übernachtungen kurzfristig um 2,1\% steigt. Die langfristigen Auswirkungen sonniger Sommersaisonen auf in- und ausländische Übernachtungen sind dabei höher, aber diese Effekte treten über einen mehrjährigen Anpassungszeitraum auf. Die Ergebnisse zeigen ferner, dass das reale Einkommen und die relativen Preise für die Nachfrage nach inländischem Tourismus nicht relevant sind, aber wichtige Determinanten der ausländischen Tourismusnachfrage sind. Die Ergebnisse von Falk (2014) zeigen, dass die Zunahme des Sonnenscheins in den letzten 50 Jahren um 35 Stunden (das entspricht einer Zunahme von 0,7 Sonnenstunden pro Jahr) die Zahl der inländischen Übernachtungen um 5,5\%, kumuliert über den gesamten Zeitraum, erhöht hat. Bei ausländischen Übernachtungen beträgt der entsprechende Anstieg $10 \%$ (wiederum kumuliert über den gesamten Zeitraum). Auf dieser Studie aufbauend untersucht Falk (2015) auch den Zusammenhang zwischen Wetterbedingungen und Tourismusnachfrage für die Sommersaison in österreichischen Bundesländern anhand von Paneldaten ${ }^{2}$ für die neun Bundesländer in Österreich für den Zeitraum von 1974 bis 2012. Die Ergebnisse bestätigen die zuvor genannten Tendenzen. Darüber hinaus zeigte sich, dass die Effekte in den einzelnen Regionen sehr unterschiedlich ausfallen, wobei die Auswirkungen auf ländliche Ziele mit vielen Seen (Salzburg, Kärnten und Oberösterreich) und auf Tieflandregionen (Burgenland und Niederösterreich) größer sind. Im Gegensatz dazu sind die variablen Wetterbedingungen für den Tourismus in Bergregionen wie Tirol weniger relevant.

Insgesamt geht Falk (2015) mit Blick auf den Sommertourismus davon aus, dass die Mehrheit der österreichischen Bundesländer von der globalen Erwärmung profitiert. Über einen längeren Zeitraum sind die Auswirkungen des Klimawandels in Form von höheren Temperaturen und erhöhter Sonneneinstrahlung auf die Tourismusnachfrage jedoch eher gering. $\mathrm{Zu}$ ähnlichen Ergebnissen beruhend auf einer repräsentativen Befragung potenzieller Gäste aus Deutschland kommen auch Pröbstl-Haider et al. (2014). Die Autoren zeigen zudem, dass die Bewertung von wärmeren Bedingungen je nach Urlaubsart und Aktivität unterschiedlich ist. Die Bedeutung von stark zunehmenden Sonnentagen für die Auswahlentscheidung einer alpinen Destination ist in weniger spezialisierten, entspannungsorientierten Urlaubersegmenten größer als in den Segmenten, die auf der Suche nach natürlicher Integrität (Naturnähe) oder einem vielfältigen Angebot für Sport und Erholung im Freien sind.

Insgesamt ist auch von einer potenziellen Saisonverlängerung insbesondere für Outdooraktivitäten und entsprechende Urlaube auszugehen, da im Zuge der Klimaerwärmung Frühling und Herbst einen etwas anderen klimatischen Charakter bekommen könnten. Die Daten der ZAMG (o.J.a) zeigen, dass es tendenziell im Frühling früher warm und im Herbst später kalt wird. Weiterhin wird von der meteorologischen Forschung von zunehmenden Starkniederschlägen ausgegangen (ZAMG o.J.b), deren unmittelbare Konsequenzen wurden bislang wenig untersucht.

Im internationalen Vergleich kommen Brice et al. (2017), die die Auswirkungen des Klimawandels auf die Erholungsaktivitäten überprüfen, zu einer Liste möglicher betroffener

\footnotetext{
${ }^{2}$ Paneldaten haben sowohl eine Zeitreihe als auch eine Querschnittsdimension, die durch die österreichischen Bundesländer repräsentiert wird.
} 
Aktivitäten. Aus ihrer Sicht sind im Sommer vor allem Wassersportarten, Beobachtung von wild lebenden Tieren, Wanderaktivitäten, aber auch kulturtouristische Aktivtäten, Fischerei und Jagd potenziell betroffen. Die zu erwartende Betroffenheit bezogen auf Österreich ist in Abschn. 7.4 zusammengefasst.

Unabhängig von der Anreise weisen die nachstehenden touristischen Aktivitäten einen eher geringen Energieverbrauch und Beitrag zum Klimawandel auf. $\mathrm{Zu}$ den sparsamsten Aktivitäten zählen etwa Reiten, Wandern, Segeln und Surfen sowie Radfahren und Mountainbiking (Veit 2002; Formayer und Kromp-Kolb 2009).

\section{Einfluss des Klimawandels auf das Landschaftsbild und die Erholungsinfrastruktur}

Im Zusammenhang mit Urlaubsaktivitäten werden in der Literatur auch negative Effekte durch eine Veränderung des Landschaftsbildes diskutiert. Entsprechende Auswirkungen könnten u. a. durch Abschmelzen der Gletscher, geschädigte Wälder oder Landschaftsveränderungen durch Erosionen, aber auch gravierende Änderungen der Landnutzung entstehen (Ammer und Pröbstl 1991; Pröbstl und Damm 2009; Pröbstl-Haider et al. 2015; Schneider et al. 2019).

Nachdem Österreich durch eine vielfältige Kulturlandschaft geprägt ist und das häufig kleinteilige Landschaftsbild einen besonderen Reiz für die touristische Nutzung im ländlichen Raum hat, gingen Pröbstl-Haider et al. (2015) der Frage nach, wie sich dann, wenn der Klimawandel Intensivierungen der Landnutzung begünstigt, das Landschaftsbild verändern würde. Es wurde insbesondere analysiert, ob die Bauern in ausgewählten Landschaften in Niederösterreich und der Steiermark auch auf Kleinstrukturen, wie Iriswiesen oder Einzelbäume, verzichten werden, wenn dies wirtschaftlich deutlich lohnender wäre. Die Befragung von insgesamt 239 Betriebsinhabern weist darauf hin, dass dann, wenn der Klimawandel eine intensive Bewirtschaftung (z. B. den Anbau von Mais) erlaubt, diese Option auch wahrgenommen wird. Derzeitige Förderungen reichen nicht aus, um die Diversität, insbesondere artenreiches Grünland, zu erhalten. Ähnliche Tendenzen sind auch in Weinbaulandschaften zu erkennen. Auch hier gehen die Anteile mit extensivem Grünland und Streuobst zurück (Pröbstl-Haider et al. 2017b).

Im Blick auf die durch Almen geprägte Gebirgslandschaft wird auch eine Nutzungsänderung oder Auflassung von Almen als Folge des Klimawandels diskutiert, die zu einer Zunahme der Verwaldung führen könnte. Studien aus der Schweiz, aber auch aus Österreich zeigen jedoch in diesem Zusammenhang, dass auch im Hinblick einer Verwaldung bzw. Offenhaltung der Landschaft bei den Touristinnen und Touristen (anders als bei den Einheimischen) von einer großen Toleranz auszugehen ist, solange nicht ein Waldanteil über $80 \%$ erreicht wird (vgl. Hunziker 2000 für die Schweiz; Pröbstl-Haider et al. 2018 für Österreich).
Auswirkungen durch erhebliche Landschaftsbildveränderungen werden auch für den Bereich des Neusiedler Sees im klimatisch relativ trockenen Teil des Burgenlandes erwartet. Der Neusiedler See weist als flachgründiger Steppensee einen maximalen Wasserstand von zwei Metern auf. Historische Aufzeichnungen belegen, dass der See aufgrund seiner geringen Wassertiefe im 18. und 19. Jahrhundert jeweils über einen längeren Zeitraum hinweg vollkommen austrocknete. Klimastudien zeigen, dass vergleichbare Ereignisse zukünftig mit höherer Wahrscheinlichkeit erwartet werden müssen: So kann z. B. eine Klimaerwärmung zu einer markanten Erhöhung der Verdunstung des Wassers des Neusiedler Sees führen und eine vier- bis sechsjährige Aufeinanderfolge extrem trockener Sommer zu einer (Teil-)Austrocknung des Sees führen (Kromp-Kolb et al. 2005). Die Tatsache, dass in der Region Neusiedler See bereits unterschiedliche Alternativen zur Vermeidung derartiger starker Wasserschwankungen diskutiert werden, zeigt, dass es Befürchtungen gibt, dass ein wiederholtes, starkes Absinken des Wasserspiegels die Attraktivität des Neusiedler Sees und der Region deutlich negativ beeinflussen und damit auch wirtschaftliche Konsequenzen haben könnte. Forschungsergebnisse zeigten hier, dass die Wirkung von Wasserschwankungen auf die Urlaubsgäste vom jeweiligen Landschaftstyp entlang des Seeufers abhängig ist (Pröbstl et al. 2007). Insbesondere schilfbetonte Bereiche des Seeufers sind in dieser Hinsicht weniger betroffen, weil sich das Landschaftsbild hier auch bei Absenken des Wasserspiegels weniger stark verändert. Allerdings variiert die Empfindlichkeit bezogen auf Wasserschwankungen entsprechend den Motiven der Urlauberinnen und Urlauber. So wurde eine hohe Empfindlichkeit bei Interesse an Naturbeobachtung festgestellt.

Verschiedene Autorinnen und Autoren untersuchten Veränderungen am Wald, z. B. durch Borkenkäfer oder andere Belastungen in Deutschland. Dabei zeigte sich, dass Wälder mit einzelnen geschädigten Bäumen von $83 \%$ nicht negativ wahrgenommen werden, bei mittlerem Schädigungsgrad gilt dies auch noch für $40 \%$ der Waldbesucherinnen und -besucher (Ammer und Pröbstl 1991). Studien von Müller und Job (2009) zeigen, dass trotz erheblicher Schäden Touristinnen und Touristen, die diese Landschaft aufsuchen, in Schutzgebieten eine neutrale Haltung gegenüber dem Borkenkäfer haben und gegen eine Bekämpfung sind. Im Allgemeinen werden jedoch stark veränderte Landschaften negativ wahrgenommen, da das Landschaftserlebnis zur wichtigsten Motivation für die Urlauberinnen und Urlauber zählt (Arnberger et al. 2018). Alle genannten Studien weisen aber auch darauf hin, dass die Akzeptanz durch Information positiv beeinflusst werden kann.

Auch die Reduktion und der Verlust von Gletschern könnten für das Urlaubserlebnis relevant sein, weil sich dadurch optische Landschaftsveränderungen ergeben. Seit dem letzten Höchststand gegen Ende der sogenannten kleinen Eiszeit um 1850 haben die österreichischen Gletscher bereits mehr als 50 \% ihrer Fläche verloren. Laut Modellrechnungen gehen bis 
Abb. 7.1 Potenzielle Auswirkungen von Gletscherabschmelzen und Permafrostdegradation auf den Bergtourismus (Pröbstl und Damm 2009). Die Strichstärke verdeutlicht die relative Häufigkeit

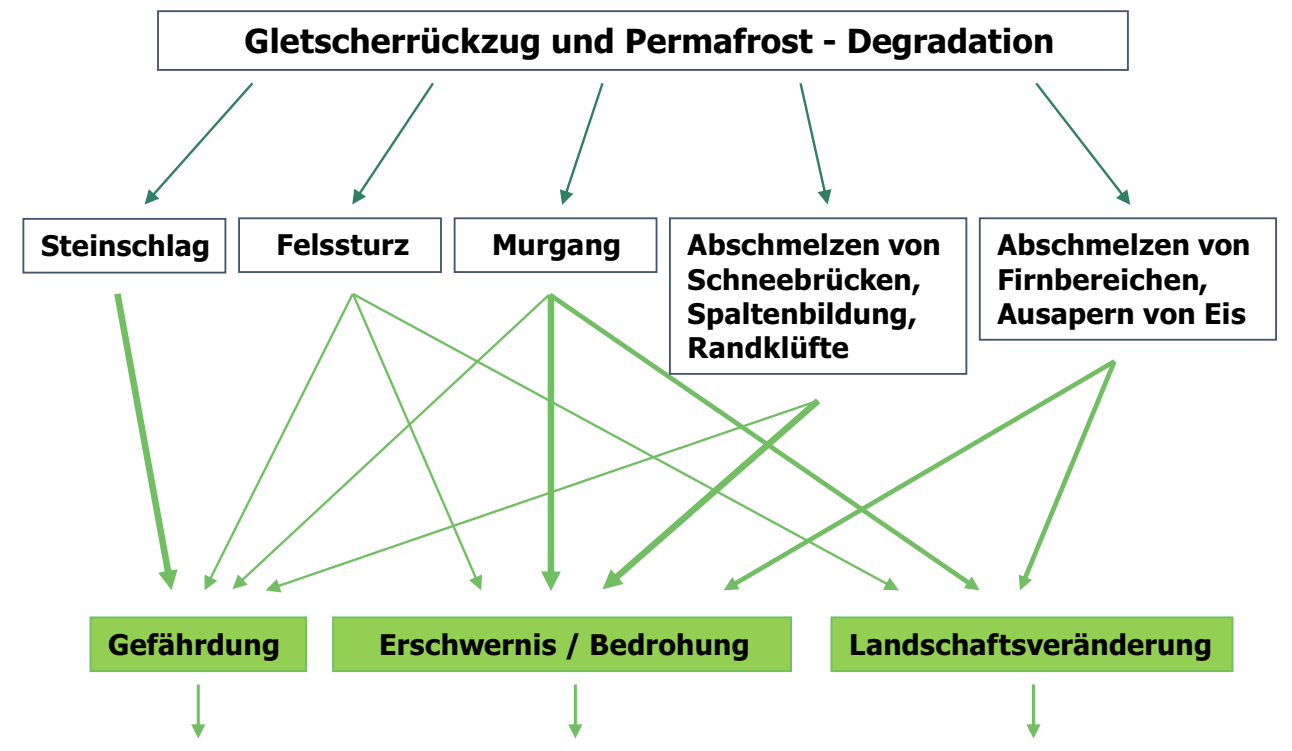

Mögliche Konsequenzen für Wanderer und Hochtouristen zum Ende des Jahrhunderts rund 83 \% der Gletscherfläche in Österreich verloren. Dabei verschwinden die kleinen und mittleren Gletscher völlig. Große Gletscher, wie die Pasterze, werden im 22. Jahrhundert nur noch in stark verkleinerter Form bestehen. Die österreichischen Gletscher werden aufgrund der geringen Gipfelhöhen früher abschmelzen als die im Mittel höher gelegenen Gletscher der Westalpen (ZAMG o.J.c). Allerdings gibt es noch keine Studie, die den Verlust zum Beispiel im Hinblick auf mögliche nicht erfolgende Buchungen quantifiziert hat. Im Hinblick auf den Bergtourismus zeigte sich bei der Destinationswahl für einen Bergurlaub in Österreich und in der Schweiz eine hohe Präferenz für einen möglichst umfassenden Ausblick, nicht jedoch speziell fokussiert auf Gletscher (Pröbstl et al. 2011; Pröbstl-Haider et al. 2016). Dies trifft bislang auch auf bekannte Gletscherregionen, wie den AletschGletscher, zu. In dieser Region sind trotz starken Rückzugs bislang keine Rückgänge der Touristinnen und Touristen zu verzeichnen, die mit dem veränderten Landschaftsbild in Verbindung zu bringen sind. In diesem Zusammenhang könnte es sich auch um das Phänomen des ,last chance tourism“ handeln: Die Nachfrage in Gletschergebieten geht deshalb nicht zurück, weil man sich die Chance nicht entgehen lassen will, noch einen Gletscher zu sehen, bevor er verschwunden ist.

Neben der Landschaftsbildveränderung durch das Abschmelzen von Gletschern ergeben sich weitere mögliche Effekte, die durch den Gletscherrückgang, Rückgang von Permafrost in Boden und Gestein sowie durch Starkregenereignisse Auswirkungen auf den Bergtourismus haben können.

Insbesondere zunehmende Ausaperung (Steinschlag-, Blockschlaggefahr), Abschmelzen von Gletscherzungen (häufig zunehmende Steilheit), Absenkung von Gletscheroberflächen (Ausbildung von Felsstufen beim Übergang von Gletscher zu Fels, vergrößerter Bergschrund) und Laufver- lagerungen von Gletscherbächen wirken sich auf die Routen für Wandern, Bergtouren und Mountainbiken aus, aber auch Kletterrouten, Schutzhütten, Seilbahnanlagen sowie Wege und Steige sind betroffen (Pröbstl und Damm 2009).

Die erwarteten Effekte umfassen (Abb. 7.1) auch neue Gefährdungen, etwa durch Steinschlag, Erschwernisse bei den Touren durch beeinträchtigte Wege sowie Auswirkungen auf das Landschaftsbild. Zur Reduzierung bzw. Vermeidung unverhältnismäßiger Risiken kann sich für Hüttenzugänge, Höhenwanderwege und Übergänge die Notwendigkeit von Anpassung, Neubau und Instandhaltung ergeben. Auch der Neubau von Infrastrukturanlagen kann erforderlich sein.

Befragungen von Bergtouristinnen und -touristen ergaben bislang, dass für das Buchungsverhalten vor allem ausschlaggebend ist, ob die Aktivitäten (z. B. Bergwandern, Klettern, Mountainbiken) grundsätzlich weiter durchgeführt werden können. Kleinteilige Veränderungen in der Hochgebirgslandschaft waren weniger relevant. Für die Tourismusdestinationen und die alpinen Vereine leiten sich daraus jedoch zukünftig erhebliche Kostensteigerungen für die Instandhaltung der Infrastruktur ab (Pröbstl und Damm 2009).

\section{Einfluss des Klimawandels auf die Ausbreitung von gesundheitlichen Risikofaktoren}

Die oben beschriebenen saisonalen Verschiebungen, insbesondere im Frühjahr, können die Blütezeit von Pflanzen beeinflussen und damit das Wohlbefinden und die touristische Eignung bestimmter Destinationen für Allergikerinnen und Allergiker wesentlich beeinflussen. Nicht nur die Veränderung durch eine früher eintretende Belastung durch einheimische Pollen (wie etwa Birke oder Hasel), sondern auch durch Ausbreitung von Neophyten, d. h. eingewanderten Arten, können sich neue Problemstellungen ergeben (Karrer et al. 2011; Moshammer 
et al. 2014). Hierzu zählt insbesondere Ragweed (Ambrosia artemisiifolia), eine ursprünglich in Nordamerika beheimatete Pflanze, die seit 1960 auch regelmäßig in Österreich vorkommt. Die Ausbreitung erfolgt langsam, aber kontinuierlich in landwirtschaftlichen Flächen Südost- und Ostösterreichs. Seit dem Jahr 2000 wird eine rasche Ausbreitung im urbanen Raum, insbesondere entlang linearer Korridore (Straßen, Wasserwege) beobachtet. In Ostösterreich sind $30 \%$ der Allergikerinnen und Allergiker sensibel auf Ragweedpollen (in Ungarn $80 \%$ ). Daher ist es wichtig, die Bedingungen langfristig $\mathrm{zu}$ prüfen und die veränderten Bedingungen für Allergiker zu kommunizieren (Moshammer et al. 2014; APCC 2018).

Weitere Effekte können durch eine erweiterte Verbreitung von Zecken, die Verbreitung von Krankheitserregern durch Mücken sowie durch lokale Insektenkalamitäten, wie dem Prozessionsspinner, erfolgen, deren Auftreten ebenfalls durch den Klimawandel begünstigt wird (APCC 2018).

Internationale Forschungsarbeiten weisen weiterhin darauf hin, dass sich durch den Klimawandel und Hitzetage die negativen Effekte von Ozon und Luftverschmutzung verstärken (Brasseur 2009). Dies gilt umso mehr, wenn anstrengende Aktivitäten im Freien und Sport ausgeübt werden (Löndahl et al. 2007; Giles und Koehle 2014).

\subsubsection{Einfluss des Klimawandels auf spezielle Aktivitäten}

\section{Wandern, Nordic Walking und Spazierengehen}

Die Aktivitäten Wandern, Nordic Walking und Spazierengehen werden von vielen Erholungssuchenden in ihrem Urlaub ausgeübt. Insgesamt ist nicht mit erheblichen Auswirkungen zu rechnen, da über das ganze Jahr hinweg gesehen die Rahmenbedingungen sich für diese Aktivitäten insgesamt eher verbessern. Insbesondere die Frühjahrs- und die Herbstsaison werden attraktiver. Hierfür ist vor allem eine Erhöhung der Sonnenscheindauer verantwortlich. Die Temperatur ist bei den Aktivitäten Wandern und Spazierengehen nicht entscheidend. Dies gilt umso mehr als die Temperaturen in der alpinen Umgebung unter anderem stark von der Höhe, der Exposition und dem Schattenwurf der Berge abhängen. In den letzten Jahrzehnten haben die Tage mit Sonnenschein und die Sonnenscheindauer insgesamt in den Alpen zugenommen und sind Teil der Klimawandelszenarien für die alpinen Reiseziele in Österreich geworden (Fleischhacker und Formayer 2007; Falk 2014, 2015). Betrachtet man die touristische Entwicklung in den österreichischen Kurorten, dann lässt sich für 36 heilklimatische Kurorte ${ }^{3}$ und Luftkurorte in Österreich seit 2014 eine

\footnotetext{
${ }^{3}$ Heilklimatische Kurorte zeichnen sich durch ein besonderes $\mathrm{Zu}$ sammenspiel von therapeutisch wirksamen bioklimatischen Reiz- und Schonfaktoren aus, wobei Belastungen wie Staub oder Allergene minimiert sein müssen (siehe Baumann et al. 2013; Rösing 2018).
}

positive Entwicklung der Sommernächtigungen durch eine Zunahme deutscher Gäste feststellen (Fleischhacker 2019).

Beeinträchtigungen durch Klimawandelfolgeeffekte können vor allem bei ausgedehnten Wanderungen durch kleinräumige auftretende schwere Gewitter eintreten, die Urlauberinnen und Urlauber direkt oder indirekt (etwa durch Murenabgänge) in Gefahr bringen können. Derzeit sind Aussagen über ihre zukünftige Entwicklung noch mit Unsicherheiten verbunden. Es wird davon ausgegangen, dass in Zukunft schwere Gewitter häufiger auftreten, weil eine wärmere Atmosphäre mehr Wasserdampf aufnehmen kann (ZAMG o.J.b; siehe auch Abschn. 2.2.2). Auf Gefahren durch Gewitter beim Bergsport weisen auch internationale Studien hin: Brocherie et al. (2015) betonen, dass in den Zeiträumen mit hoher Gewitterwahrscheinlichkeit auch meist mehr Menschen unterwegs sind.

\section{Bergwandern, Klettern und Hochgebirgstouren}

Die gesonderte Auswertung von Destinationen mit Schwerpunkt Berg- und Alpintourismus zeigt rückblickend auf die letzten 10 Jahre (Fleischhacker 2019) eine Zunahme, die deutlich über den Anstiegszahlen für den Sommertourismus in Österreich insgesamt liegt (Abb. 7.2). Diese touristische Entwicklung spiegelt sich auch in den Mitgliederzahlen wichtiger alpiner Vereine in Österreich. So stiegen die Mitgliederzahlen beim österreichischen Alpenverein von ca. 330.000 im Jahr 2006 auf ca. 521.575 im Jahr 2017 (ÖAV 2017). Der Tourismus mit Gastgewerbe- und Beherbergungsbetrieben ist - auch in den größeren Höhenlagen - wirtschaftlich bedeutend. Allein der Österreichische Alpenverein betreibt 235 Hütten mit 13.000 Schlafplätzen und über 350.000 Nächtigungen (ÖAV 2015), von denen sich viele in den durch den Klimawandel stärker betroffenen Höhenlagen befinden.

Nachstehend sind die Auswirkungen vor allem auf bergtouristische Aktivitäten in höheren Lagen zusammengestellt (siehe dazu auch Abb. 7.1 von Pröbstl und Damm 2009).

In den Hochregionen der Alpen reagiert das Eis von Gletschern und Permafrost sensibel auf Klimaänderungen. Gletscherschwund, Anstieg der Temperatur in Bereichen mit Permafrost sowie eine Zunahme von Hanginstabilitäten und Massenbewegungen sind Anzeichen für die Folgen des Klimawandels. Diese beeinflussen in erheblichem Umfang das gegenwärtige und künftige Naturgefahrenpotenzial für den Bergsport (Pröbstl und Damm 2009; Brocherie et al. 2015).

Viele Gletschergebiete sind Ausgangspunkt von Wanderungen und hochalpinen Touren. Die vorhandenen Hütten sind zum Teil ganzjährig bewirtschaftet. Durch den Rückgang des Permafrosts wird eine Zunahme von Muranrissen befürchtet, sie entstehen u. a. dort, wo in der Vergangenheit Bodeneis abgeschmolzen ist. Darüber hinaus sind Muranrisse oft im Gletscherrückzugsgelände der vergangenen Jahrzehnte zu finden. Die räumliche Verbreitung möglicher Anrissbereiche von Muren kann zukünftig Gebäude, Wanderwege, Fahrstraßen 


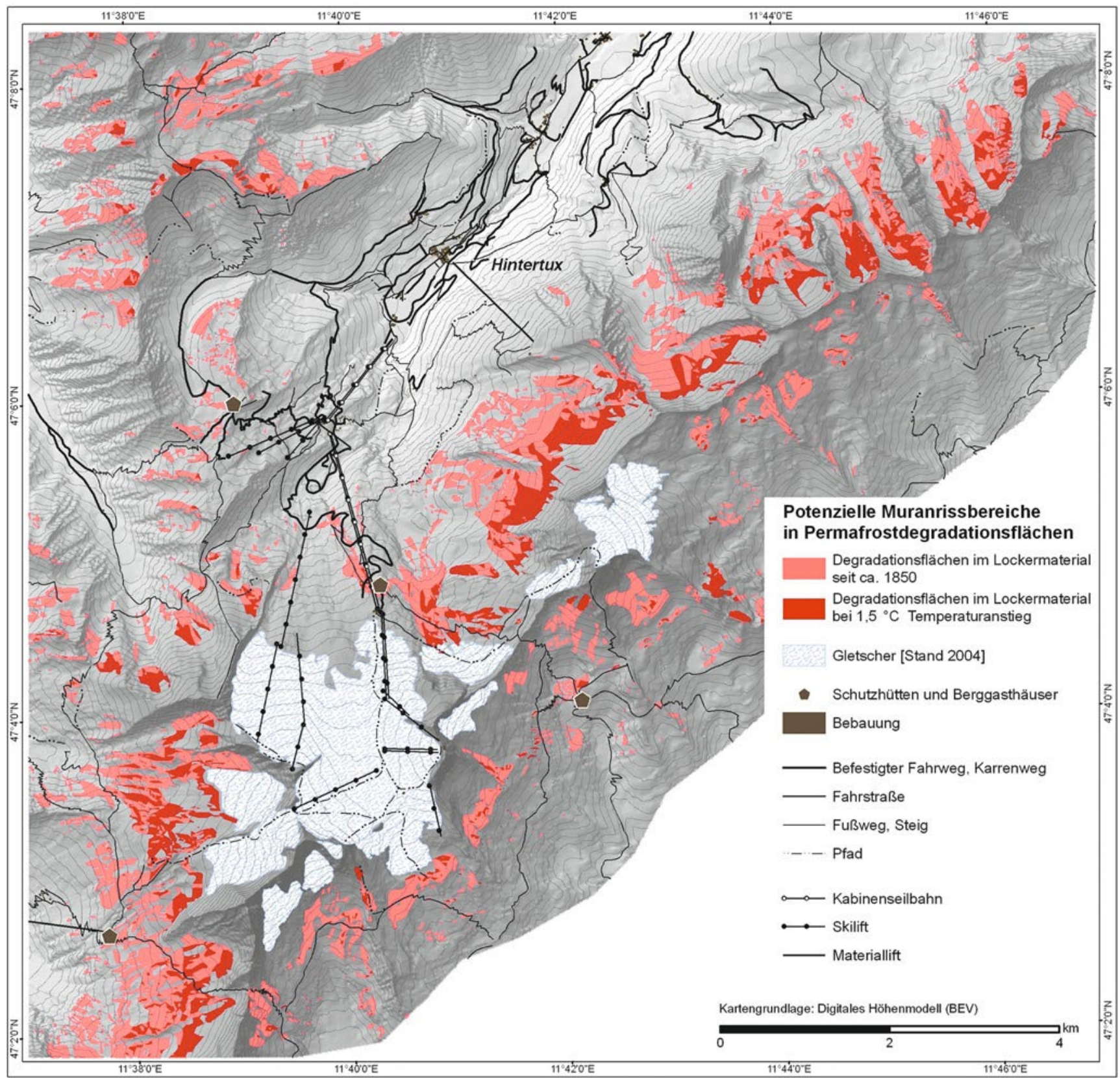

Abb. 7.2 Mögliche Anrissbereiche von Muren in Lockergesteinen über degradiertem flächenhaften Permafrost des Tuxer Hauptkammes. (Pröbstl und Damm 2009)

und Seilbahnanlagen direkt (innerhalb der Prozessbereiche) und indirekt (z. B. Ausbreitungsgebiet einer Murablagerung) betreffen (Patek 2007; Pröbstl und Damm 2009).

Bei weiterem Abschmelzen von Klufteis im Zuge einer fortschreitenden Erwärmung ist davon auszugehen, dass sich neue Anbruchsbereiche von Sturzprozessen entwickeln werden. Die räumliche Verbreitung von Anrissbereichen von Steinschlag-, Blockschlag- und Felssturzprozessen betrifft überwiegend Kletterrouten und hochalpine Wege und Steige (Pröbstl und Damm 2009).
Die Abb. 7.2 und 7.3 verdeutlichen am Beispiel der Situation der Hintertuxer Gletscherregion die aufwendige Berechnung und Simulation der Gefahrenbereiche durch den Rückgang von Gletschereis und Permafrost (Pröbstl und Damm 2009). Deutlich erkennbar sind die potenziellen Gefahren durch Muren (Abb. 7.2) und Steinschlag, Blockschlag oder Felsstürze (Abb. 7.3) für die touristische Infrastruktur (Berghütten, Wanderwege und Liftanlagen). Auf diesen Berechnungen und Simulationen bauen Abschätzungen des geomorphologischen Gefahrenpotenzials auf. 


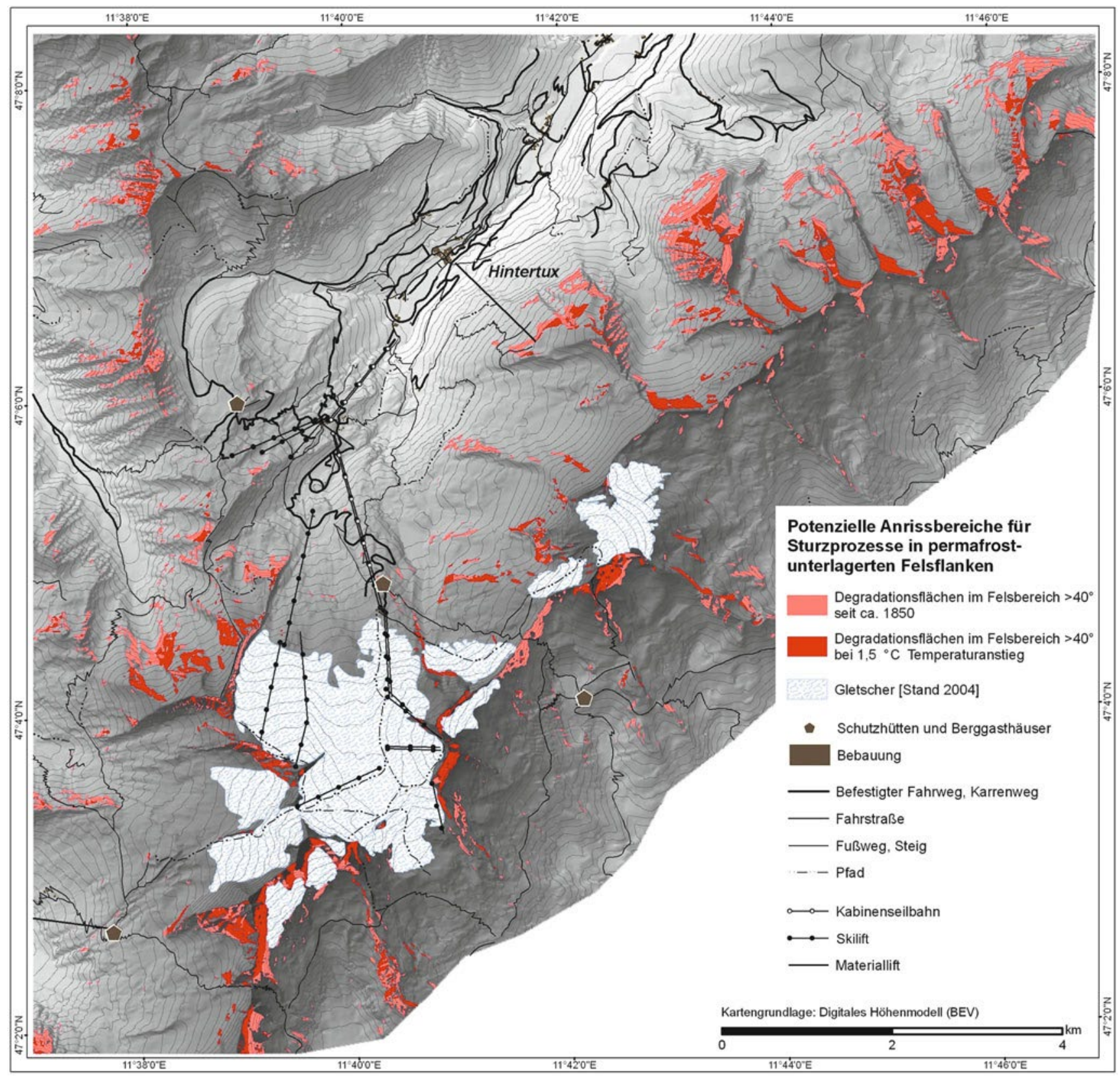

Abb. 7.3 Mögliche Anrissbereiche von Steinschlag-, Blockschlag- und Felssturzprozessen in Felsflanken über degradiertem flächenhaften Permafrost des Tuxer Hauptkammes. (Pröbstl und Damm 2009)

Darüber hinaus ergeben sich weitere Einschränkungen für den Bergtourismus. Infolge des ausgedehnten Rückzugs der Gletscherzungen oder des vollständigen Abschmelzens von Gletschern führen klassische Hochtouren- und Gebirgswanderwege heute vielfach bereits über Moränenschutt und zum Teil schwer begehbare Gletscherschliffe. Entsprechende Routen sind hierdurch nicht nur insgesamt beschwerlicher, sondern auch zeitaufwendiger und für die durchschnittliche Wanderin bzw. den durchschnittlichen Wanderer damit zumindest zum Teil riskanter geworden.
Die Beachtung und Reaktion auf die genannten Risiken sind unter den Bergtouristinnen und -touristen nicht homogen. Insgesamt lassen sich drei verschiedene Typen unterscheiden (Pröbstl-Haider et al. 2016). Die größte Gruppe (49 \%) legt bei der Bergwanderung besonderen Wert auf den Ausblick, intakte Wege und eine attraktive Landschaft. Im Hinblick auf die Beurteilung alpiner Risiken ist diese Gruppe eher unsicher. Sollten Probleme mit Steinschlag und Personenschäden bekannt werden, werden sie ihr Ausflugsziel ändern. Die zweite Gruppe (39 \%) kann als besonders an 
der Bergwelt interessiert beschrieben werden. Sie reagieren sehr sensibel auf alle Arten von Risiken, besonders an Wegen und durch Steinschlag. Sie sind vertraut mit alpinen Gefahren und bleiben den Bergen auch bei zukünftig ungünstigeren Bedingungen weitgehend „treu“. Die dritte Gruppe (12\%) ist noch stärker auf ein möglichst natürliches Umfeld bei der Bergtour fixiert. Sie stellen die geringsten Ansprüche an die Infrastruktur. Natürliche Landschaftsveränderungen, wie Rutschungen oder Muren, werden ebenfalls in hohem Maße toleriert. Im Hinblick auf Steinschlag fällt ebenfalls ein hohes Risikobewusstsein auf. Sie bleiben den Bergen auch unter sich ändernden Rahmenbedingungen treu. Die Autorinnen weisen darauf hin, dass der Ermittlung und Kommunikation der Risiken eine große Bedeutung zukommt, um negativen Effekten für den Tourismus vorzubeugen.

\section{Baden in Naturseen und Tauchen}

Die Nutzung von Seen gehört zu den wichtigen Urlaubsangeboten in Österreich mit ca. 12,2 Mio. Nächtigungen (Fleischhacker und Formayer 2007). Insgesamt ist davon auszugehen, dass sich die Bedingungen für den Badetourismus an Österreichs Seen im Zusammenhang mit dem Klimawandel eher verbessern. Die meisten österreichischen Seen sind eingebettet in ein spektakuläres Alpenpanorama und werden in Zukunft unter den Bedingungen des Klimawandels attraktiver. Die auch bei Fleischhacker und Formayer (2007) und Fleischhacker (2019) dargestellten positiven Entwicklungstrends beruhen auch auf der steigenden Zahl von Tagen mit Sonnenschein und hohen Temperaturen. Es wird davon ausgegangen, dass die Saison verlängert wird. Aktuell wird von einer Zunahme der Sommertage (d. h. Tage mit mehr als $25^{\circ} \mathrm{C}$ ) um $40 \%$, einer Verdopplung der Hitzetage (d. h. Tage mit Temperaturen über $30^{\circ} \mathrm{C}$ ), einer Halbierung kälterer Tage mit weniger als $20^{\circ} \mathrm{C}$ und von einem Anstieg der Oberflächenwassertemperatur um ca. $2^{\circ} \mathrm{C}$ ausgegangen (BMWFJ 2012; für das verwendete regionalisierte Klimamodell MM5 siehe das Projekt reclip:more bzw. Loibl et al. 2007; siehe auch Abschn. 2.2.2). Daraus werden positive wirtschaftliche Auswirkungen für die gesamte Region erwartet (Chladek 2005; BMWFJ 2012; Greil 2012). Allerdings zeigt eine Untersuchung von Greil (2012) am Attersee, dass viele Gäste an österreichischen Badeseen dort einen Zweitwohnsitz besitzen. Unter den oben genannten klimatischen Bedingungen wollen zwei Drittel der Zweitwohnungsbesitzerinnen und -besitzer ihren Urlaub künftig verlängern bzw. die Seen öfter besuchen. Demgegenüber wird sich trotz der verbesserten Bedingungen die Aufenthaltsdauer der Urlauberinnen und Urlauber dort nicht ändern, da die Zeiträume durch die Erwerbstätigkeit bestimmt werden. Die Abweichungen lassen sich durch Unterschiede in der sozialen Struktur und im Alter erklären. Dieser Umstand ist bei regionalökonomischen Abschätzungen zu berücksichtigen.
Weiterhin kann der Wasserstand in Badebereichen durch den Klimawandel beeinflusst werden. Eine besondere Betrachtung der Bedingungen am Neusiedler See zeigte, dass, solange der See optisch ausreichend attraktiv ist und als Wasserfläche wirksam ist, die Veränderungen durch mögliche eingeschränkte Bademöglichkeiten für die Urlauberinnen und Urlauber durch Pools oder künstlich angelegte Freibäder kompensiert werden können (Pröbstl et al. 2007). Weiterhin zeigen die Untersuchungen, dass ein Urlaub am Neusiedler See nicht automatisch mit einem Badeurlaub gleichzusetzen ist, sondern verschiedene Gästesegmente weitere Erwartungen und Interessen im Hinblick auf natur-, kultur- und weinbezogene Angebote besitzen und diese teilweise - je nach Segment - auch kompensatorisch wirken (Pröbstl et al. 2007).

Veränderungen des Wasserstandes können darüber hinaus auch die Wassertemperatur des Gewässers oder der Badebereiche beeinflussen. Änderungen der Wassertemperatur von Badeteichen oder kleinen Seen können unter bestimmten Bedingungen das Auftreten von Zerkarien, auch als Badedermatitis bezeichnet, begünstigen. Auch wenn die Zerkarien an der Hautoberfläche absterben, sind die Rötung der Haut, der Juckreiz oder bei Sensibilisierung die Pustel- bzw. Quaddelbildung unangenehm. Zerkarien finden sich in stehenden Süßgewässern, vorrangig mit geringer Wassertiefe. Seltener treten sie in tieferen Wasserzonen auf. Die Parasiten können sich nur vermehren und gedeihen, wenn ihre benötigten Wirte - Wasserschnecken und Enten - anwesend sind. Faktoren, die das Auftreten von Zerkarien begünstigen, sind stehende Süßgewässer, eine niedrige Wassertiefe (insgesamt oder im Uferbereich), das Vorhandensein von Wasserschnecken und Wasservögeln, Schilfgürtel oder andere Wasserpflanzen sowie artenarme Umweltbedingungen (wenige Fische im Wasser). Wenn durch den Klimawandel länger andauernde Hitzeperioden gefördert werden und eine hohe Badewassertemperatur erzeugt wird, dann erhöht sich unter den oben genannten Bedingungen die mögliche Beeinträchtigung durch Zerkarien bei Badenden und tauchenden Gästen ohne Tauchanzug (Moshammer et al. 2014).

Algenblüten in Badeseen waren bisher eher Folge von Nährstoffeinträgen in Gewässer. Änderungen der Wassertemperatur könnten das Vorkommen von Algen begünstigen. Werden in ein Gewässer größere Mengen an Nährstoffen wie Phosphor und Stickstoff eingetragen, dann fördert dies das Wachstum von im Wasser schwebenden und mikroskopisch kleinen pflanzlichen Organismen, zu denen die Blaualgen (wissenschaftlich Cyanobakterien) gezählt werden. Durch Auftreiben der Algen entstehen oft grünlich blaue oder rote Teppiche an der Wasseroberfläche, die dann als Algenblüte bezeichnet werden und vor allem während warmer und niederschlagsarmer Sommermonate auftreten können. Massenansammlungen von Cyanobakterien verschlechtern die Wasserqualität durch eine Verringerung des Lichteinfalls für die am Boden lebenden Wasserpflanzen und durch eine erhöhte Sauerstoffzehrung durch absterbende Algen (Dokulil 
und Teubner 2012). Viele Cyanobakterien produzieren Stoffe verschiedenster chemischer Zusammensetzung, die zum Teil flüchtig sind und unangenehm riechen. Andere Stoffe sind für Mensch und Tier hochgiftig, allen voran das Microcystin (ein Heptapeptid), für das aufgrund seiner weltweiten Verbreitung von der WHO ein Grenzwert von $1 \mu \mathrm{g}$ pro Liter für die maximal zulässige Konzentration im Trinkwasser festgesetzt wurde. Im Hitzesommer 2018 wurden nicht nur Badende, sondern auch Spaziergängerinnen und Spaziergänger mit Hunden in Österreich vor kontaminierten Tümpeln, Schwimmteichen und Uferzonen gewarnt (ORF 21.07.2018).

\section{Fischen als Urlaubs- und Freizeitaktivität}

Es ist davon auszugehen, dass der Klimawandel die Urlaubsaktivität Fischen bzw. Angeln stark beeinflussen wird. Wie bereits beim Baden und Tauchen dargestellt, sind Änderungen der Wassertemperatur zu erwarten, was wiederum negative Auswirkungen auf den Sauerstoffgehalt im Wasser hat. Wie Melcher et al. (2013) zeigen, beeinflusst das Temperaturregime alle Lebensstadien von Fischpopulationen und wirkt sich unter anderem auf das Migrationsverhalten, die Entwicklung, das Laichen, die Fruchtbarkeit und das Wachstum sowie den Stoffwechsel, die Atmung und die Toleranz gegenüber Parasiten aus. Bereits geringe Temperaturveränderungen können ursprüngliche Lebensgemeinschaften langfristig verändern. Neben der Wassertemperatur ist eine mögliche Beeinträchtigung durch den Klimawandel auch im Hinblick auf die Wasserstände und damit die Habitateigenschaften des Gewässers (Ernährungsgrundlage, Versteck, Anbindung an andere Gewässer usw.) möglich.

Niedermair et al. (2008) erwarten, dass bis 2050 die Lebensräume der Kaltwasserfische in Österreich um 20-25 \% schrumpfen werden. Dies bedeutet eine Verschiebung von meist 40-50 km flussaufwärts und ist in allen Fischregionen Österreichs in ähnlichem Ausmaß zu erkennen. Nachdem einzelne Arten, wie z. B. Äsche, Bachforelle und Huchen, bereits infolge anderer anthropogener Eingriffe in ihrem Bestand stark gefährdet sind, können diese zusätzlichen klimabedingten Beeinträchtigungen einzelne Arten an den Rand des Aussterbens bringen. Die wärmeren Gewässer bieten langfristig bessere Lebensbedingungen für Karpfen und exotische Fischarten (Burghardt-Holm 2009). Langzeitanalysen der letzten 30 Jahre zeigen nach Angaben von Melcher et al. (2013) vor allem in Gewässerabschnitten unterhalb von Seen eine Zunahme von wärmetolerierenden Arten (z. B. Aitel). Negative Veränderungen zeigen sich auch in künstlich veränderten Teilstücken, etwa vor einem Stauwehr, in denen sich die Veränderungen noch deutlicher zeigen (Schmutz et al. 2004). Mit den erhöhten Wassertemperaturen steigt auch die Gefahr von Krankheiten bei Fischen. Dies gilt insbesondere dann, wenn die Wassertemperaturen über einen Zeitraum von zwei bis vier Wochen über $15^{\circ} \mathrm{C}$ liegen (Meili et al. 2004). Die genannten Faktoren, wie Habitatveränderungen,
Krankheiten und Stress, wirken zudem zusammen. Das Ausmaß wird jedoch zusätzlich von den jeweiligen natürlichen Rahmenbedingungen, wie Beschattung, Lebensraumheterogenität, Lage im Gewässer usw. beeinflusst. Daher sind allgemeine Aussagen im Hinblick auf eine Veränderung der touristischen Nutzung schwierig abzuleiten.

Eine Literaturübersicht von Hunt (2005) zeigt, dass im Hinblick auf die erholungsbezogene Fischerei neben dem Fang ein vielfältiges Set an weiteren sozialen und biologischen Einflussfaktoren die Attraktivität des Fischens beeinflusst. Hierzu gehören die Verfügbarkeit der bevorzugten Fischart, die Fischgröße, Regelungen und Einschränkungen des Fischfangs, vorhandene Einrichtungen sowie das soziale und ästhetische Umfeld. Daher ist auch für die spezifischen Angebote in Österreich von einer komplexen Situation auszugehen, bei der u. a. die bevorzugten Techniken des Fischens (zum Beispiel Fliegenfischen), die Attraktivität der zu fischenden Arten, das Setting (insbesondere die umgebende Landschaft) und die Anwesenheit weiterer Personen eine entscheidende Rolle spielen (Johnston et al. 2013).

Insbesondere im Urlaub steht meist nicht der Ertrag, sondern das Erlebnis im Mittelpunkt. Hier unterscheiden sich auch die Ansprüche der ,gelegentlichen“ Fischer, der ,technisch versierten" Fischer und derer, bei denen vor allem das Umfeld (Setting) stimmen muss. Während die gelegentlichen Fischer auch in Zukunft mit Karpfen, Hecht u. v. a. Arten auch unter den Bedingungen des Klimawandels gute Bedingungen und attraktive Angeboten vorfinden können, ist dies bei den technisch versierten Anglern und denen, die besonderen Wert auf das Angeln in alpinen Gewässern legen, zunehmend weniger gegeben. Beworben wird derzeit sehr häufig das Fliegenfischen auf Bachforellen. Bereits heute sind schon Einschränkungen der touristischen Angebote, wie zum Beispiel ein Verbot der Entnahme von Äschen zu finden. Wird dies aufgrund der Erwärmung, wie oben dargestellt, noch weniger möglich sein, dann wird das Angebot für die technisch versierten Fischer und solche, die ein bestimmtes naturnahes Ambiente suchen, kleiner und weniger attraktiv. Unter diesen Annahmen sind in Anlehnung an Lewin et al. (2006) Abwanderungen von Urlauberinnen und Urlaubern mit diesem spezifischen Interesse zu erwarten. In diesem Zusammenhang ist auch zu beachten, dass der ökonomische Wert des Angelsportes (Lizenzpreise) bei den inzwischen gefährdeten heimischen Kaltwasserarten am höchsten ist. Auf ähnliche Effekte verweisen Hunt und Moore (2006).

\section{Wassersportaktivitäten (Kanusport, Rafting und Segeln)}

Szenarien zu den möglichen Auswirkungen des Klimawandels zeigen starke Abnahmen der Niederschläge im Sommer und damit verbunden zunehmende Niederwasserstände in Österreich. Allerdings ergeben sich hier deutliche Unterschiede in Abhängigkeit von der Höhenlage (Abschn. 2.2.2). Bisherige 
Studien zu den Auswirkungen der Niederwasserstände zielen vor allem auf die Schifffahrt (Haas et al. 2008). Für die Urlaubsaktivitäten Kanusport, Rafting und Segeln sind der Einfluss des Klimawandels auf die Gewässer und insbesondere die Wassertiefe von besonderer Relevanz. Die Betroffenheit des Kanusports wird von Bristow und Jenkins (2018) mit dem Skisport verglichen. Für Österreich liegen Ergebnisse bezogen auf den Kanusport und das Segeln am Neusiedler See vor.

Eine Studie von Jindrich (2012) zu Klimawandel und Kanusport zeigt, dass es sich um eine beliebte Urlaubsaktivität in Österreich handelt, die aufgrund der natürlichen Gegebenheiten am häufigsten in Form von alpinem Kajakfahren bzw. alpinem Wildwasserfahren ausgeübt wird (ca. $80 \%$ ). Die bevorzugten Gebiete liegen in den Bundesländern Steiermark und Tirol, insbesondere im Salzkammergut, den Wildalpen, im Gesäuse und im Ötztal. Nachdem alle Flüsse und Seen nur bei geeigneten Wasserständen, d. h. ab ca. $30 \mathrm{~cm}$ Wassertiefe, befahren werden können (Zeilner 2007; DSHS o.J.), gefährdet ein niedriger Wasserstand die Sportausübung insgesamt. Darüber hinaus erhöht ein niedriger Wasserstand auch die Gefahren für Urlauberinnen und Urlauber. In flachen Gewässern steigt zudem die Gefahr der Grundberührung oder der Sedimentaufwirbelung, wodurch es vermehrt zu ökologischen Belastungen kommen kann.

Die Untersuchung von Jindrich (2012) bestätigt weiterhin, dass sich aus der Sicht der Kanutinnen und Kanuten der Wasserstand in den letzten Jahren geändert hat und immer mehr Niedrigwasserstände, vor allem im Sommer, vorkommen. Die Befragten beschreiben mehrheitlich eine Verschiebung der Abflussmaxima, die sie auf den Klimawandel zurückführen. Die Kanufahrenden verwiesen auch darauf, dass insgesamt Wildwasser seltener befahrbar sind und vielen Schwankungen unterliegen, sodass auf Flachwasser, wie Seen, ausgewichen wird, wo es keine Einschränkungen durch Niederwasser gibt. Die Ergebnisse werden durch internationale Studien bestätigt (Scott und Lemieux 2010; Bowker et al. 2014; Bristow und Jenkins 2018).

Ergebnisse liegen auch für die Destination Neusiedler See vor (Pröbstl et al. 2007). Eine Befragung von Urlauberinnen und Urlaubern zeigte dort, dass für ein bestimmtes Gästesegment das Segeln ein Kernmotiv für den Urlaub darstellt und Einschränkungen dieser Aktivität für entsprechend interessierte Urlauberinnen und Urlauber nicht kompensierbar sind. Eine mögliche Einschränkung des Segelreviers für bestimmte Bootsklassen aufgrund einer geringen Wassertiefe wird daher negativ bewertet. In diesem Fall ist von einer Abwanderung entsprechender Urlaubersegmente auszugehen.

\section{Flugsportarten (Gleitschirmfliegen, Segelfliegen, Ballon- oder Drachenfliegen)}

Im Hinblick auf die möglichen Auswirkungen der Klimaänderungen für Sportfliegen und Ballonfahren müssen nach Haas (o.J.) die verschiedenen Jahreszeiten unterschieden und die jeweiligen Bedingungen separat betrachtet werden. Die nach- stehenden Ausführungen basieren, nachdem es dazu keine wissenschaftlichen Publikationen gibt, auf Aussagen von Aktiven, Vereinen und Verbänden in diesem Bereich aus dem Jahr 2018. Die Forschungsdefizite werden durch die meteorologischen Forschungseinrichtungen in Österreich bestätigt.

Im Zusammenhang mit der Zunahme der Niederschlagstätigkeit im Winter wird erwartet, dass es weniger günstige Wetterlagen für Ballonfahrten und Sportfliegen in den Wintermonaten geben wird. Nachdem Segelflieger in dieser Jahreszeit ohnehin nicht fliegen können, sind sie eher indirekt betroffen, zum Beispiel dadurch, dass für die ersten Starts im Frühjahr der Untergrund auf der Start- und Landebahn zu feucht ist. Bezogen auf den Sommer werden mögliche Effekte von Trockenperioden und Wetterextremereignissen diskutiert. Die Folgen von Sommertrockenheit sind komplex und betreffen die Flugsportarten in unterschiedlicher Weise. Einerseits werden häufiger als bisher stabile Schichtungen mit geringer Bewölkung und wolkenlose Bedingungen erwartet. Daraus ergeben sich dem Deutschen Gleitschirm und Drachenflugverband e. V. zufolge mehr günstige Wetterlagen für Ballonfahren und für Motorfliegen. Dieselben Bedingungen beeinflussen jedoch die Tragfähigkeit der Ballone wegen des Temperaturanstieges in ungünstiger Weise. Auch für Segelflieger ergeben sich danach wegen der hohen Stabilität häufiger weniger günstige Wetterlagen im Sommer, da trotz der Sonneneinstrahlung nur schwache Thermik entsteht. Weiterhin beeinflusst die $\mathrm{Zu}$ nahme von Wetterextremen zwischen den Trockenperioden den Flugsport negativ. Neben schweren Gewittern mit Hagel, Turbulenz und weiteren Wetterrisiken, die generell für alle Luftsportarten ungünstig sind, wird auch eine Zunahme der Häufigkeit von Luftwirbeln (Dust Devils) mit extremen Wetterrisiken für die Luftfahrt erwartet (Schubert 2010).

Es scheint einen Trend zu geben, dass sich günstiges Segelflugwetter vom Sommer weg in das Frühjahr und zum Herbst hin verschiebt. Höhere Temperaturen führen zu einer Verlängerung der Übergangsjahreszeiten Frühjahr und Herbst. Das bedeutet, dass die Thermik im Frühjahr früher beginnt und im Herbst später endet, das ist zwar ungünstig für Ballonfahrten in diesen Jahreszeiten, aber günstig für Segelflüge, falls gestartet werden kann. Betrachtet man die Länge der täglichen Thermikzeiten, dann ergibt sich eine Verkürzung des Zeitfensters für Ballonfahrten, sowohl am Morgen als auch am Abend, gleichzeitig kommt es aber zu einer Verlängerung des Zeitfensters für das Segelfliegen oder das Gleitschirmfliegen. Abnehmende Windgeschwindigkeiten, vor allem im Herbst (September-Oktober), können sich günstig auf das Ballonfahren auswirken.

Die Bedingungen in den Alpen sind durch die Exposition und die Berg-/Talwindsysteme vielerorts noch komplexer. Die Diskussion betrifft in diesem Zusammenhang besonders die Thermik. In sommerlichen, trockenheißen Witterungsperioden setzt die Thermik bei Zufuhr kontinentaler Luft unter Hochdruckeinfluss früher und kräftiger ein. Im Einfluss höher reichender und stärkerer Talwinde wird die Ablösung 
Abb. 7.4 Beitrag des Fahrradtourismus zur direkten Wertschöpfung im Jahr 2008. (Datenquelle: Miglbauer et al. 2009; Grafik: Alice Wanner und Claudia Hödl)

\section{Direkte Wertschöpfung durch den Radverkehr in Österreich 2008 (in Mio. €)}

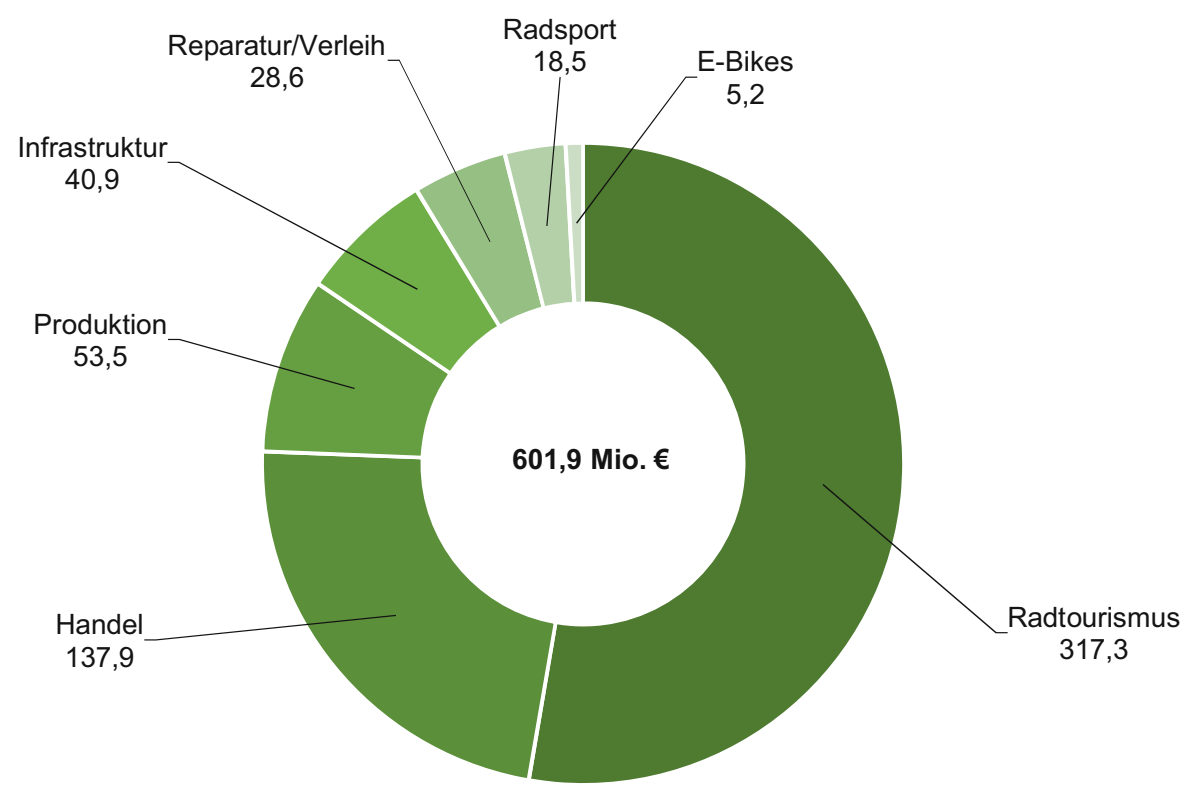

der Thermik turbulenter. Die Häufigkeit von Luftwirbeln (Tromben, Dust Devils) nimmt zu. Gerade auf der Alpennordseite, wo das Thermikfliegen an den Südhängen der Gebirgsgruppen systematisch im Lee der aus Norden wehenden Talwinde stattfindet, wird daher ein Anstieg des Unfallrisikos - auch für geübte Pilotinnen und Piloten - erwartet (Schubert 2010). Ein weiterer Einfluss wird durch sich verändernde Talwinde erwartet. Talwinde können quer, entgegengesetzt zur oder auch mit der Höhenströmung jederzeit erhebliche Windgeschwindigkeiten erreichen. Dies ist abhängig von den Windgeschwindigkeiten des überregionalen und an den Alpen verstärkten Druckgradienten. Insbesondere heißere Sommer verändern die Talwinde im Hochdruckeinfluss. Sie setzen bereits tageszeitlich früher ein, halten länger an, werden vertikal mächtiger und sind im Tagesverlauf deutlich stärker. Damit nehmen sie - nach Ansicht der Verbände - in den Monaten Juni bis August gefährlichen Einfluss auf den Flugsport.

Die beschriebenen Veränderungen zeigten sich in heißen Sommern, z. B. 2015 und 2019, als durch die hohen Temperaturen und die veränderte Thermik Paraglider bis auf den Gipfel des Mont Blanc kamen (O'Connor 2015; Armstrong 2019)

Für Flugschulen ergeben sich Einschränkungen im Ausbildungsbetrieb. Nachdem Flugschulen darauf hinweisen, dass diese Veränderungen vor allem für Wenigflieger und Ungeübte ein Problem darstellen können und Anpassungsstrategien in der Ausbildung zu diskutieren sind, ist mit Auswirkungen auf den Tourismus zu rechnen.

\section{Mountainbiken und Radfahren}

Der Radsport als zentrale Urlaubsaktivität hat, wie eingangs dargestellt, erheblich zugenommen und wird inzwischen als eigene Urlaubsform statistisch geführt. Derzeit wird von 18,6 Mio. Mountainbike-Nutzern und 40,4 Mio. Tourenradlerinnen und -radlern im Alpenraum ausgegangen (Pechlaner et al. 2015). Ein deutliches Wachstum ist beim Verkauf von E-Bikes zu erkennen. In Österreich wurden 2017 über 120.000 E-Bikes verkauft, 67.000 davon waren E-Mountainbikes (ÖAMTC 2019). In Deutschland wurden 2018 rund 980.000 E-Bikes verkauft. Dies entsprach $36 \%$ Zuwachs im Vergleich zum Vorjahr. Damit hat in Deutschland fast jedes vierte verkaufte Rad einen E-Motor (Fahrradportal 2019). Nachdem von dem deutschen Zweirad-Industrie-Verband ein mittel- bzw. langfristiger Anstieg des Marktanteils von E-Bikes auf 30-35\% erwartet wird, ist auch von einer Wirkung auf die Nachfrage in Österreich auszugehen.

Der Radurlaub gehört in Österreich mit $13 \%$ zu den beliebtesten Urlaubsarten im Sommer (WKO 2018). Bei den deutschen Radurlauberinnen und -urlaubern liegt Österreich auf Platz 1 der ausländischen Reisedestinationen (BMVIT 2013). Die direkte Wertschöpfung durch Radverkehr beträgt 601,9 Mio. $€$, über die Hälfte wird durch den Radtourismus erzielt (Abb. 7.4).

Die Abb. 7.5 verdeutlicht die räumliche Verteilung der wichtigsten Radrouten in Österreich. Zu diesen zählen auch die vier durch Österreich verlaufenden Radwege des europäischen Radfernroutennetzes EuroVelo (EV 6, 7, 9 und 13) ${ }^{4}$.

\footnotetext{
${ }^{4}$ Die Europäischen Radfernrouten EV 6 und EV 7 werden zwar nicht explizit in der Abb. 7.5 genannt, ihr Verlauf entspricht aber großteils den abgebildeten Hauptradrouten (EV $6 \bumpeq$ Donauradweg, EV $7 \cong$ Tauern-, Alpe-Adria- und Drauradweg). Einzig EV 13 wird nicht abgebildet; diese verläuft entlang der österreichischen Grenze zur Tschechischen Republik, Slowakei und Ungarn. Für detaillierte Informationen siehe https://www.eurovelo.at/.
} 
Abb. 7.5 Wichtige Radrouten in Österreich. (Radlobby-Radtourismus 2016)

\section{Österreichs 14 Hauptradrouten}

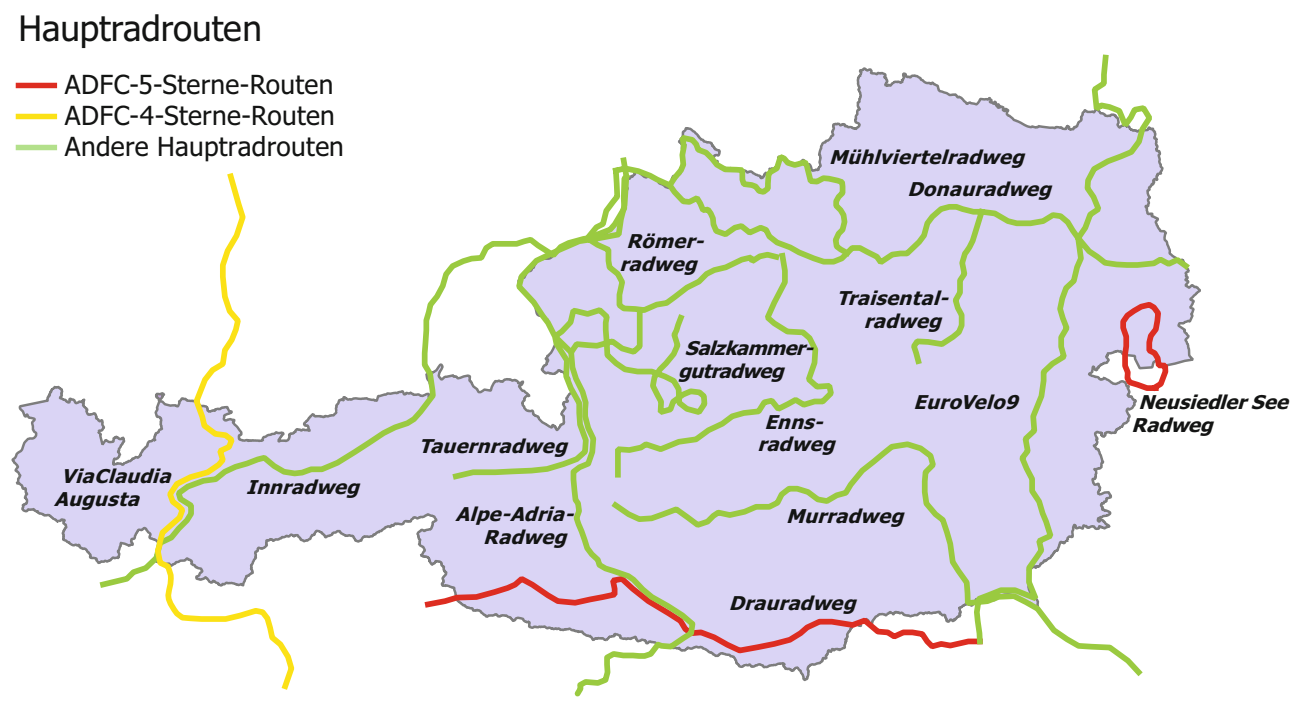

Der Verlauf dieser touristisch relevanten Routen gestaltet sich überwiegend entlang von Gewässern (vgl. Enns, Donau, Traisen, Inn, Drau oder Mur).

Die Verlängerung der Saison wirkt sich grundsätzlich positiv auf den Radtourismus aus, insbesondere die Frühjahrs- und Herbstsaison werden attraktiver. Bei einer detaillierten Betrachtung der Auswirkungen muss zwischen den in Abb. 7.5 dargestellten Radrouten, die vor allem für mehrtätige Touren mit dem Trekkingrad entwickelt wurden, und der Nutzung des Mountainbikes unterschieden werden. Die Urlauberinnen und Urlauber, die auf den Radrouten unterwegs sind, können durch Starkregenereignisse und längere Hitzeperioden im Sommer betroffen sein. Hitzetage, die in Talräumen durch eingeschränkten Luftaustausch besonders wirksam sind, können die üblichen Streckenabschnitte pro Tag einschränken und zudem zu den oben genannten gesundheitlichen Problemen bei körperlicher Anstrengung führen (vgl. Unterkap. Einfluss von Temperatur, Sonnenscheindauer und Niederschlägen in Abschn. 7.3.1).

Beim Mountainbiken können zu den oben genannten Effekten (Hitze, Gewitter, lokale Starkregen) auch Beeinträchtigungen durch den Verlust oder Beschädigung der Wege, Gefahren durch Murenabgänge, Steinschlag und Rutschungen hinzukommen (Abb. 7.1). Die Betroffenheit ist hier mit dem Bergwandern (siehe dort) vergleichbar (Pröbstl und Damm 2009).

Trotz dieser Betroffenheit wird der Radtourismus im Zusammenhang mit Anpassungsstrategien diskutiert. So könnte das Radfahren im Hinblick auf die touristische Wertschöpfung langfristig das „neue Skifahren“ darstellen und mögliche Einschränkungen im Wintersport kompensieren (z. B. Rottenberg 2016). Weiterhin wird von einem Umstieg aufs Radfahren, als wichtige Urlaubsaktivität, ein positiver Impuls für das Verhalten im Alltag erwartet (siehe Kap. 13 Anpassungsstrategien und Kap. 3 Mobilität).

\section{Golfen}

Die Auswirkungen des Klimawandels auf den Golftourismus werden international diskutiert (Scott et al. 2018). Zwar wird allgemein davon ausgegangen, dass sich durch den Klimawandel voraussichtlich die Golfsaison insgesamt deutlich verlängert, allerdings wird - je nach Lage - auch mit erheblichen Problemen durch Trockenheitsstress gerechnet (Scott und Jones 2007). Auch in Verbindung mit den Folgen der touristischen Entwicklung insgesamt wird darauf hingewiesen, dass nicht nur der Wasserbedarf von Touristinnen und Touristen bei der Übernachtung betrachtet werden dürfe, sondern auch ,wasserintensive“ Aktivitäten, wie der Golfsport, einzubeziehen seien (Gössling et al. 2015).

Im Zusammenhang mit dem Klimawandel wurden im Jahr 2018 erhebliche Trockenheitsschäden an der Vegetation, insbesondere an Abschlagsplätzen auf Golfplätzen und Putting Greens, kritisch diskutiert, da europaweit viele Golfplätze die betroffenen Bereiche nicht mehr ausreichend bewässern und damit für attraktive Bedingungen für Erholungssuchende und Urlaubende sorgen konnten (Himmel 2018). Nachdem Rasengräser bis zu 90 \% aus Wasser bestehen, benötigt $1 \mathrm{~m}^{2}$ Rasenfläche bei einer Temperatur von $20{ }^{\circ} \mathrm{C}$ täglich ca. 21 Wasser, um Verluste auszugleichen. Bei $30{ }^{\circ} \mathrm{C}$ sind es bereits $5 \mathrm{l} / \mathrm{m}^{2}$. Ein Absterben ist bei hohen Lufttemperaturen von ca. $40{ }^{\circ} \mathrm{C}$ bzw. Bodentemperaturen 
um $50{ }^{\circ} \mathrm{C}$ zu beobachten, da dann überlebenswichtige Proteine in der Pflanze zerstört werden (Voß und Thörner o.J.). Entsprechende Temperaturen können an heißen Sommertagen dann relativ schnell erreicht werden, wenn die Flächen ganztägig der Sonne ausgesetzt sind und wenn nach Süden ausgerichtete Hanglagen betroffen sind (Voß und Thörner o.J.). Bei gleichzeitig auftretendem Wind steigt der Wasserbedarf von Rasenflächen weiter an.

Bei einem 18-Loch-Golfplatz wird in Mitteleuropa im Durchschnitt von einem Verbrauch von 50-100 Mio. Liter Wasser pro Jahr ausgegangen (Scott et al. 2018). Bei rund 80 Golfplätzen in Österreich ergibt sich daraus ein Wasserbedarf von 4-8 Mrd. Liter. Damit weist der Golftourismus im Hinblick auf Trockenheitsstress eine hohe Verletzbarkeit auf, dem meist mit Bewässerungen begegnet wird. Allerdings sind diese mit anderen Belangen abzuwägen. Dazu gehören u. a. die Trinkwasserversorgung, die landwirtschaftliche Nutzung, aber auch Belange des Natur- und Artenschutzes (Rodriguez Diaz et al. 2007). So zählt auch im Alpenraum der Klimawandel zu den wichtigsten Umweltfragen im Zusammenhang mit dem Golfsport ${ }^{5}$.

Holz (2015) hat im Rahmen einer Befragung von Greenkeepern aus Deutschland sowie angrenzenden europäischen Ländern festgestellt, dass das Thema klimatische Veränderungen in der Praxis bereits eine wichtige Rolle spielt. Die Onlineumfrage zeigte, dass $65 \%$ der Befragten bereits Folgen des Klimawandels feststellen konnten. Diese betrafen vor allem eine Erhöhung des Pflegebedarfs (30 \%) und einen erhöhten Aufwand bei der Bewässerung (23\%). Diese Veränderungen führten bei der Hälfte der Befragten zu einer durchschnittlichen Erhöhung der monatlichen Arbeitszeiten von mehr als 5 Stunden, die meist für die Beregnungsanlage, deren Kontrolle und Wartung anfielen. Rund $45 \%$ der Greenkeeper sehen bereits insgesamt negative Auswirkungen auf den Betrieb zukommen, nur $16 \%$ können positive Effekte durch den Klimawandel, etwa in einer verlängerten Saison, erkennen. So erstaunt nicht, dass $80 \%$ bereits heute eine tägliche Aufzeichnung von Wetterdaten durchführen. Die Mehrheit der Greenkeeper (78 \%) gab weiterhin an, dass sie bereits ihre übliche Bewässerungsstrategie (insbesondere mehr und häufigere Wassergaben) ändern mussten. Etwa $25 \%$ der Befragten veränderten aufgrund der Folgen der Klimaerwärmung auch die Schnitthäufigkeit und Pflege der Flächen. Allerdings nutzen nur wenige Manager (14 \%) die Möglichkeit der Bodenfeuchtemessung als wichtige Maßnahme zur sparsamen und kontrollierten Wassergabe.

Abb. 7.6 verdeutlicht die Problematik für Österreich und zeigt, dass sich eine große Zahl an Golfplätzen bereits jetzt in trockenen Gebieten befindet. Diese können in Zukunft von durch den Klimawandel bedingten häufiger auftretendem Wassermangel betroffen sein. Anhaltspunkte für die

\footnotetext{
${ }^{5}$ Vgl. https://www.golfsuisse.ch.
}

Verletzlichkeit liefern auch die Analysen zur Betroffenheit von landwirtschaftlichem Grünland. Danach ist von einer potenziellen Betroffenheit vor allem in Bereichen Niederösterreichs nördlich des Alpenhauptkammes, Bereichen in der Süd- und Oststeiermark, im südlichen Kärnten sowie im Burgenland auszugehen (Birngruber et al. 2011).

In besonders betroffenen Regionen kann es daher zu Engpässen bei der Beregnungswasserversorgung kommen. Bei einer Wasserentnahme von Oberflächenwasser aus Seen und Flüssen sowie bei oberflächennahen Grundwasserentnahmen ist aufgrund absinkender Wasserspiegel auch ein Ausfall der Beregnungswasserversorgung möglich (Himmel 2018). Bei Golfanlagen, die nicht über ausreichend Wasser verfügen oder keine Fairway-Beregnungsanlage haben, kann es auch zum Totalausfall der Rasengesellschaften kommen. Der Umfang der möglichen Auswirkungen hängt von den verfügbaren Wasserressourcen und den einsetzbaren Bewässerungsanlagen ab. Allerdings sind vielerorts die Wasserressourcen für die Pflege und Bewässerung begrenzt. Das Erteilen von Wasserentnahmerechten durch die zuständigen Behörden hängt immer von der regionalen Grundwasserneubildung ab. Auch in diesem Zusammenhang wird der Einfluss des Klimawandels spürbar. Für den Süden, Norden und Westen Österreichs wird eine Zunahme der Winterniederschläge erwartet, sodass die Grundwasserneubildung in diesen Regionen gleich bleiben oder sogar zunehmen könnte. In niederschlagsarmen Regionen im Osten Österreichs ist jedoch eine Abnahme der Grundwasserneubildung wahrscheinlich, sodass dort der Nutzungsdruck auf den Grundwasserkörper voraussichtlich steigen wird (BMLFUW 2017).

\section{Naturerlebnisangebote im Zusammenhang mit Schutzgebietstourismus}

In Österreich sind rund $27 \%$ des Bundesgebietes naturschutzrechtlich geschützt. Einen strengeren Schutz, in Form von Nationalparken, Naturschutzgebieten oder Natura-2000-Gebieten, genießen ca. $16 \%$ der Fläche, $11 \%$ sind vor allem aufgrund ihrer landschaftlichen Schönheit und Vielfalt geschützt, z. B. in Form von Landschaftsschutzgebieten und geschützten Landschaftsteilen. Viele dieser geschützten Landschaftsteile besitzen auch eine hohe Bedeutung für den Tourismus (ÖROK Atlas 2015) und bieten besondere Naturerlebnisangebote (Führungen, Lehrpfade, spezielle Einrichtungen) an.

Im Zusammenhang mit der Aktivität Naturbeobachtung und Naturerlebnis wird eine steigende Nachfrage erwartet (Pröbstl-Haider und Haider 2014; Pröbstl-Haider und Melzer 2015; Pröbstl-Haider und Pütz 2016; Schamel und Job 2017). Auch im Hinblick auf den Klimawandel wird erwartet, dass dieses Segment verbesserte Rahmenbedingungen vorfindet, da von einer verlängerten Saison und Temperaturerhöhung, die den Aufenthalt in der Natur begünstigen werden, ausgegangen wird. Insgesamt bestätigt eine Auswertung für Orte mit Schutzgebietstourismus (Fleischhacker 2019) diesen po- 


\section{Klimatische Wasserbilanz}

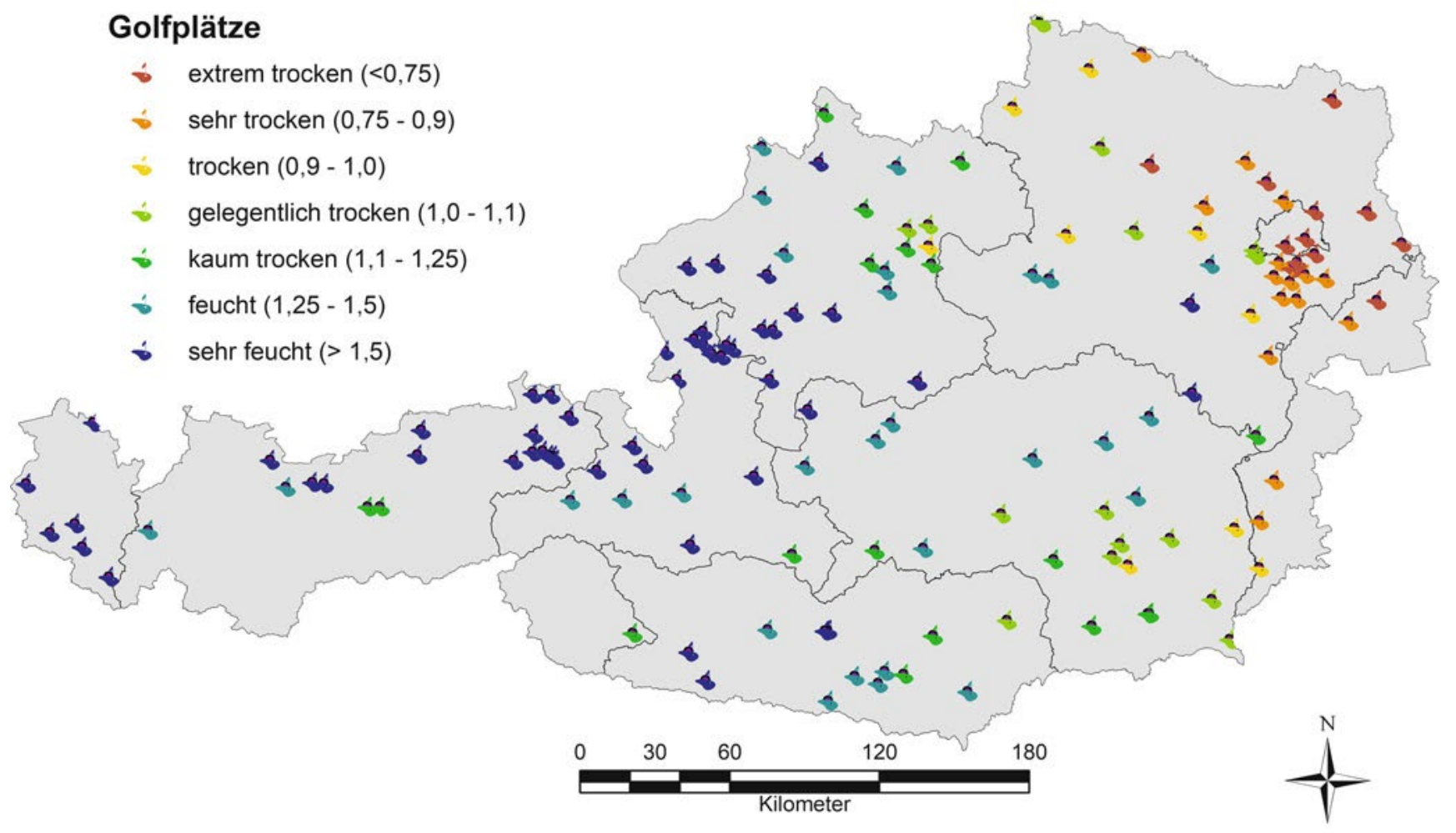

Abb. 7.6 Verteilung von Golfplätzen in Österreich, die von Wassermangel bedroht sind. (Datenquelle: ZAMG, INCA, UBA, ESRI; Grafik: Herbert Formayer). Die klimatische Wasserbilanz ist hier als

sitiven Trend. Betrachtet wurden dabei 247 Gemeinden mit Flächenanteilen an ausgewählten gemanagten großflächigen Schutzgebieten, wie Nationalparks, Naturparke, Ramsar-Gebiete und Biosphärenparks. Naturerlebnisangebote als spezifische Aktivität können, müssen aber nicht mit geschützten Lebensräumen verbunden sein. Die Literatur (vgl. BMWFJ 2012) fasst diesen Aspekt jedoch oftmals zusammen.

Durch den Klimawandel werden im Hinblick auf das Naturerlebnis und den Schutzgebietstourismus allgemein aber auch negative Effekte durch den Verlust an Biodiversität, Verlust an einzigartigen Naturphänomenen (wie zum Beispiel Gletscher), Beeinträchtigungen des Erlebnisses durch Wetterextreme und durch Landschaftsveränderungen auf Almen oder durch Überschwemmungen erwartet (BMWFJ 2012).

Allerdings muss man herausstellen, dass sich diese grundsätzlich geäußerten Bedenken (abgesehen von Auswirkungen auf die Zugänglichkeit) nicht durch Forschungsarbeiten belegen lassen. So konnten bislang Besucherrückgänge im Bereich von sich stark zurückziehenden Gletschern ebenso wenig nachgewiesen werden wie Effekte durch eine veränderte Biodiversität im Berggebiet. Nicht nachgewiesen ist auch der Effekt, dass die nachweisbaren Auswirkungen auf die Biodiversität, wie zum Beispiel phänologische Verschiebungen, Veränderungen des Vogelzuges oder der deutliche
Verhältnis Jahresniederschlag zu potenzieller Evapotranspiration dargestellt. Ein Wert von 1 bedeutet daher, dass Verdunstung und Niederschlag gleich groß sind.

Rückgang einzelner Pflanzen, sofern diese dem Klimawandel zuzuordnen waren, zu touristisch messbaren Veränderungen geführt hätten. Dies liegt wohl auch daran, dass Gäste die Verhältnisse in der Regel nicht vergleichen können und diese als einmaliges Ereignis erleben (vgl. auch Schwankungen des Wasserstands im Nationalpark Neusiedler See in Pröbstl et al. 2007). Im Blick auf weitere erhebliche Landschaftsveränderungen siehe auch die Ausführungen in Abschn. 7.3.1.

Bislang zeigt ein Blick auf Schutzgebietstourismus und Wetterbedingungen eher eine ausgleichende Wirkung. So wurde in Jahren mit deutlich niederschlagsreicheren Sommern eine längere Verweildauer der Gäste im Vergleich zu Gebieten außerhalb von Schutzgebieten nachgewiesen (Fleischhacker und Pauer 2001; siehe auch Abschn. 7.4 zu den Anpassungsstrategien).

\subsection{Anpassungs-, Minderungsmaßnahmen und Strategien}

\subsection{1 Überblick}

Bevor im Detail für jede der wesentlichen Sommeraktivitäten Anpassungs- und Minderungsmaßnahmen sowie strategische 
Konzepte entwickelt werden, werden zu Beginn des Abschnitts ein Überblick und eine Zusammenfassung der beschriebenen Effekte vorgestellt. Dieser Überblick hebt die Aktivitäten hervor, bei denen die Erforderlichkeit von Maßnahmen besonders hoch ist, und zeigt bei welchen Aktivitäten auch positive Langzeitwirkungen zu erwarten sind.

Diese Bezüge sind in Abb. 7.7 und 7.8 nachstehend dargestellt. Abb. 7.7 listet die erwarteten positiven Wirkungen auf. Dabei zeigt sich, dass durch die Temperaturänderung mit hoher Sicherheit positive Effekte für Wandern, Radfahren, Baden, Wassersport, Flugsportarten und Golf erwartet werden. Die Mitigation bezieht sich hier überwiegend auf Maßnahmen im Zusammenhang mit der Anreise (Kap. 3), der Übernachtung (Kap. 4) und der Gastronomie (Kap. 5).

Auf die weiteren in Kap. 2 dargestellten klimainduzierten Phänomene ergeben sich die in Abb. 7.8 dargestellten Effekte, die in den nachstehenden Unterkapiteln zusammen mit Mitigations- und Anpassungsmaßnahmen beschrieben werden.

Die Abbildung zeigt, dass die Urlaubsaktivität Fischen und der Hochgebirgstourismus mit Bergtouren und Klettern erheblich betroffen sind und trotz Mitigation und Adaption mit Destinationswechsel gerechnet werden muss. Für beide Aktivitäten sind spezifische Forschung und Monitoring erforderlich. Von Hitze sind Wandern und Radfahren in geringem bis mäßigen Umfang betroffen, wobei entsprechende Adaptionsmaßnahmen gesetzt werden können. Anders verhält es sich bei Flugsport mit bislang wissenschaftlich nicht untersuchten Veränderungen der Thermik, die bis zum Destinationswechsel führen können. Belastende Effekte ergeben sich auch beim Klettern. Bei länger anhaltenden Trockenheitsperioden werden gravierende Folgen für Baden, Fischen, Wassersport, Klettern und Golf für wahrscheinlich erachtet. Trotz Anpassungs- und Mitigationsmaßnahmen sind Destinationswechsel und/oder Aufgabe der Aktivität möglich. Im Bereich Fischen, Klettern und Golf wird Forschungs- und Monitoringbedarf gesehen.

Für die meisten Aktivitäten werden eher geringe Effekte durch lokale Starkniederschläge und kleinräumige Gewitterstürme erwartet, da Anpassungsmaßnahmen möglich sind. Dies gilt nicht für das Klettern und Flugsportarten. Daher wird im Bereich des Wassersports und Flugsports der Aufbau eines Frühwarnsystems für erforderlich gehalten.

Die Betroffenheit der einzelnen Aktivitäten und mögliche Maßnahmen sind in Abschn. 7.4.2 ausführlich beschrieben. Die Zusammenstellung zeigt, dass für viele Natursportaktivitäten, die im Mittelpunkt eines Urlaubs stehen, die Überwachung von Veränderungen (aktivitätsbezogenes Umweltmonitoring) die Grundlage für die Gefahrenminimierung bildet. Dies gilt zum Beispiel im Hinblick auf die Pollenbelastung, Wassertemperaturen, Niederschlagsverteilung oder die Veränderung von Thermik. Ein weiterer wichtiger Aspekt betrifft die technische Anpassung, wie etwa Anpassung der Geräte oder der Ausübung. Schließlich kann die Betroffenheit auch zu einer Neupositionierung des Produkts bzw. Angebots führen.

Abb. 7.7 Klimainduzierte Phänomene mit positiver Wirkung für touristische Aktivitäten und darauf ausgerichtete Mitigationsmaßnahmen

\begin{tabular}{|c|c|c|c|}
\hline $\begin{array}{l}\text { Wirkung klima- } \\
\text { induzierter } \\
\text { Phänomene } \\
\text { auf Aktivitäten }\end{array}$ & Mögliche Folgen & $\begin{array}{l}\text { Erheblichkeit der } \\
\text { Veränderung/ } \\
\text { Bewertungssicherheit }\end{array}$ & Mitigation \\
\hline \multicolumn{4}{|c|}{ Temperaturänderung } \\
\hline Wandern & $\begin{array}{l}\text { Saison- } \\
\text { verlängerung }\end{array}$ & +1 & $\begin{array}{l}\text { Siehe Anreise (Kap. 3), Übernachtung } \\
\text { (Kap. 4) und Gastronomie (Kap. 5) }\end{array}$ \\
\hline Radfahren & $\begin{array}{l}\text { Saison- } \\
\text { verlängerung }\end{array}$ & +1 & $\begin{array}{l}\text { Siehe Anreise (Kap. 3), Übernachtung } \\
\text { (Kap. 4) und Gastronomie (Kap. 5), } \\
\text { Ausleihen der Fahrräder vor Ort, anstelle } \\
\text { des Transports mit dem Pkw }\end{array}$ \\
\hline Baden & $\begin{array}{l}\text { Saison- } \\
\text { verlängerung, } \\
\text { verbesserte } \\
\text { Bedingungen }\end{array}$ & +1 & $\begin{array}{l}\text { Siehe Anreise (Kap. 3), Übernachtung } \\
\text { (Kap. 4) und Gastronomie (Kap. 5) }\end{array}$ \\
\hline Wassersport & $\begin{array}{l}\text { Saison- } \\
\text { verlängerung }\end{array}$ & +1 & $\begin{array}{l}\text { Siehe Anreise (Kap. 3), Übernachtung } \\
\text { (Kap. 4) und Gastronomie (Kap. 5) }\end{array}$ \\
\hline Flugsport & $\begin{array}{l}\text { Saison- } \\
\text { verlängerung }\end{array}$ & +1 & $\begin{array}{l}\text { Siehe Anreise (Kap. 3), Übernachtung } \\
\text { (Kap. 4) und Gastronomie (Kap. 5) }\end{array}$ \\
\hline Golf & $\begin{array}{l}\text { Saison- } \\
\text { verlängerung }\end{array}$ & +1 & $\begin{array}{l}\text { Siehe Anreise (Kap. 3), Übernachtung } \\
\text { (Kap. 4) und Gastronomie (Kap. 5) }\end{array}$ \\
\hline
\end{tabular}

Legende:

Erheblichkeit der Veränderung für den Tourismus:

Es sind nur erhebliche positive Effekte dargestellt, klimainduzierte Phänomene ohne Wirkungen sind nicht dargestellt.

+1: positive Wirkung

Sicherheit der Aussage:

Hoch 


\begin{tabular}{|c|c|c|c|c|c|}
\hline 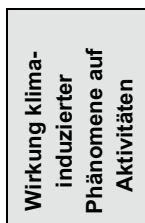 & Mögliche Folgen & 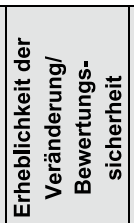 & $\begin{array}{c}\text { Mitigation } \\
\text { (Maßnahmen, zur Reduktion der } \\
\text { Treibhausgasemissionen, zusätzliche } \\
\text { Maßnahmen zu Anreise (Kap. 3), } \\
\text { Ubernachtung (Kap. 4) und Gastronomie } \\
\text { (Kap. 5) }\end{array}$ & $\begin{array}{c}\text { Adaption } \\
\text { (Anpassungsmaßnahmen zur Vermeidung negativer Effekte } \\
\text { durch den Klimawandel) }\end{array}$ & 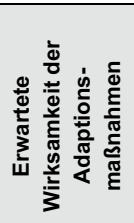 \\
\hline
\end{tabular}

\section{Temperaturänderung}

\begin{tabular}{|l|l|c|}
\hline Fischen & $\begin{array}{l}\text { Verschiebung der } \\
\text { Fischarten- } \\
\text { zusammensetzung, } \\
\text { Verluste attraktiver Arten }\end{array}$ & -3 \\
\hline Klettern & $\begin{array}{l}\text { Verlust von Permafrost, } \\
\text { Steinschlagrisiko, } \\
\text { Verschlechterung der } \\
\text { Verbindungen im } \\
\text { Gletscherbereich }\end{array}$ & -3 \\
\hline
\end{tabular}

Gewässerbegleitende Pflanzmaßnahmen und Renaturierung von Gewässern, Abwägung mit energetischer Nutzung und

Wasserentnahme keine
Lebensraumverbessernde Maßnahmen, Pflanzmaßnahmen zur Beschattung (Kühlung des Wassers und Erhaltung des Sauerstoffgehalts), Destinationswechsel wahrscheinlich

Information und angepasstes Kartenmaterial,

Sicherung gefährlicher Bereiche durch Netze, Ausbau bzw. Verlegung von Wegen und Steigen, neue Streckenführungen, Verschiebung des Zeitfensters (Klettern eher in den Morgenstunden), Destinationswechsel möglich

Hitze

\begin{tabular}{|l|l|c|l|}
\hline Wandern & $\begin{array}{l}\text { Kreislaufbelastend bei } \\
\text { Langstreckenwanderungen }\end{array}$ & -1 & keine \\
\hline Radfahren & $\begin{array}{l}\text { Kreislaufbelastend am Berg } \\
\text { und bei Langstrecken }\end{array}$ & -2 & keine \\
\hline Flugsport & Veränderungen der Thermik & -2 & $\begin{array}{l}\text { Anlagen zur Energiegewinnung auf } \\
\text { Hangaranlagen und Gebäuden der } \\
\text { Flugschulen. }\end{array}$ \\
\hline Klettern & $\begin{array}{l}\text { Zunahme von Risiken in } \\
\text { Höhenlagen }\end{array}$ & -3 & keine \\
\hline
\end{tabular}

Trockenperioden

\begin{tabular}{|l|l|c|}
\hline Baden & $\begin{array}{l}\text { Mögl. Belastungen z. B. } \\
\text { durch Algenwuchs und } \\
\text { Zerkarien }\end{array}$ & -1 \\
\hline Fischen & $\begin{array}{l}\text { Wasserstand reduziert, } \\
\text { Belastung der Fische, } \\
\text { Verlagerung der Bestände }\end{array}$ & -3 \\
\hline Wassersport & $\begin{array}{l}\text { Wasserstand reduziert, } \\
\text { Sperrung von Gewässern, } \\
\text { Zunahme von Risiken }\end{array}$ & -3 \\
\hline Klettern & $\begin{array}{l}\text { Steinschlaggefahr wegen } \\
\text { Permafrostrückgang }\end{array}$ & \\
& $\begin{array}{l}\text { Hoher Bewässerungs- } \\
\text { bedarf, Verschlechterung } \\
\text { der Spielbedingungen }\end{array}$ & -3 \\
\hline Golf & & -3 \\
& & \\
\hline
\end{tabular}

keine

Anpassungsmaßnahmen können mit der Energiegewinnung aus Wasserkraft im Konflikt stehen und die Mitigation reduzieren (Abwägung), Vorbeugend Pflanzmaßnahmen an Gewässern keine

keine

(Hitzewarndienst), Versorgungsstationen als Teil der Angebotsentwicklung

Information (Hitzewarndienst), Versorgungsstationen als Teil der Angebotsentwicklung

Bei Ballon- und Drachenfliegern ggf. Verlegen der Start- und Landeplätze, Stabilisierung der Fluggeräte, Destinationswechsel möglich Information (Hitzewarndienst), Zusammenarbeit mit Berghütten, Verschiebung des Zeitfensters (Klettern eher in den Morgenstunden)

Gewässerkontrolle, Verhaltensregeln beachten, ggf. Verzicht auf den Badebetrieb (Sperrung), Anlage von Pools anstelle natürlicher Gewässer Wasserzuführung durch Auflösung von Aufstauungen, Förderung der Vernetzung und Durchgängigkeit der Gewässer um Fischwanderungen zu ermöglichen, Verbesserung der Gewässerlebensräume mit Beschattung des Gewässers und Renaturierung, Destinationswechsel möglich

Information, Anlage von künstlichen Strecken mit zupumpbarem Wasser, Sperrung gefährlicher natürlicher Gewässer/-abschnitte, Destinationswechsel möglich

Information und angepasstes Kartenmaterial, Sicherung gefährlicher Bereiche durch Netze, Ausbau bzw. Verlegung von Wegen und Steigen, neue Streckenführungen, Verschiebung des Zeitfensters (Klettern eher in den Morgenstunden), Destinationswechsel möglich

Analgen zur Energiegewinnung auf Einsatz von Bewässerung, Wetting Agents,

Betriebsgebäuden zur Kompensation des Energiebedarfs, Umgestaltung und Baumpflanzungen zur Erhöhung beschatteter Bereiche

\section{Veränderung der Grasarten, Erhöhung des Anteils an} Roughs, Umgestaltung und Änderung der „Idealvorstellungen“ im Golfplatzdesign, Destinationswechsel möglich

Lokale Starkniederschläge

\begin{tabular}{|l|l|c|l|l|}
\hline Wandern & Gefährdung im Berggebiet & -1 & Keine & $\begin{array}{l}\text { Mediale Frühwarnsysteme (Wetterbericht) unterstützt } \\
\text { durch touristische Betriebe }\end{array}$ \\
\hline Radfahren & Gefährdung Im Berggebiet & -1 & Keine & $\begin{array}{l}\text { Mediale Frühwarnsysteme (Wetterbericht) unterstützt } \\
\text { durch touristische Betriebe }\end{array}$ \\
\hline Wassersport & $\begin{array}{l}\text { Gefährdungen und Risiken } \\
\text { bei Wildbächen }\end{array}$ & -2 & Keine & $\begin{array}{l}\text { Frühwarnsysteme durch Anbieter, Destinationen und } \\
\text { Fachverband }\end{array}$ \\
\hline Klettern & Erhöhung der Risiken & -3 & keine & Mediale Frühwarnsysteme (Wetterbericht) \\
\hline
\end{tabular}

Abb. 7.8 Klimainduzierte Phänomene und deren Auswirkungen für touristische Aktivitäten und Möglichkeiten von Mitigations- und Adaptionsmaßnahmen 
Kleinräumige Gewitterstürme

\begin{tabular}{|l|l|c|l|l|}
\hline Wandern & Gefährdung im Berggebiet & -1 & Keine & Mediale Frühwarnsysteme \\
\hline Radfahren & Gefährdung Im Berggebiet & -1 & keine & Mediale Frühwarnsysteme \\
\hline Wassersport & $\begin{array}{l}\text { Gefährdungen und Risiken } \\
\text { bei Wildbächen }\end{array}$ & -1 & keine & $\begin{array}{l}\text { Frühwarnsysteme durch Anbieter, Destinationen und } \\
\text { über die Medien }\end{array}$ \\
\hline Flugsport & $\begin{array}{l}\text { Erhöhung gefährlicher } \\
\text { Turbulenzen }\end{array}$ & -3 & $\begin{array}{l}\text { Anlagen zur Energiegewinnung } \\
\text { (z. B. Hangaranlagen und Gebäuden } \\
\text { der Flugschulen) }\end{array}$ & $\begin{array}{l}\text { Verbesserung der Schulungen und Ausbildung, } \\
\text { Stabilisierung der Geräte }\end{array}$ \\
\hline Klettern & Erhöhung der Risiken & -3 & $\begin{array}{l}\text { Ausstattung von Berghütten mit } \\
\text { Anlagen zur Energiegewinnung }\end{array}$ & Mediale Frühwarnsysteme \\
\hline Golf & Gefahr durch Blitzeinschlag & -1 & $\begin{array}{l}\text { Ausstattung von Gebäuden mit } \\
\text { Anlagen zur Energiegewinnung }\end{array}$ & $\begin{array}{l}\text { Betriebliche Informationen und Frühwarn- } \\
\text { einrichtungen, Anlage von sicheren Betriebs- } \\
\text { gebäuden }\end{array}$ \\
\hline
\end{tabular}

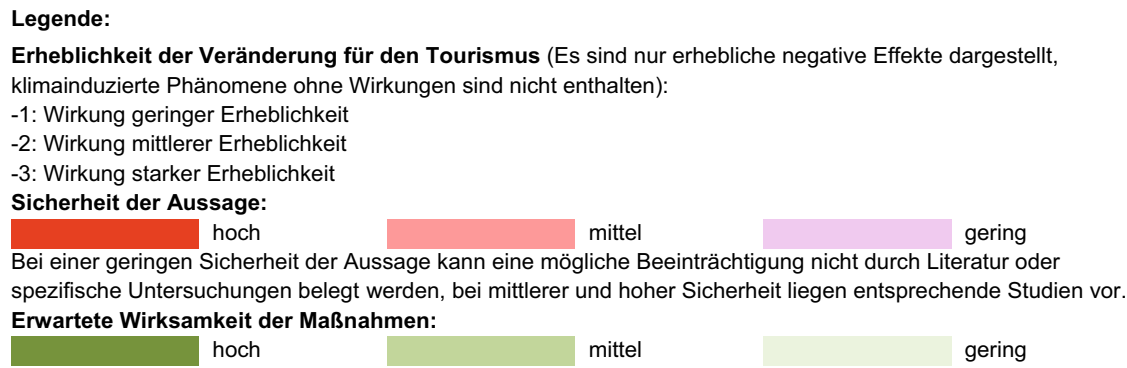

F: Forschung erforderlich

M: Monitoring erforderlich

Abb.7.8 (Fortsetzung)

Abb. 7.8 zeigt weiterhin, dass nur wenige Möglichkeiten zur Mitigation bestehen. Diese beziehen sich meist auf die Energiegewinnung auf Gebäuden für den Sportbetrieb sowie Pflanzmaßnahmen. Die Möglichkeiten zur Adaption sind vielfältiger.

Neben den klimainduzierten Einflussfaktoren, die wesentlich darüber entscheiden werden, ob die bislang aufgesuchten Destinationen weiter attraktiv sind, gibt es auch Ergebnisse aus der sozialwissenschaftlichen Forschung und der Verhaltensökonomie, die bei der Entwicklung von Anpassungsstrategien zu berücksichtigen sind (vgl. auch Kap. 13). Wichtige Aspekte sind nachstehend aufgeführt:

Als besonders wichtig erwies sich der Stellenwert, den die Aktivität für den einzelnen Gast besitzt. Die internationale Literatur spricht in diesem Fall von „specialisation“6 (Needham et al. 2013; Needham und Vaske 2013). Forschungsergebnisse zeigen, dass Personen, die ihrer Aktivität eine hohe Spezialisierung entgegenbringen, die Aktivität auch unter dem Einfluss des Klimawandels eher beibehalten wollen und gegebenenfalls den Ort dafür ändern (Beardmore et al. 2013).

Auf den Klimawandel bezogene Untersuchungen zum Sommertourismus zeigen weiterhin, dass das touristische Angebot nicht nur im Hinblick auf einzelne Aktivitäten gedacht werden darf, sondern im Sinne „multivariater Pakete“ betrachtet wer-

\footnotetext{
${ }^{6}$ Der englische Begriff ,specialisation“ umfasst mehr als die Spezialisierung auf eine bestimmte Aktivität, sondern bezieht in diesem Kontext auch Aspekte wie Erfahrung, Hingabe, Engagement und Zeitaufwand mit ein.
}

den sollte (Pröbstl-Haider et al. 2015). Das bedeutet, dass neben Angeboten für Sport- und Freizeitaktivitäten im Freien auch die Siedlungsgröße, Einkaufsmöglichkeiten, Veranstaltungen und das Naturerlebnis eine Rolle spielen. Bei entsprechenden Adaptionsmaßnahmen und Strategien gilt es daher auch das Indoorangebot (vgl. Kap. 8), die Gastronomie und das Beherbergungsangebot (vgl. Kap. 4 und 5) mit zu betrachten.

Eine repräsentative Umfrage zum deutschen Markt zeigte, dass die Befragten, die sich nicht für die Alpen interessierten, die schwankenden Wetterbedingungen in den Alpen als viel negativer empfanden als Personen, welche die Alpen bereits besucht haben (Pröbstl-Haider et al. 2015). Daher kommt der Kommunikation der zu erwartenden Wetterbedingungen und ggf. auch klimainduzierter Veränderungen eine wichtige Rolle zu.

\subsubsection{Anpassungs-, Minderungsmaßnahmen und Strategien für einzelne Aktivitäten}

\section{Wandern, Nordic Walking und Spazierengehen}

Insgesamt sind nur geringe Anpassungsmaßnahmen für diese Aktivitäten erforderlich (vgl. dazu auch Ausführungen zum Bergwandern), da die potenzielle Betroffenheit eher gering ist.

Im Hinblick auf die dargestellte Problematik durch Ambrosia (Ragweed), die bei einem Temperaturanstieg von $2{ }^{\circ} \mathrm{C}$ eine verbesserte Konkurrenzfähigkeit besitzt, liegen inzwi- 
schen konkrete Bekämpfungsmaßnahmen vor (Karrer et al. 2011), die von Informationskampagnen begleitet werden sollten. Die Umsetzung kann jedoch nicht durch den Tourismus erfolgen. So zählen die Verwendung von zertifiziertem Saatgut in der Landwirtschaft und die Reinigung von Mahdund Erntemaschinen nach dem Einsatz in einer betroffenen Fläche zu den wichtigen Präventionsmaßnahmen. In diesem Zusammenhang sind eine interdisziplinäre Kooperation und ein umfangreiches Monitoring eine entscheidende Voraussetzung. Die Kooperation sollte im Idealfall den öffentlichen Gesundheitsdienst, Land- und Forstwirtschaft, Straßenbau und -erhaltung, Gartenbauämter und vergleichbare Stellen der öffentlichen Verwaltung umfassen. Das öffentliche Gesundheitswesen ist im Rahmen dieser Zusammenarbeit für die Bewusstseinsbildung bei den Entscheidungsträgern der involvierten Fachbereiche sowie die Förderung der Beobachtung der Pollensituation und der epidemiologischen Allergiedaten zuständig (vgl. Moshammer et al. 2014).

\section{Bergwandern, Klettern und Hochgebirgstouren}

Im Bereich des Bergwanderns, des Kletterns und der Hochgebirgstouren gibt es bereits viele Vorschläge für Anpassungsstrategien, die dazu beitragen können, die Sicherheit in den Bergen unter den Bedingungen des Klimawandels zu verbessern (Braun 2009; Pröbstl und Damm 2009). Dazu gehören zunächst Maßnahmen und Verhaltensweisen, die den Gast selbst betreffen. Eine Befragung von Touristinnen und Touristen ergab, dass die sorgfältige Planung einer Tour und Wanderung durch Bergsportler und Bergurlaubende als wichtigste eigene Maßnahme angesehen wird (96\% Zustimmung). Als fast ebenso geeignet wird ein angepasstes Verhalten $-z$. B. ein früherer Aufbruch, um erhöhten Steinschlag im Laufe des Tages auszuweichen - eingestuft (93\% Zustimmung). In den Kontext mit der räumlichen und zeitlichen Planung gehört auch die Verwendung von geeignetem und aktuellem Karten- und Informationsmaterial. Dies halten $79 \%$ der Befragten für eine gute Adaptionsmaßnahme. Auch die Kommunikation mit der Hüttenbewirtschaftung oder entgegenkommenden Wanderinnen und Wanderern wird von vielen als wichtig erachtet $(76 \%)$. Nur mehr die Hälfte findet den Gebrauch eines Helms (57\% Zustimmung) oder das Mitführen des Mobiltelefons (ca. $53 \%$ Zustimmung) als ausreichende Anpassungsmaßnahme (Pröbstl und Damm 2009). In der Literatur wird in diesem Zusammenhang auch auf weitere vorbeugende Maßnahmen wie Risikokarten und neue Inhalte in der Ausbildung verwiesen (Braun 2009; Pröbstl und Damm 2009).

Weitere Anpassungsstrategien betreffen die zu erwartenden negativen Auswirkungen auf die alpine Infrastruktur. Als Folge des Klimawandels könnte der Aufwand für die Sanierung und Erhaltung von Wegen, Hütten, Beschilderung und weiteren Infrastruktureinrichtungen so stark ansteigen, dass die Arbeit, die bislang überwiegend von den alpinen Vereinen geleistet wurde, deren Möglichkeiten in Zukunft überschreiten könnte (Behm et al. 2006). Aus der Sicht der befragten Bergurlauberinnen und Bergurlauber (Pröbstl und Damm 2009) sollten die investiven Maßnahmen, wie die bautechnische Sanierung von Wegen, schützende Netze, Gebäudesanierung usw., nicht länger von den alpinen Vereinen getragen werden, sondern sie werden eher als Aufgabe der Länder (32\%), der Gemeinden (22\%), der Tourismuswirtschaft (21\%) und der Republik (18\%) gesehen. Maßnahmen, wie die Herstellung von Risikokarten, werden primär als Aufgabe des Landes und des Bundes gesehen und erst nachrangig als Aufgabe der Tourismuswirtschaft eingestuft. Dagegen werden Markierungen, Hinweisschilder, Führungen und Schulungen von der Mehrheit der Befragten weiterhin als Aufgabe der alpinen Vereine betrachtet. Bei Wartung, Schutzmaßnahmen und Markierung sehen immerhin knapp ein Viertel der Befragten auch die Gemeinden in der Pflicht. Zieht man eine Finanzierung der Anpassungsmaßnahmen durch die Bergtouristinnen und -touristen selbst in Erwägung, dann vermitteln die vorliegenden Befragungsergebnisse eine unterschiedliche Bereitschaft zur Mitwirkung (Pröbstl-Haider et al. 2016). Die große Gruppe der eher unerfahrenen Bergwanderinnen und -wanderer, die bei einer Tour besonderen Wert auf den Ausblick, intakte Wege und eine attraktive Landschaft legen (Anteil 49\%), sind bereit für die Erhaltung dieser Qualität einen finanziellen Beitrag, z. B. in Form einer Parkplatzgebühr, zu leisten. Auch eine bergerfahrene Gruppe (Anteil $39 \%$ ) ist bereit, für ein sicheres Bergerlebnis einen finanziellen Beitrag zu leisten. Die dritte, besonders risikobewusste und sehr erfahrene Gruppe innerhalb der Bergtouristinnen und -touristen (12\%) ist stark an einem natürlichen Umfeld interessiert und möchte keinen finanziellen Beitrag für Anpassungsmaßnahmen zur Erhöhung der Sicherheit leisten.

Im Rahmen des StartClim-Projekts „AlpinRiskGP“ (Lieb et al. 2010) wurde ein Werkzeug entwickelt, um Gefahrenstellen für sturz- und flächenhafte Abtragungsprozesse durch Gletscherschwund und auftauenden Permafrost auf alpinen (markierten) und hochalpinen (unmarkierten) Bergwegen und Routen zu identifizieren. Damit wird die Implementierung gezielter Maßnahmen, wie das Auflassen oder die Neuanlage von Wegen oder die Einrichtung eines Wegeinformationssystems, erleichtert.

Ein Beitrag zur Reduktion der Treibhausgasemissionen (Mitigation) kann auch durch die umweltfreundliche Gestaltung der Berghütten (z. B. Einsatz von Fotovoltaik) u. Ä. geleistet werden (für weitere Maßnahmen im Bereich der Beherbergung siehe Abschn. 4.4).

\section{Baden in Naturseen und Tauchen}

Anpassungsstrategien im Blick auf den Badetourismus (Chladek 2005; BMLFUW 2010; Pröbstl 2011; Pröbstl et al. 2012; Greil 2012) zeigen, dass zwischen den alpinen Seen, kleineren Badeseen und dem Angebot im Bereich des Neusiedler Sees unterschieden werden muss. Bei den 
größeren alpinen Seen sind die Perspektiven positiv und Anpassungsstrategien tendenziell nicht erforderlich (Pröbstl et al. 2012). Dies liegt u. a. daran, dass die regionale Wertschöpfung vieler Seeanliegergemeinden vom Zweitwohnungsbesitz mitbestimmt wird (u. a. auch durch Abgaben) und der Inlandstourismus rasch auf gute Wetterbedingungen für einen Badeurlaub reagiert. Dies entspricht auch den einschlägigen Einschätzungen von Expertinnen und Experten (Chladek 2005; Fleischhacker und Formayer 2007). Die Entwicklungen im Sommer 2018, der besonders warm war, bestätigen diese positiven Einschätzungen. So stieg mit den stabilen guten Wetterbedingungen der Anteil der Inlandsurlaubenden stark an (Österreich Werbung 2018b). Die österreichischen Badeseen könnten zunehmend an Gästen gewinnen, wenn im Mittelmeerraum ein weiterer Temperaturanstieg im Sommer erfolgt. Bei einer Befragung gaben ca. $30 \%$ der heimischen Strand- und Badeurlauber an, im Falle extremer Hitze anstatt der Mittelmeerstrände die österreichischen Seen aufsuchen zu wollen (Fleischhacker et al. 2009). Jeder sechste Gast plante, zukünftig bei extremer Hitze nicht mehr einen Badeurlaub zu bevorzugen, sondern stattdessen etwas anderes unternehmen zu wollen, wie z. B. einen Wanderurlaub in den Alpen.

Am Neusiedler See könnte durch eine erhebliche Reduktion des Wasserspiegels der Tourismus negativ betroffen sein. Hier wurden daher Anpassungsstrategien differenziert untersucht. Dabei zeigt sich, dass diese entsprechend den verschiedenen touristischen Segmenten und Zielgruppen unterschiedlich ausfallen müssen. Für Familien waren Pools als Anpassungsstrategie akzeptabel. Bei älteren Gästesegmenten kann durch eine Diversifizierung im Bereich des Kultur- und Naturtourismus eine Kompensation erreicht werden (z. B. Exkursionen, Führungen, Weinerlebnisangebote; Pröbstl et al. 2007; Pröbstl 2011).

Bei kleineren Badeseen, die sich wesentlich stärker erwärmen, ist gesundheitsbezogenen Belastungen durch entsprechende Anpassungsmaßnahmen zu begegnen. Zur Vermeidung einer Zerkariendermatitis wird empfohlen, auf das Füttern von Enten in Badegewässern zu verzichten, um diese nicht anzulocken und damit zum bevorzugten Ansiedeln im Badegewässer beizutragen. Fetthaltige Cremes etc. stellen für die Larven eine gewisse Barriere dar und erschweren das Eindringen in die Haut, belasten jedoch das Gewässer. Hilfreich ist auch das Abduschen nach dem Schwimmen sowie gutes Abfrottieren im Anschluss. Nasse Badekleidung sollte nach dem Schwimmen gewechselt und mit Leitungswasser gespült werden. Weiterhin wird empfohlen, nicht zu lange in seichtem Wasser zu schwimmen, zu tauchen bzw. zu waten.

Zur Vermeidung weiterer Gesundheitsbelastungen an erwärmten Gewässern kommt einem Gewässermonitoring und einer entsprechenden Kommunikation potenzieller Belastungen eine besondere Bedeutung zu.

\section{Fischen als Urlaubs- und Freizeitaktivität}

Anpassungsstrategien sind in diesem Bereich besonders wichtig. Mit ansteigenden Wassertemperaturen sind eine weitere Verkleinerung der Lebensräume von Fischarten sommerkühler Gewässer sowie die Zunahme temperatursensitiver Fischkrankheiten zu erwarten. Maßnahmen, die den ungünstigen Konsequenzen der Klimaveränderungen entgegenwirken können, stellen die Verbesserung und Vernetzung der Lebensräume der Fische sowie eine Verbreiterung und Bepflanzung des Uferstreifens dar. Neben einem erforderlichen Monitoring der Fischbestände, die u. a. im Rahmen der EU-Wasserrahmenrichtlinie erfolgt, ist hier eine sektorenübergreifende Zusammenarbeit notwendig, um zumindest die bestehende Qualität für den Tourismus zu erhalten.

\section{Wassersportaktivitäten (Kanusport, Rafting und Segeln)}

Im Bereich des Kanusports sind Anpassungen bereits zu beobachten. Jindrich (2012) ermittelte, dass die Kanufahrenden auf die zunehmenden Zeiträume mit Niederwasser bereits reagieren. Immerhin 56,7 \% der befragten Kanusportlerinnen und -sportler weichen bei vorherrschendem Niederwasser auf andere Flüsse und Gewässer aus. Dabei wird in Regionen ausgewichen, die sich in Gletschernähe und im Alpenraum befinden (Ötztal, Salzkammergut und Wildalpen). Sehr häufig befinden sich die Ausweichorte auch außerhalb von Österreich, u. a. in Slowenien. Innerhalb des Kanusports wird im Zusammenhang mit Niedrigwasserständen, aber auch kleinräumigen Hochwasserereignissen die Zunahme von Gefahrensituationen und Verletzungsgefahren diskutiert (Zeilner 2007; Jindrich 2012). Daher kommt auch hier einem Monitoring der Gewässerbedingungen eine besondere Bedeutung zu. In diese Aufgabe könnten auch Verantwortliche des Kanusports (Verbände, Vereine, Kanuschulen oder Kanuklubs) aktiv miteinbezogen werden. Potenzial für Anpassungsmaßnahmen besteht auch durch Gewässerrenaturierungen, wie dem Rückbau einer Wehranlage oder der Beseitigung von Uferverbauungen, wenn dadurch eine durchgängige Befahrbarkeit entsteht oder die Strecke für den Kanuslalom interessant wird (Zeilner 2007). Weiterhin werden auch technische Anpassungsmaßnahmen diskutiert. Dazu gehören künstliche Strecken bzw. Wildwasseranlagen, bei denen mithilfe von Pumpen oder Zuflüssen die Verhältnisse in der Anlage (Veränderung von Geschwindigkeit und Verlauf) an die Sportlerinnen und Sportler angepasst werden können (BINGK o.J.). Diese Anlagen unterliegen somit nicht den natürlichen Schwankungen und können eine Alternative bei lang anhaltendem Niedrigwasserstand darstellen. Eine weitere Strategie könnte auch darin bestehen, bei Kraftwerksbauten oder anderen technischen Bauten an Gewässern künstliche Passagen oder Slalomstrecken einzuplanen, um möglichst viele Optionen für die Ausübung der Sportart im eigenen Land zu behalten (Zeilner 2007). 
Die Erhaltung des Segelns kann ebenfalls Anpassungsmaßnahmen erfordern, wenn es sich um ein Gewässer handelt, bei dem häufig Niedrigwasserstände auftreten. Dies trifft für die großen alpinen Seen in der Regel nicht zu, wurde aber am Neusiedler See als Problem diskutiert. Nachdem das Schwert für die Steuerung der Segelboote benötigt wird, sind häufig auftretende Niederwasserstände nicht kompensierbar (Pröbstl et al. 2007). Im Zusammenhang mit Anpassungsstrategien wird vielfach vorgeschlagen, Ausfahrtsstrecken und Bereiche der Marinas tiefer auszubaggern oder als Ultima Ratio bestimmte Bootsklassen auszuschließen. Nicht überall ist eine technische Kompensation möglich und sinnvoll. Extremes Niedrigwasser kann am Neusiedler See technisch kaum mehr kompensiert werden. Die veränderten Risiken müssen in die Kommunikation einbezogen werden.

Zum Rafting liegen keine Studien vor. Die Bedingungen und Anpassungsstrategien sind mit den Ansatzpunkten im Kanusport vergleichbar.

\section{Flugsportarten (Gleitschirmfliegen, Segelfliegen, Ballon- oder Drachenfliegen)}

Die Anpassungsstrategien betreffen im Bereich des Flugsports vor allem Ergänzungen bei der Ausbildung der Pilotinnen und Piloten und eine Verbesserung der Geräte. Bei der Ausbildung geht es vor allem darum, den Flugsport im Hinblick auf die Wetterbedingungen und Wetterphänomene zu sensibilisieren und zu erreichen, dass die Pilotinnen und Piloten die jeweiligen Verhältnisse richtig einschätzen können (Schubert 2010). Bei Schulungen sollten sensible Geräte eingesetzt werden, damit sich die Auszubildenden die Rückmeldungen der bewegten Luft besser einprägen. Die Anpassungen bei der Ausbildung erfordern differenzierte Forschungsarbeiten zu den veränderten Windverhältnissen.

Weiterhin ist auch eine technische Anpassung bei einzelnen Flugsportarten möglich. Beim Gleitschirmfliegen wird wegen einer immer früher und heftiger einsetzenden Thermik empfohlen, klappstabile, sogenannte fehlerverzeihende Geräte beim Flug einzusetzen.

Einen Beitrag zur Mitigation können Anlagen zur Energiegewinnung auf Sportanlagen (z. B. Hangar) darstellen.

\section{Mountainbiken und Radfahren}

Bei den Anpassungsstrategien ist zwischen dem Mountainbiken einerseits und dem Radfahren auf Langstrecken andererseits zu unterscheiden. Beim Mountainbiken ist mit einem vergleichbar hohen Aufwand für die Sanierung und Erhaltung von Wegen, Hütten, Beschilderung und weiteren Infrastruktureinrichtungen wie beim Bergwandern zu rechnen. Auch hier werden weitere Anpassungsmaßnahmen durch spezielle Risikokarten, verbesserte Markierungen und Hinweisschilder erforderlich (siehe Abschnitt Bergwandern). Auch die vielerorts geplante neue Entwicklung von Mountainbike- und Radstrecken muss die veränderten Rahmenbedingungen im
Zusammenhang mit dem Klimawandel, insbesondere Erosionsgefahren, besonders betrachten. Hödl und Pröbstl-Haider (2016) stellen dazu eine Zusammenschau der zu beachtenden Umweltaspekte nach Schutzgütern zusammen. Pröbstl-Haider et al. (2017a) beschreiben, wie eine stakeholderbasierte, nachhaltige touristische Planung und Produktentwicklung im Bereich des Mountainbiking in Österreich aussehen kann.

Bei den Langstreckenradwegen kommt es darauf an, durch eine entsprechende Ausstattung an Infrastruktureinrichtungen den Schutz gegenüber Starkregenereignissen, Gewittern, aber auch einer besonderen Hitze zu erhöhen, damit insbesondere die Langstreckenradrouten auch unter den Bedingungen des Klimawandels attraktiv bleiben. Im Rahmen der Arbeitsgruppe Radtourismus wurde eine Studie zu „Qualitätskriterien für Radrouten und Radbetriebe in Österreich“ erstellt (BMNT 2018). Die zielgruppenspezifisch aufbereiteten Leitfäden für fahrradfreundliche Betriebe und zur Optimierung von Radrouten für den Tourismus beinhalten eine $\mathrm{Zu}$ sammenstellung von Empfehlungen bestehend aus Mindestanforderungen, Zusatzkriterien sowie nützlichen Tipps für die praktische Umsetzung (BMNT 2018). Die Umsetzung des ADFC-Zertifizierungssystems fahrradfreundliche Betriebe zeichnet Betriebe entlang der Topradwege Österreichs mit dem ,bett+bike“ Gütesiegel aus. Das Projekt wird von der ARGE Radtouren in Österreich weitergeführt. ${ }^{7}$

\section{Golfen}

Anpassungsstrategien und Maßnahmen sind vor allem dort erforderlich, wo Golfplätze und Golfresorts dem Trockenheitsstress ausgesetzt sind (vgl. für Österreich Abb. 7.6). Mögliche Anpassungsstrategien betreffen das Management von Golfplätzen, aber auch die Bewusstseinsbildung, das Golfplatzdesign und die Erwartungshaltung bzw. Wahrnehmung durch die Gäste (Carrow et al. 2009; Scott et al. 2018).

Um die Golfplatzpflege professionell zu betreiben, müssen Anpassungen bei der Bewässerung und bei der Pflege erfolgen. Um den Stress der Rasenpflanzen zu minimieren, werden in Hitze- und Trockenperioden die Rasenpflege angepasst und die Schnitthöhen erhöht, insbesondere bei den Greens und Fairways. Die heraufgesetzte Schnitthöhe bei den Greens führt zu einer geringeren Ballrollgeschwindigkeit, trägt aber dazu bei, Hitzeschäden an den Pflanzen zu vermeiden (Klapproth 2015). Um den Wasserbedarf zu senken, ist es auch hilfreich, die verwendeten Rasensorten anzupassen. Hier haben sich insbesondere Zusammensetzungen basierend auf dem Rotschwingl (Festuca-Arten) empfohlen, die sich durch eine höhere Hitze- und Trockenheitstoleranz auszeichnen und einen geringeren Wasserbedarf haben. Auch die Neuzüchtung von weniger stressempfindlichen Rasensorten für Golf- und

\footnotetext{
7 Eine Übersicht der aktuell zertifizierten Betriebe findet sich sowoh auf der Webseite Rad-Tourismus-Österreich (RTÖ) unter http://www. radtouren.at/radhotels.html als auch unter http://www.bettundbike.de/.
} 
Sportplätze, die auch resistenter gegen Pilzkrankheiten sind, wird von der Branche angeregt. Idealerweise sollten die Neuzüchtungen auch mit weniger Stickstoffdüngung auskommen können (Voß und Thörner o.J.). Weiterhin kann ein spezielles Wassermanagement hilfreich sein. Dazu wird bei extremer Hitze punktuell dadurch entgegengewirkt, dass zur Mittagszeit die Pflanzen und der Boden durch kurze Beregnung abgekühlt werden. Dem Beregnungswasser wird oft ein Benetzungsmittel (Wetting Agent) ${ }^{8}$ beigemischt, das die Oberflächenspannung des Wassers herabsetzt und damit ein Eindringen des Wassers in die oft hydrophoben Böden erleichtert. Auch die Gestaltung mit Bäumen und Sträuchern kann einen positiven Einfluss haben, weil durch Beschattung die Oberflächentemperatur niedriger gehalten werden kann.

Als wichtigste Anpassungsstrategie beim Golftourismus wird jedoch eine Erweiterung der Bewässerungsanlagen gesehen und eine Erhöhung der zulässigen Entnahmemengen aus Grund- oder Oberflächengewässern. Eine möglichst umweltschonende Bewässerung erfordert eine kontinuierliche Erfassung der Wetterbedingungen, der Bodenfeuchte sowie der erfolgten Pflegemaßnahmen, um die Beregnungsgaben möglichst bedarfsgerecht festlegen zu können (Klapproth 2015). Allerdings geht jede Art der Bewässerung mit einer Erhöhung des Energieaufwandes einher und trägt so zum Klimawandel weiterhin bei. Daher setzen internationale Anlagen auf eine ganzheitliche Strategie basierend auf golfspezifischen Umwelt- und Nachhaltigkeitssiegeln und EMAS-Zertifizierungen (Fürnweger 2016). Dazu gehören u. a. folgende Aspekte:

- Reduktion der intensiven Bewirtschaftung (nur auf Grüns und Abschlägen),

- naturnahe Gestaltung der Gewässer und Gebüschgruppen (Verschattung, Kühlung),

- Schutz vorhandener Biotope und Uferbereiche (Vernetzung der Biotope, Schattenwurf),

- möglichst viel Hard Roughs (seltene Mahd und Abfuhr des Pflanzmaterials),

- Speicherteiche für Platzbewässerung,

- standortgerechte Rasensorten (Verzicht auf Pestizide und Chemikalien),

- Bewusstseinsbildung bei Personal und Golferinnen und Golfern (Golfplatzpflege).

Scott et al. (2018) empfiehlt darüber hinaus noch eine detaillierte Erfassung der Verbrauchszahlen für Wasser wie in Kanada, um das Bewusstsein in den Unternehmen bzw. Vereinen

\footnotetext{
${ }^{8}$ Das Benetzungsmittel verbessert die Wasseraufnahme und Wasserspeicherfähigkeit, unterstützt damit die bedarfsgerechte Wasser- und Nährstoffversorgung der Rasengräser und beugt Trockenstress vor (Beetsma 2015). Laut Neururer (2013) wird der Einsatz von Wetting Agents bzw. von sonstigen Boden- und Pflanzenhilfsstoffen im Düngemittelgesetz 1994 idgF und der Düngemittelverordnung 2004 idgF geregelt.
}

zu fördern und Vergleichsdaten zu erhalten. Weiterhin bestehen langfristige Möglichkeiten im Zusammenhang mit einem Redesign, bei dem besonders wasserbeanspruchende Teile der Anlage umgestaltet werden. In diesem Zusammenhang fordern verschiedene Autorinnen und Autoren auch ein Umdenken bei den Gästen, Sporttreibenden und Management dahin gehend, wie ein Golfplatz auszusehen hat, und fordern mehr Naturnähe, mehr natürliche Schwierigkeiten und eine Abkehr von Einheitsgrün und einer standardisierten Bunkerlandschaft (Keast 2001; Wheeler und Nauright 2006; Scott et al. 2018). Ein sparsames Wasser- und Energiemanagement, Biodiversität und eine sportlich wie ästhetisch attraktive Anlage sollten nicht länger als Widerspruch gesehen werden.

Mitigation betrifft auch hier die Nutzung der baulichen Anlagen zur Energiegewinnung und Baumpflanzungen auf der Anlage.

\section{Naturerlebnis im Zusammenhang mit Schutzgebietstourismus}

Die Auswertung der Literatur zeigt, dass der Tourismus in Schutzgebieten durch eine verlängerte regionale Aufenthaltsdauer in den Sommermonaten geprägt ist und zur touristischen Wertschöpfung beiträgt (Fleischhacker und Pauer 2001; Knaus und Backhaus 2014). Fleischhacker und Pauer (2001) zeigen, dass in Jahren mit vorherrschend schlechtem Wetter in den Sommermonaten die durchschnittliche Aufenthaltsdauer in österreichischen Nationalparkregionen um einen Tag länger als in vergleichbaren Regionen außerhalb war. Im Hinblick auf den Klimawandel können vor allem folgende Wirkungen der Schutzgebiete für nationale Anpassungsstrategien genutzt werden (Pröbstl-Haider und Pütz 2016):

- Verstärkung der Marke „Alpenurlaub“ als naturnaher, ursprünglicher Erholungsurlaub, Förderung des Natururlaubs,

- Verlängerung der Aufenthaltsdauer durch „Schlechtwetterprogramm",

- Bereitstellen eines Netzwerkes an Naturerlebnisprogrammen als Grundlage für die Destinationswahl.

Je besser die regionale Kooperation und Markenbildung erfolgen, desto besser sind auch die Akzeptanz des Schutzgebietes in der Bevölkerung und die ökonomischen Effekte. Dabei wird empfohlen, sich zukünftig vor allem an anspruchsvollen Zielgruppen zu orientieren. Ziel ist die Entwicklung von nachhaltigen Nischenprodukten, die eine wachsende Nachfrage nach authentischen Produkten von hoher Qualität befriedigen (Pröbstl und Müller 2012; Sloan et al. 2012). In Österreich zeigt sich dies unter anderem in der erfolgreichen Vermarktung vieler sogenannter Genussregionen mit regionalen Produkten (Kastner 2010) und der Entwicklung von zertifizierten Angeboten in besonders schöner Lage. Hierzu gehören in Österreich u. a. die „Naturidyllhotels“ oder die 
„Biohotels“ mit einer klaren Positionierung und einem Qualitätsversprechen durch eine gemeinsame nachhaltige Marke (Pröbstl und Müller 2012). Dabei wird vielfach bewusst die Verbindung zu Schutzgebieten hergestellt, z. B. durch Produkte aus der Nationalparkregion Hohe Tauern oder die Hervorhebung von Schutzgebieten in der Nähe der Hotels. Folgt man einer repräsentativen Studie (Pröbstl-Haider und Haider 2014) für den deutschen Quellmarkt (d. h. Befragung am Wohnort), dann ist für etwa ein Drittel der potenziellen Besucher des Alpenraums der Nationalpark ein wichtiges Entscheidungskriterium bei der Destinationswahl. Weiterhin stellen Naturerlebnisangebote ein stark nachgefragtes Angebot dar (Pröbstl-Haider et al. 2014). Entsprechende touristische Produkte bilden Ansatzpunkte für witterungsunabhängige Angebote, die dazu geeignet erscheinen, auch Verluste in anderen Urlaubsformen ggf. kompensieren zu können (Pröbstl 2011; Pröbstl-Haider und Melzer 2015).

\subsection{Handlungsfelder, Kommunikations- und Forschungsbedarf}

\subsubsection{Wichtige Ansatzpunkte für Handlungen, zu erwartende Chancen und Barrieren, Kooperationsnotwendigkeiten}

Es lassen sich vier zentrale Handlungsfelder im Bereich der touristisch relevanten Outdoor-Recreation-Aktivitäten im Sommer ableiten. Hierzu gehören Strategien zur Risikovermeidung, Angebotsverbesserung, Anpassung, Frühwarnsysteme mit angeschlossenem Monitoring:

- Bei Flug- und Wassersportarten, Baden, Klettern und Hochgebirgstouren geht es darum, Risiken zu vermeiden, um die Aktivitäten im Urlaub attraktiv zu erhalten sowie Verletzungen und negativen Erlebnissen vorzubeugen.

- Beim Golfsport sollte - um die Attraktivität zu erhalten - in ein forschungsbasiertes naturschutzfachliches Management investiert werden, um einen effizienteren, verträglicheren Betrieb zu ermöglichen.

- Bei Fisch- und Angelsport müssen, um das Erlebnis zu erhalten, geeignete Anpassungsmaßnahmen im Bereich der Gewässerpflege, Begleitplanung, Durchgängigkeit der Gewässer und des Managements investiert werden.

- Für viele Aktivitäten ist ein Frühwarnsystem erforderlich, das durch ein naturwissenschaftliches Monitoring ergänzt werden sollte. Dazu sollte die für den Tourismus erforderliche Datenerfassung mit anderen Monitoringkonzepten kombiniert werden (wie zum Beispiel Monitoringkonzepte im Rahmen der EU-Wasserrahmenrichtlinie (WRRL), Natura-2000, Monitoring zu Permafrost u. Ä.).
Chancen und Ansatzpunkte für neue Produktentwicklungen werden im Bereich des Radtourismus und des Umweltmanagements im Bereich des Golftourismus sowie im Naturerlebnis- und Schutzgebietstourismus gesehen. Ein Ausbau bestehender Produkte sollte sich mit Blick auf eine Förderung der saisonalen Ränder, insbesondere Frühjahr und Herbst, konzentrieren.

Im Bereich der Risikovorsorge und des Risikomanagements, insbesondere für Aktivitäten im Gebirge (z. B. Klettern, Bergwandern, Drachenfliegen, Mountainbiken), kann die föderale Struktur eine Barriere darstellen. Dies gilt auch für ein abzustimmendes Monitoring und gemeinsame Informationsangebote.

\subsubsection{Ansatzpunkte: Akzeptanzsteigerung und Awareness Raising bei Entscheidungstragenden, Stakeholdern, Konsumentinnen und Konsumenten}

Die Aktivitäten im Outdoorbereich sind mit Blick auf die Folgen für den Klimawandel insgesamt eher gering bis mäßig belastend. Allerdings nehmen die Gefahrensituationen und die Belastungen für die Einzelne bzw. den Einzelnen, zum Beispiel durch Hitzetage, Starkregenereignisse, zu. Wenn in diesem Zusammenhang die Eigenverantwortung der Touristinnen und Touristen gestärkt werden soll, dann ist eine geeignete Information mit entsprechender Aufbereitung, zum Beispiel als App, erforderlich. Die Gäste sollten sich über die Verhältnisse informieren können sowie Hinweise auf mögliche Einschränkungen bzw. Empfehlungen für Aktivitäten mit lokalem Bezug erhalten.

Darüber hinaus ist dann, wenn vermieden werden soll, dass die Berichterstattung zu Gefahren den Tourismus belastet, eine Kooperation zwischen den touristischen Stakeholdern, den Tourismusregionen und den jeweiligen Bundesländern erforderlich. Neben der Information sind auch gemeinsame Anstrengungen zur Bereitstellung bzw. Wiederherstellung von Infrastruktur, wie Wegen, Schutzhütten, Markierungen und Leitsystemen, ein wichtiger Ansatzpunkt für Anpassungsstrategien. Im Hinblick auf die Erhaltung dieser notwendigen Basisinfrastruktur muss eine Bewusstseinsänderung dahin gehend erreicht werden, dass dieser in Zukunft erhebliche Mehraufwand nicht der Freiwilligenarbeit alpiner Vereine allein überlassen werden kann.

\subsubsection{Wissensbereiche und Forschungsbedarf}

Die Zusammenstellung in Abb. 7.8 zeigt eine Reihe von Themenfeldern mit zusätzlichem Forschungsbedarf auf, der in vielen Fällen nur durch eine interdisziplinäre Forschung behandelt werden kann. 
Für maßgeschneiderte Anpassungsstrategien ist es erforderlich zu erkennen, ob und inwieweit die jeweiligen Aktivitäten für die verschiedenen Zielgruppen bei der Destinationswahl entscheidungsrelevant sind. Ziel einer entsprechenden Forschung ist es, Erkenntnisse dahin gehend zu erhalten, welche Bedeutung die verschiedenen Bausteine eines Urlaubs (Region, Hotel, Aktivitäten, Küche usw.) haben. Differenzierte wissenschaftliche Kenntnisse sind auch erforderlich, um die Relevanz der Aktivitäten für die Destinationswahl und evtl. auch mögliche Wechsel ausloten zu können. Weiterhin sollte es auch das Ziel sein, herauszuarbeiten, ob und inwieweit Sommeraktivitäten Nebenprodukte darstellen oder aber der Schlüssel zum Urlaub in Österreich sind. Dies ist wichtig, um zu erkennen, wo und wann die Gefahr eines Destinationswechsels gegeben ist.

Zur Erforschung des touristischen Potenzials empfiehlt sich der Bereich des Radtourismus. Im Mittelpunkt sollte hier die nachhaltige Entwicklung stehen. Ein wesentlicher Ansatzpunkt könnte in diesem Zusammenhang die Tatsache sein, dass derzeit rund $80 \%$ der Radtouristinnen und -touristen ihren Urlaub selbst zusammenstellen. Zu überprüfen wäre, ob und inwieweit die bestehenden Anteile an Radtouristinnen und -touristen und deren Beitrag zur Wertschöpfung zu steigern wären, wenn Packages vermehrt entwickelt und angeboten würden. Dies könnte auch dann der Fall sein, wenn Packages auf verschiedene Zielgruppen (bzw. Bikes, wie E-Mountainbikes, Trekkingbikes usw.) zugeschnitten wären. Weiterhin wäre interessant, ob eine Erweiterung des Angebots in Frühjahr und Herbst erzielbar ist und unter welchen Voraussetzungen.

Im Bereich des Golftourismus besteht Forschungsbedarf im Hinblick auf geeignete Anpassungsstrategien, um rasche und nachhaltige Anpassungen zu erreichen und Reboundeffekte, zum Beispiel aufgrund einer verstärkten Bewässerung, zu vermeiden.

Wenn Risiken und Gefahren vermieden werden sollen, dann ist Forschung auch im Bereich der Indikatoren und Frühwarnsysteme erforderlich, beispielsweise um Überlastungen und nicht angemessene Aktivitäten bei Hitze und/oder Luftbelastungen zu vermeiden. Im Hinblick auf die menschliche Gesundheit und Well-being könnte hier der UTCI (Universal Thermal Climate Index) einen Mehrwert darstellen, der Überanstrengungen vorbeugt und als besonderer Service empfunden werden könnte. Auch Aussagen bezogen auf die individuelle Belastbarkeit, zum Beispiel in Verbindung mit Alter, Fitness, Geschlecht, Akklimatisierung, sind möglich. Forschungsarbeiten mit spezieller Ausrichtung auf das österreichische Angebot sind hierzu erforderlich (Piskuta et al. 2012; Brocherie et al. 2015).

Im Zusammenhang mit dem stark wachsenden Segment des Bergtourismus zeigte sich, dass quantitative Forschungsarbeiten zu den Folgen von klimawandelbedingten Landschaftsveränderungen (z. B. bei Verlust eines Gletschers) und eine Untersuchung etwaiger negativer Konsequenzen dieser
Veränderungen auf das Buchungsverhalten oder die Zufriedenheit der Gäste fehlen. Bislang wurde dieser Zusammenhang in der Literatur nur als mögliche Folge genannt.

Wenn Gesundheitsschäden vorgebeugt werden soll, ist die bestehende Forschung zur Ausbreitung von Ambrosia vor einem touristischen Hintergrund zu ergänzen und entsprechend zu erweitern. Forschung zu Allergenen sollte die Angebote in Luftkurorten ergänzen, das Potenzial für den Gesundheitstourismus erhalten und die Betriebe in diesem Bereich unterstützen. Wenn eine Zunahme von Risiken und Unfällen vermieden werden soll, dann werden auch im Bereich des Flugsports detaillierte Forschungsarbeiten gebraucht, die gemeinsam mit den Betrieben im Flugsport das komplexe System von Thermik und Talwinden im Zusammenhang mit Wetterlagen untersuchen und für Schulungsmaterialien (Flugschulen) aufbereiten.

\subsubsection{Systemdynamiken/Zusammenhänge/ Reboundeffekte aus anderen Bereichen}

Der Tourismus unterscheidet sich von vielen anderen vom Klimawandel betroffenen Sektoren insofern, als dass die Wahl eines Reiseziels eine individuelle und freiwillige Handlung ist. Anpassungsstrategien, Risikowahrnehmung und -einschätzung unterscheiden sich daher grundlegend von anderen Bereichen, wie etwa der Landnutzung (Pröbstl-Haider und Haider 2013). Das Verständnis des Konsumentenverhaltens und der Verhaltensänderung ist daher sehr wichtig.

Die Anpassung kann hier ,,mit den Füßen“9 erfolgen, wenn andere Destinationen, andere Länder, andere Reisemittel und Aktivitäten ausgewählt werden. Die Schwelle, bestimmte Verhältnisse (noch) zu tolerieren, wie etwa ein Golfresort mit erheblichen Hitzeschäden an Abschlagsplätzen und Putting Greens, liegt damit deutlich geringer, denn die internationale Auswahl an attraktiven Golfresorts ist groß, um in diesem Beispiel zu bleiben. Die Qualität, mit der die beabsichtigten Aktivitäten, wie Skifahren, Golfspielen, Baden usw., ausgeübt werden können, ist vielfach für die Destinationswahl entscheidend und hat sich in den letzten 10 Jahren deutlich gewandelt. Hat der Gast eine Bindung zu einer Region, dann werden auch die Anpassungsstrategien einer Destination stärker wahrgenommen und in die Entscheidungen miteinbezogen und es wird vor Ort bewertet, ob die vorgenommenen Anpassungsmaßnahmen wirksam sind und eine Erhaltung oder Steigerung der Attraktivität erreicht wurde.

Im Zusammenhang mit Tourismus und Erholung ist die finanzielle, ökologische und soziokulturelle Anpassungsfähigkeit von Einzelpersonen ebenfalls von großer Bedeutung. Führen beispielsweise technische Anpassungsmaßnahmen,

\footnotetext{
${ }^{9}$ Die Abstimmung „mit den Füßen“ meint die Reise zu alternativen Destinationen.
} 
wie Pools, Beschneiungsanlagen oder Golfplatzbewässerungen, zu steigenden Kosten, dann kann dies die Anpassungsfähigkeit oder -bereitschaft einzelner Touristinnen und Touristen übersteigen.

Diese Effekte ebenso wie die Nichtbeachtung kommunizierter Risiken besitzen Einfluss auf die Destinationswahl. In diesem Zusammenhang stellt sich auch die Frage, wie viele negative Erfahrungen schlussendlich zu einer Anpassung, ggf. auch Abwanderung, führen (z. B. Wechselentscheidungen von der italienischen Küste zu österreichischen Seen oder von einem niedrig gelegenen österreichischen Skigebiet in Schweizer Hochlagen).

Die Entwicklung spezifischer Anpassungsstrategien erfordert eine ganzheitliche Betrachtung des Urlaubs von der Bewerbung, der Destinationswahl über die Anreise bis hin zu den Aktivitäten. Beim Tourismus handelt sich auch nicht um ein geschlossenes System, sondern es müssen daher auch die Rahmenbedingungen integriert werden. Hierein fallen nicht nur Flug- oder Benzinpreise, sondern auch die Attraktivität anderer Destinationen, die Promotion von speziellen Urlaubsformen, wie etwa der Kreuzschifffahrt oder asiatischen Lifestyleprodukten in exotischer Umgebung. Forschungsbedarf ergibt sich in diesem Zusammenhang auch dahin gehend, dass diese Prozesse nicht für alle Aktivitäten und Zielgruppen gleich ablaufen, sondern die Einflussfaktoren für die Hauptmotive (Kernaktivitäten) des Urlaubs, wie zum Beispiel Baden, Wandern, Radfahren, jeweils getrennt ermittelt werden müssen.

\subsection{Zusammenfassung}

Die vorliegenden Forschungsergebnisse zeigen, dass sich insgesamt die zu erwartende Saisonverlängerung tendenziell positiv auf die österreichische Tourismusbranche auswirken wird, da viele Sommeraktivitäten dadurch länger ausgeübt werden können (hohe Übereinstimmung, starke Beweislage). Es lässt sich auch ein positiver Zusammenhang zwischen einer zunehmenden Sonnenscheindauer und Übernachtungen nachweisen. Darüber hinaus verändert der Klimawandel die Rahmenbedingungen für die Aktivitäten in der freien Landschaft, wie gesundheitliche Belastungen und das Landschaftsbild. Gerechnet wird mit einer stärkeren Verbreitung von Zecken, Mücken, invasiven Arten oder allergenen Pflanzen (Ambrosia) sowie mit erhöhten Gesundheitsrisiken beim Baden, z. B. durch Algenbildung oder Zerkarien (hohe Übereinstimmung, mittlere Beweislage). Im Hinblick auf das Landschaftsbild können durch die Folgen von Extremereignissen, durch Nutzungsintensivierungen bei verbesserten landwirtschaftlichen Produktionsbedingungen, aber auch umgekehrt durch Nutzungsaufgabe Auswirkungen entstehen (hohe Übereinstimmung, schwache Beweislage).

Bezogen auf die Vielzahl der Aktivitäten müssen die potenziellen Folgen des Klimawandels differenziert betrachtet werden, da hohe Abweichungen bestehen. Eine starke Betroffenheit ergibt sich vor allem bei Klettern und Hochtouren, Fischen, Golf, Wasser- und Flugsportarten (hohe Übereinstimmung, schwache Beweislage). Insbesondere zunehmende Ausaperung (Steinschlag-, Blockschlaggefahr), Abschmelzen von Gletscherzungen (häufig zunehmende Steilheit), Absenkung von Gletscheroberflächen (Ausbildung von Felsstufen beim Übergang vom Gletscher zum Fels, vergrößerter Bergschrund) und Laufverlagerungen von Gletscherbächen sowie der Verlust von Permafrost durch erhöhte Temperaturen haben Auswirkungen auf die Aktivitäten Wandern, Bergtourengehen und Mountainbiken. Aber auch die damit zusammenhängende Infrastruktur, wie Kletterrouten, Schutzhütten, Seilbahnanlagen sowie Wege und Steige, und die Sicherheit der Gäste bei deren Benutzung sind betroffen. Beim Fischen liegen die Ursachen vor allem in der Erwärmung der Gewässer. Längere Trockenheitsperioden beeinträchtigen den Wassersport durch geringe Wasserstände, die vor allem das Ausüben von Kanusport und Segeln beeinträchtigen können, und den Golftourismus durch Ausfallen der trockenheitssensiblen Rasen, falls nicht ausreichend bewässert werden kann oder darf. Die Flugsportarten sind durch veränderte Windverhältnisse und Thermik betroffen. Alle genannten Beeinträchtigungen sind so gravierend, dass sie zu einem Destinations- oder Aktivitätswechsel führen können. Für die Tourismusdestinationen und teilweise auch die alpinen Vereine leiten sich daraus jedoch zukünftig deutliche Kostensteigerungen für die Instandhaltung der oben erwähnten Infrastruktur ab.

Bei allen Aktivitäten in der freien Landschaft können erhebliche gesundheitliche Effekte durch Hitze ausgelöst werden. Diese können von Hitzewallungen, einem Kreislaufkollaps (Synkope), Krämpfen über Erschöpfungszustände bis zu Desorientierung reichen. Muskuläre Beanspruchung, Dehydrierung und starker Elektrolytverlust wirken hier zusammen und können durch weitere Faktoren wie Fettleibigkeit, geringe Fitness, unzureichende Akklimatisation sowie andere Belastungen wie Sonnenbrand verstärkt werden (hohe Übereinstimmung, starke Beweislage).

Die Möglichkeiten, im Bereich der Aktivitäten Treibhausgasemissionen zu reduzieren, sind sehr eingeschränkt und beschränken sich im Wesentlichen auf die alternative Energiegewinnung im Zusammenhang mit Betriebsgebäuden (z. B. Fotovoltaik oder thermische Solaranlagen an Berghütten, Hangars, Golfanlagen u. Ä.; hohe Übereinstimmung, schwache Beweislage).

Auffallend ist, dass viele Zusammenhänge, wie etwa die Veränderung der Windverhältnisse und der Thermik, nicht oder kaum untersucht sind. Es bestehen im Hinblick auf die Sommeraktivitäten in Österreich erhebliche Forschungsdefizite, die die Beweislage negativ beeinflussen.

Aus den beschriebenen Ergebnissen lassen sich Konsequenzen für den Tourismus ableiten: Auch wenn die Attraktivität des Sommers insbesondere im Berggebiet steigt, so 
muss jedoch darauf hingewiesen werden, dass der Sommertourismus mögliche Verluste aus dem Winter nicht kompensieren kann (Müller und Weber 2008; Falk 2014, 2015; hohe Übereinstimmung, mittlere Beweislage). Müller und Weber (2008) erwarten für die Schweiz beispielsweise, dass nur etwa die Hälfte der Verluste durch Steigerungen im Sommer aufgefangen werden können.

Eine wesentliche Herausforderung für die verhaltensbezogene Forschung im Tourismus, im Vergleich zu anderen vom Klimawandel betroffenen Sektoren, besteht darin, dass die Kunden flexibel reagieren und Anpassungsprozesse auch durch Abwanderungen erfolgen. Aufgrund der unabhängigen Wahlentscheidungen zumeist außerhalb Österreichs über die Teilnahme am Tourismus sind methodische Fragen von hoher Relevanz. Daher sind Trends vorausschauend zu beachten.

Die Ergebnisse dieser Zusammenstellung zeigen weiterhin, dass unterschiedliche Gästesegmente, zum Beispiel mit verschiedenen Motiven und Kernaktivitäten, unterschiedlich reagieren (hohe Übereinstimmung, starke Beweislage). Dies gilt nicht nur für positive Entwicklungen (z. B. mehr Tage mit Sonnenschein), sondern auch im Hinblick auf kompensatorische Bedingungen. Während ältere Touristinnen und Touristen am Neusiedler See angeben, dass wasserbezogene Aktivitäten auch durch kulturlandschaftstouristische Angebote und Wein kompensiert werden können, trifft das für segelnde Gäste nicht zu (Pröbstl et al. 2007). Dies zeigte sich auch bei anderen Studien, dass die bevorzugte Ausrichtung des Urlaubs die Reaktion beeinflusst. Zusätzliche Sonnentage waren für ein entspannungsorientiertes Segment relevant (Pröbstl-Haider et al. 2014). Naturorientierte und aktivitätsorientierte Segmente erweisen sich in dieser Studie jedoch als deutlich anspruchsvoller. Hier müssen bezogen auf den Urlaub in den Alpen beim naturorientierten Segment auch der Siedlungscharakter, eine natürliche Umgebung und gute Wanderbedingungen angeboten werden. Während die aktivitätsorientierte Gruppe von lebhaften Gemeinschaften, Outdoorsportmöglichkeiten und anderen Programmen angezogen wird (hohe Übereinstimmung, mittlere Beweislage).

Die Zusammenstellung zeigt auch, dass die Attraktivität bestimmter Regionen oder spezifischer Aktivitäten für Touristinnen und Touristen komplex ist und nicht nur von einem einzigen Faktor abhängt, wie beispielsweise von der Temperatur oder der Anzahl von Tagen mit Sonnenschein. Es handelt sich vielmehr um ein Zusammenspiel verschiedener Faktoren, bei denen auch die Präferenz für naturnahe Bedingungen, bestimmte Aktivitäten oder Ereignisse eine entscheidende Rolle spielt (hohe Übereinstimmung, mittlere Beweislage). Insbesondere die Präferenz für naturnahe, gesunde oder gesundheitsfördernde Rahmenbedingungen erfordert eine stärkere Verschränkung eines touristischen und naturwissenschaftlichen Monitorings, um die erwünschten Rahmenbedingungen bestmöglich zu erhalten. Hier ist auch eine stärkere sektorenübergreifende Zusammenarbeit erforderlich. Auch ist hier auf die für den Tourismus erforderliche Art und Aufbereitung der Daten mehr als bisher einzugehen.

Offensichtlich haben die Unterschiede in den Segmenten in Kombination mit den gewünschten Erlebnissen und Aktivitäten einen signifikanten Einfluss auf das zukünftige Verhalten unter den Bedingungen des Klimawandels. Die Auswirkungen des Klimawandels auf die Wahl des Reiseziels im Sommertourismus scheinen komplexer zu sein, als die ersten Studien in diesem Bereich nahelegen.

\section{Kernaussagen - Kapitel 7}

- Im Bereich der urlaubsrelevanten Aktivitäten im Sommer zeigt sich, dass sich durch klimainduzierte Phänomene eine starke Betroffenheit für Klettern und Hochtouren, Fischen, Golf, Wasser- und Flugsportarten ergibt. Diese können zu einem Destinations- oder Aktivitätswechsel führen (hohe Übereinstimmung, schwache Beweislage).

- Die Möglichkeiten, im Bereich der Aktivitäten Treibhausgasemissionen zu reduzieren, sind sehr eingeschränkt und beschränken sich im Wesentlichen auf die alternative Energiegewinnung im Zusammenhang mit Betriebsgebäuden (z. B. Fotovoltaik oder thermische Solaranlagen an Berghütten, Hangars, Golfanlagen u. Ä.; hohe Übereinstimmung, schwache Beweislage).

- Anpassungsmöglichkeiten sind in vielen Bereichen grundsätzlich möglich, zum Beispiel durch vermehrte Bewässerung auf Golfplätzen, Bau von Pools bei Problemen der Nutzung natürlicher Gewässer sowie Wegeneubau und Schutzmaßnahmen im Gebirge. Diese sind jedoch kostenintensiv und beeinflussen teilweise das Urlaubserlebnis (hohe Übereinstimmung, mittlere Beweislage).

- Ein mediales Frühwarnsystem (bezogen auf Hitze, Gewitter und Starkregen) wäre wichtig, um Anpassungsmaßnahmen der Betriebe und Gäste zu ermöglichen (hohe Übereinstimmung, mittlere Beweislage).

- Im Gegensatz zu den Aktivtäten im Winter bestehen bei den Sommeraktivitäten in vielen Bereichen erhebliche Forschungsdefizite (hohe Übereinstimmung, mittlere Beweislage).

- Ökonomische Verluste durch Schneemangel im Winter können durch den Sommerurlaub mit anderen Aktivitäten in der derzeitigen Form nicht ausgeglichen werden (hohe Übereinstimmung, starke Beweislage).

- Der Klimawandel wird durch die höheren Temperaturen in den Übergangsjahreszeiten zu positiven Effekten für Wandern, Radfahren, Baden, Wassersport und Golf und einer Saisonverlängerung beitragen (hohe Übereinstimmung, mittlere Beweislage). 


\section{Literatur}

Allex, B., Brandenburg, C., Liebl, U., Gerersdorfer, T. \& Czachs, C. (2013) Hot Town, Summer in the City - Entwicklung von hitzerelevanten Anpassungsstrategien im Städtetourismus. In: Schrenk, M., Popovich V., Zeile, P. \& Elisei, P. (Hrsg.) Proceedings of the $18^{\text {th }}$ International Conference on Urban Planning, Regional Development and Information Society (REAL CORP 2013), S. 393-398. CORP (Competence Center of Urban and Regional Planning), SchwechatRannersdorf, Österreich. Online unter: https://conference.corp.at/ fileadmin/proceedings/CORP2013 proceedings.pdf (letzter Zugriff: 24.05.2020)

Amelung, B. \& Viner, D. (2006) Mediterranean tourism: exploring the future with the tourism climatic index. Journal of SustainableTourism 14(4), 349-366. DOI: https://doi.org/10.2167/jost549.0

Ammer, U. \& Pröbstl, U. (1991) Freizeit und Natur: Probleme und Lösungsmöglichkeiten einer ökologisch verträglichen Freizeitnutzung. Verlag Paul Parey, Hamburg, Deutschland.

APCC (2014) Österreichischer Sachstandsbericht Klimawandel 2014 (AAR14). Austrian Panel on Climate Change (APCC), Verlag der Österreichischen Akademie der Wissenschaften (ÖAW), Wien, Österreich. Online unter: http://www.austriaca.at/APCC_AAR2014.pdf (letzter Zugriff: 24.03.2020).

APCC (2018) Österreichischer Special Report Gesundheit, Demographie und Klimawandel (ASR18). Austrian Panel on Climate Change (APCC), Verlag der Österreichischen Akademie der Wissenschaften (ÖAW), Wien, Österreich. Online unter: https://austriaca.at/APCC ASR18.pdf (letzter Zugriff: 24.05.2020).

Armstrong, M. (2019) Relief from heatwave for northern France but south still sizzles (Artikel vom 07.01.2019). EURONEWS, Lyon, Frankreich. Online unter: https://www.euronews.com/2019/06/30/ relief-from-heatwave-for-northern-france-but-south-still-sizzles (letzter Zugriff: 25.10.2019).

Arnberger, A., Ebenberger, M., Schneider, I.E., Cottrell, S., Schlueter, A.C., von Ruschkowski, E., Venette, R.C., Snyder, S.A. \& Gobster, P.H. (2018) Visitor preferences for visual changes in bark beetleimpacted forest recreation settings in the United States and Germany. Environmental Management 61(2), 209-223. DOI: https:// doi.org/10.1007/s00267-017-0975-4

Backhaus, N., Buser, C., Butticaz, M., Jorio, D. \& Speich, M. (2013) Wirtschaftliche Auswirkungen des Sommertourismus im UNESCO Biosphärenreservat Val Müstair Parc Naziunal. Schriftenreihe Humangeographie 27. Geographisches Institut der Universität Zürich, Zürich, Schweiz. DOI: https://doi.org/10.5167/uzh-80488

Baumann, R., Brandstätter, M., Heimburger, G., Kranabetter, A., Moshammer, H., Oitzl, S., Rau, G., Schauberger, G., Schauer, U., Scheicher, E., Schopper, A., Weber, A \& Wieger, G. (2013) Richtlinie zur Erfassung und Bewertung der Luftqualität in Kurorten. Kommission für Klima und Luftqualität der Österreichischen Akademie der Wissenschaften (ÖAW), Wien, Österreich. Online unter: https://www. oeaw.ac.at/fileadmin/kommissionen/klimaundluft/Kurorte-RL-Originalformat-A5.pdf (letzter Zugriff: 24.05.2020).

Beardmore, B., Haider, W., Hunt, L.M. \& Arlinghaus, R. (2013) Evaluating the ability of specialization indicators to explainfFishing preferences. Leisure Sciences 35(3), 273-292. DOI: https://doi.org/ 10.1080/01490400.2013.780539

Beetsma, J. (2015) The differences between wetting agents and dispersants. Prospector Knowledge Center, Overland Park, KS, USA. Online unter: https://knowledge.ulprospector.com/2282/pc-differences-between-wetting-agents-and-dispersants/ (letzter Zugriff: 22.10.2019)

Behm, M., Raffeiner, G.\& Schöner, W. (2006) Auswirkungen der Klimaund Gletscheränderung auf den Alpinismus. Umweltdachverband, Wien, Österreich.
Bigano, A., Hamilton, J.M. \& Tol, R.S. (2006) The impact of climate on holiday destination choice. Climatic Change 76(3-4), 389-406. DOI: https://doi.org/10.1007/s10584-005-9015-0

BINGK (o.J.) Ingenieurbaukunst made in Germany: Wildwasseranlage, bei Leipzig. Bundesingenieurkammer (BINGK), Berlin, Deutschland. Online unter: http://bingk.de/wp-content/uploads/2015/02/ Wildwasseranlage_nahe_Leipzig.pdf (letzter Zugriff: 24.05.2020).

Birngruber, H., Hiess, H., Jiricka, A., Kleinbauer, I. \& Pröbstl, U. (2011) CLISP - Climate Change Adaptation by Spatial Planning in the Alpine Space: Model Region Upper Austria (Model Region Report). European Territorial Cooperation "Alpine Space" Programme 2007-2013. Online unter: https://www.yumpu.com/de/document/ $\mathrm{read} / 8814850 /$ climate-change-adaptation-by-spatial-planning-inthe-alpine-clisp (letzter Zugriff: 24.05.2020).

BMLFUW (2010) Auf dem Weg zu einer nationalen Anpassungsstrategie: 2. Entwurf, Policy Paper (Stand Oktober 2010). Bundesministerium für Land- und Forstwirtschaft, Umwelt und Wasserwirtschaft (BMLFUW), Wien, Österreich. Online unter: https://www. umweltbundesamt.at $/ \mathrm{ms} / \mathrm{klimawandelanpassung} / \mathrm{de} /$ nationaleanpassungsstrategie/kwa_strategieschritte/kwa_ppaper/ (letzter Zugriff: 10.07.2019)

BMLFUW (2017) Klimawandel in der Wasserwirtschaft - Follow up zur ZAMG/TU-Wien Studie (2011) Anpassungstrategien an den Klimawandel für Österreichs Wasserwirtschaft im Auftrag von Bund und Ländern. Bundesministerium für Land- und Forstwirtschaft, Umwelt und Wasserwirtschaft (BMLFUW), Wien, Österreich. Online unter: https://www.bmlrt.gv.at/wasser/wasser-oesterreich/foerderungen/ trinkwasser_abwasser/aktuelle projekte/klimawandel_wasserwirtschaft.html (letzter Zugriff: 01.04.2020).

BMNT (2018) Tourismusradverleih: Kurzfassung der Bestandserhebung Radverleihsysteme in Österreich mit Fokus auf touristischer Nutzung. Bundesministerium für Nachhaltigkeit und Tourismus (BMNT), Wien, Österreich. Online unter: https://www.bmlrt.gv.at/ service/publikationen/tourismus/tourismusradverleih.html (letzter Zugriff: 24.05.2020).

BMVIT (2013) Der Radverkehr in Zahlen: Daten, Fakten und Stimmungen. Bundesministerium für Verkehr, Innovation und Technologie (BMVIT), Wien, Österreich. Online unter: https://www.bmk. gv.at/themen/fuss radverkehr/publikationen/riz.html (letzter Zugriff: 24.05.2020).

BMWFJ (2012) Klimawandel und Tourismus in Österreich 2030: Auswirkungen, Chancen \& Risiken, Optionen \& Strategien (StudienKurzfassung). Bundesministerium für Wirtschaft, Familie und Jugend (BMWFJ), Wien, Österreich. Online unter: https://www.wko. at/branchen/tourismus-freizeitwirtschaft/hotellerie/130318_Klimawandel_u._Tourismus_in_Oe._2030_Kurzfassung.pdf (letzter Zugriff: 12.05 .2020$)$.

Bowker, J.M., Askew, A.E., Poudyal, N., Zarnoch, S.J., Seymour, L. \& Cordell, H.K. (2014) Climate change and outdoor recreation participation in the southern United States. In: Vose, J.M. \& Klepzig, K.D. (Hrsg.) Climate change adaption and mitigation management options: a guide for natural resource managers in southern forest ecosystems. S. 421-450. CRC Press, Boca Raton, FL, USA. Online unter: https://www.srs.fs.usda.gov/pubs/books/2014/climatechange 2014.pdf (letzter Zugriff: 24.05.2020).

Brasseur, G.P. (2009) Implications of climate change for air quality. World Meteorological Organization (WMO) Bulletin 58(1), 10-15. Online unter: https://ane4bf-datap1.s3-eu-west-1.amazonaws.com/ wmocms/s3fs-public/article bulletin/related_docs $/ 58$ _ b brasseur en.pdf?CdfDcZa22gnMU.vScuq2JmVb kUwEBNs (letzter Zugriff: 24.05.2020).

Braun, F. (2009) Sommer-Bergtourismus im Klimawandel: Szenarien und Handlungsbedarf am Beispiel des hochalpinen Wegenetzes. Dissertation, Universität für Bodenkultur Wien, Österreich. Online unter: https://zidapps.boku.ac.at/abstracts/download.php?dataset id=7618\&property_id=107 (letzter Zugriff: 24.05.2020). 
Brice, B., Fullerton, K., Hawkes, K.L., Mills-Novoa, M., O’Neill, B. \& Pawlowski, W.M. (2017) The impacts of climate change on natural areas recreation: a multi-region snapshot and agency comparison. Natural Areas Journal 37(1), 86-97. DOI: https://doi. org $/ 10.3375 / 043.037 .0111$

Bristow, R.S. \& Jenkins, I. (2018) Travel behaviour substitution for a white-water canoe race influenced by climate induced stream flow. Leisure/Loisir 42(1), 25-46. DOI: https://doi.org/10.1080/1492771 3.2017.1403861

Brocherie, F., Girard, O. \& Millet, G.P. (2015) Emerging environmental and weather challenges in outdoor sports. Climate 3(3), 492-521, DOI: https://doi.org/10.3390/cli3030492

Burkhardt-Holm, P. (2009) Klimawandel und Bachforellenrückgang gibt es einen Zusammenhang? Resultate aus der Schweiz. Environmental Sciences Europe 21, 177-185. DOI: https://doi.org/10.1007/ s12302-009-0043-7

Cai, M., Ferrise, R., Moriondo, M., Nunes, P.A. \& Bindi, M. (2011) Climate change and tourism in Tuscany, Italy: what if heat becomes unbearable? FEEM Working Paper, No. 67.2011. DOI: https://doi. org/10.2139/ssrn.1942347

Carrow, R.N., Duncan, R. \& Waltz, C. (2009) BMPs and water-use efficiency/conservation plan for golf courses: template and guidelines ( $2^{\text {nd }}$ revision, November 2009). Online unter: https://cdn.cybergolf.com/images/994/BMPsWaterCons09.pdf (letzter Zugriff: 24.05.2020).

Chladek, K. (2005) Wie „klimaresistent“ ist der Badetourismus? Integra: Zeitschrift für Integrativen Tourismus und Entwicklung 2/05, 20-22. Online unter: https://docs.google.com/viewer?a=v\&pid=sites\&srcid=bmYtaW50Lm9yZ3xkaWdpdGFsZS1iaWJsaW90aGVr fGd4OjI2N2VkOGE5N2Y5M2FjYjI (letzter Zugriff: 24.05.2020).

Dokulil, M.T. \& Teubner, K. (2012) Deep living Planktothrix rubescens modulated by environmental constraints and climate forcing. Hydrobiologia 698(1), 29-46. DOI: https://doi.org/10.1007/s10750-0121020-5

DSHS (o.J.) Natursport Info: Kanufahren. Deutsche Sporthochschule Köln (DSHS), Deutschland. Online unter: https://www.natursport.info/natursportarten/zu-wasser/kanusport/ (letzter Zugriff: 24.05.2020).

Fahrradportal (2019) Deutscher Fahrradmarkt 2018 mit neuen Rekorden: Marktanteil von Elektrofahrrädern wächst auf 23,5 Prozent. Deutsches Institut für Urbanistik gGmbH im Auftrag des Bundesministeriums für Verkehr und digitale Infrastruktur, Berlin, Deutschland. Online unter: https://nationaler-radverkehrsplan.de/de/impressum (letzter Zugriff: 28.05.2020).

Falk, M. (2014) Impact of weather conditions on tourism demand in the peak summer season over the last 50 years. Tourism Management Perspectives 9, 24-35. DOI: https://doi.org/10.1016/j. tmp.2013.11.001

Falk, M. (2015) Summer weather conditions and tourism flows in urban and rural destinations. Climatic Change 130(2), 201-222. DOI: https://doi.org/10.1007/s10584-015-1349-7

Fleischhacker, V. (2019) Tendenzen der Nachfragesegmente des Sommer- und Wintertourismus in Österreich. ITR - Institut für touristische Raumplanung Ges.m.b.H., Tulln an der Donau, Österreich.

Fleischhacker, V. \& Formayer, H. (2007) Die Sensitivität des Sommertourismus in Österreich auf den Klimawandel. Endbericht von StartClim2006.D1 in StartClim2006: Klimawandel und Gesundheit, Tourismus, Energie. Online unter: http://www.startclim.at/fileadmin/ user_upload/reports/StC106D1.pdf (letzter Zugriff: 24.05.2020).

Fleischhacker, V. \& Pauer, P. (2001) Nationalparks und Tourismus in Österreich 2001 (Kurzfassung). Im Auftrag des Bundesministeriums für Wirtschaft und Arbeit (BMA). ITR - Institut für touristische Raumplanung Ges.m.b.H., Tulln an der Donau, Österreich. Online unter: https://docplayer.org/30095024-Nationalparks-und-tourismusin-oesterreich-2001.html (letzter Zugriff: 24.05.2020).
Fleischhacker, E., Formayer, H., Seisser, O., Wolf-Eberl, S. \& KrompKolb, H. (2009) Auswirkungen des Klimawandels auf das künftige Reiseverhalten im österreichischen Tourismus am Beispiel einer repräsentativen Befragung der österreichischen Urlaubsreisenden. BOKU-Met Report 19. Im Auftrag des Bundesministeriums für Wirtschaft, Familie und Jugend (BMWFJ), Wien, Österreich. Online unter: https://meteo.boku.ac.at/report/ (letzter Zugriff: 05.05.2020).

Formayer, H. \& Kromp-Kolb, H. (2009) Klimawandel und Tourismus in Oberösterreich. Im Auftrag der Oberösterreichischen Landesregierung und Oberösterreich Tourismus. BOKU-Met Report 18. Online unter: https://meteo.boku.ac.at/report/BOKU-Met_Report_18_online.pdf (letzter Zugriff: 24.05.2020).

Fürnweger, E. (2016) EMAS-Zertifizierung von Golfplätzen. Masterarbeit am Institut für Landschaftsentwicklung, Erholungs- und Naturschutzplanung (ILEN), Universität für Bodenkultur Wien, Österreich. Online unter: https://abstracts.boku.ac.at/download.php?dataset_id=14295\&property_id=107 (letzter Zugriff: 25.05.2020).

Giles, L.V. \& Koehle, M.S. (2014) The health effects of exercising in air pollution. Sports Medicine 44(2), 223-249. DOI: https://doi. org/10.1007/s40279-013-0108-Z

Gössling, S., Hall, C.M. \& Scott, D. (2015) Tourism and water. Channel View Publications, Bristol, Vereinigtes Königreich.

Greil, K. (2012) Auswirkungen des Klimawandels auf den Seentourismus am Attersee aus der Sicht der Urlauber mit Zweitwohnsitz am Attersee. Masterarbeit am Institut für Landschaftsentwicklung, Erholungs- und Naturschutzplanung (ILEN), Universität für Bodenkultur Wien, Österreich. Online unter: http://epub.boku.ac.at/ obvbokhs/download/pdf/1036036? originalFilename=true (letzter Zugriff: 25.05.2020).

Haas, L. (o.J.) Der Klimawandel schlägt Wellen. DHV-info 185, 44-47. Online unter: https://www.dhv.de/fileadmin/user_upload/files/2015/ Artikel_Sicherheit/Artikel_Meteo/2014_185_klimawandel.pdf (letzter Zugriff: 25.05.2020).

Haas, W., Weisz, U., Balas, M., McCallum, S., Lexer, W., Pazdernik, K., Prutsch, A., Radunsky, K., Formayer, H., Kromp-Kolb, H. \& Schwarzl, I. (2008) Identifikation von Handlungsempfehlungen zur Anpassung an den Klimawandel in Österreich: 1. Phase, 2008AustroClim. Im Auftrag des Bundesministeriums für Land- und Forstwirtschaft, Umwelt und Wasserwirtschaft (BMLFUW), Wien, Österreich.

Hamilton, J.M. (2004) Climate and the destination choice of German tourists. FEEM Working Paper, No. 21.2004. DOI: https://doi. org/10.2139/ssrn.504362

Hamilton, J.M., Maddison, D.J., \& Tol, R.S. (2005) Effects of climate change on international tourism. Climate Research 29(3), 245-254. DOI: https://doi.org/10.3354/cr029245

Hatje, T. (2016) Vom Kiez bis zum Kap. Outdoor-Ein Spezial des Zeitverlages. DIE Zeit Nr. 13/2016, 78.

Himmel, P. (2018) Deutschlands Golfplätze kämpfen mit Hitze und Wasserknappheit. deutsche golf online $\mathrm{GmbH}$, München, Deutschland. Online unter: www.golf.de/publish/panorama/panoramanews/60115405/die-grosse-duerre (letzter Zugriff: 04.05.2019).

Hödl, C. \& Pröbstl-Haider, U. (2016) Mountainbiken im Wald: ein Beitrag zur kritischen Diskussion. Naturschutz und Landschaftsplanung 48(4), 122-131. Online unter: https://www.nul-online. de/artikel.dl1/NuL04-16-Inhalt-AK3-122-131-1_NTAwNzYxNA. PDF?UID=8022CE2CC134112C42FB83D9CC49E1F881070E3C 0815BB (letzter Zugriff: 25.05.2020).

Holtzhausen, L.M. \& Noakes, T.D. (1997) Collapsed ultraendurance athlete: proposed mechanisms and an approach to management. Clinical Journal of Sport Medicine 7(4), 292-301. Online unter: https://journals.lww.com/cjsportsmed/Abstract/1997/10000/Collapsed_Ultraendurance_Athlete_Proposed.6.aspx (letzter Zugriff: 25.05.2020).

Holz, C. (2015) Automatische Bewässerung von Golfanlagen unter besonderer Berücksichtigung des Klimawandels. Bachelorarbeit an der Hochschule Geisenheim University, Deutschland. In Zusammen- 
arbeit mit dem Greenkeeper Verband Deutschland (GVD) und dem Deutschen Golf Verband (DGV)-Arbeitskreis Golfplatzbewässerung. Umfrageergebnisse online unter: https://www.greenkeeperverband. de/fileadmin/content/Dokumente/Umfrageergebnisse/Umfragen ab_2012.pdf (letzter Zugriff: 25.05.2020).

Hunt, L.M. (2005) Recreational fishing site choice models: insights and future opportunities. Human Dimensions of Wildlife 10(3), 153-172. DOI: https://doi.org/10.1080/10871200591003409

Hunt, L.M. \& Moore, J. (2006) The potential impacts of climate change on recreational fishing in Northern Ontario. Climate Change Research Report (CCRR-04). Ontario Forest Research Institute, Ministry of Natural Resources, Sault Ste. Marie, ON, Kanada. Online unter: http://www.climateontario.ca/MNR Publications/276905.pdf (letzter Zugriff: 25.05.2020).

Hunziker, M. (2000) Einstellungen der Bevölkerung zu möglichen Landschaftsentwicklungen in den Alpen. Eidgenössische Forschungsanstalt WSL, Birmensdorf, Schweiz.

Jendritzky, G. \& de Dear, R. (2009) Adaptation and thermal environment. In: Ebi, K.L., Burton, I. \& McGregor, G.R. (Hrsg.) Biometeorology for Adaptation to Climate Variability and Change, S. 9-32. Springer, Dordrecht, Niederlande. DOI: https://doi.org/10.1007/978$1-4020-8921-3 \quad 2$

Jindrich, K. (2012) Auswirkungen des Klimawandels auf den Kanusport in Österreich. Masterarbeit am Institut für Landschaftsentwicklung, Erholungs- und Naturschutzplanung (ILEN), Universität für Bodenkultur Wien. Online unter: http://epub.boku.ac.at/obvbokhs/ download/pdf/1083269? originalFilename=true (letzter Zugriff: 25.05.2020).

Johnston, F.D., Arlinghaus, R. \& Dieckmann, U. (2013): Fish life history, angler behaviour and optimal management of recreational fisheries. Fish and Fisheries 14(4), 554-579. DOI: https://doi.org/ 10.1111/j.1467-2979.2012.00487.x

Juschten, M., Brandenburg, C., Hössinger, R., Liebl, U., Offenzeller, M., Prutsch, A., Unbehaun, W., Weber, F. \& Jiricka-Pürrer, A. (2019) Out of the city heat - way to less or more sustainable futures? Sustainability 11(1), 214. DOI: https://doi.org/10.3390/su11010214

Karrer, G., Milakovic, M., Kropf, M., Hackl, G., Essl, F., Hauser, M., Mayer, M., Blöch, C., Leitsch-Vitalos, M., Dlugosch, A., Hackl, G., Follak, S., Fertsak, S., Schwab, M., Baumgarten, A., Gansberger, M., Moosbeckhofer, R., Reiter, E., Publig, E., Moser, D., Kleinbauer, I. \& Dullinger, S. (2011) Ausbreitungsbiologie und Management einer extrem allergenen, eingeschleppten Pflanze - Wege und Ursachen der Ausbreitung von Ragweed (Ambrosia artemisiifolia) sowie Möglichkeiten seiner Bekämpfung (Endbericht, Projekt-Nr: 100198, Akronym: RAGWEED). Online unter: https://www.dafne.at/ $\mathrm{prod} /$ dafne_plus_common/attachment_download/c5a83cbf7dad360 671e9a271e1d2c48e/Endbericht-RAGWEED-ProjektNr-100198.pdf (letzter Zugriff: 25.05.2020).

Kastner, R. (2010) GenussRegionen Marketing - Dreijahresbericht 2008-2010. Zitiert in: Hochwarter, E. (2014) Einfluss der „, GenussRegion Österreich" auf die regionale Entwicklung anhand der Beispiele „Zickentaler Moorochsen" und „Pöllauer Hirschbirne“, S. 29-33. Masterarbeit am Institut für Landschaftsentwicklung, Erholungs- und Naturschutzplanung (ILEN), Universität für Bodenkultur Wien. Online unter: https://abstracts.boku.ac.at/download.php?dataset_id=10861\&property_id=107 (letzter Zugriff: 31.05.2020)

Keast, M. (2001) Going for the green. Canadian Wildlife Magazin, Spring 2001. Zitiert in: Wheeler, K. \& Nauright, J. (2006) A global perspective on the environmental impact of golf. Sport in Society 9(3), 427-443. DOI: https://doi.org/10.1080/17430430600673449

Kerle, K.K. \& Nishimura, K.D. (1996) Exertional collapse and sudden death associated with sickle cell trait. Military Medicine 161(12), 766-767. DOI: https://doi.org/10.1093/milmed/161.12.766

Klapproth, A. (2015) Klimawandel wahrgenommen. Köllen Druck + Verlag GmbH, Bonn-Buschdorf, Deutschland. Online unter: https:// www.golfmanager-greenkeeper.de/greenkeeper-online/fachbeitraege-greenkeeper/praxis/wasser-und-bewaesserung-auf-golfanlagen/wasser-auf-golfanlagen-klimawandel-wahrgenommen.html (letzter Zugriff: 21.02.2019).

Knaus, F. \& Backhaus, N. (2014) Touristische Wertschöpfung in Schweizer Pärken. Swiss Academies Factsheets 9(3), 1-6. DOI: https://doi.org/10.5167/uzh-96957

Kromp-Kolb, H., Eitzinger, J., Kubu, G., Formayer, H., Haas, P. \& Gerersdorfer, T. (2005) Auswirkungen einer Klimaänderung auf den Wasserhaushalt des Neusiedler Sees. Im Auftrag der Burgenländischen Landesregierung. BOKU-Met Report 1. Online unter: https://meteo.boku.ac.at/report/BOKU-Met_Report_01_online.pdf (letzter Zugriff: 25.05.2020).

Lewin, W.-C., Arlinghaus, R. \& Mehner, T. (2006) Documented and potential biological impacts of recreational fishing: insights for management and conservation. Reviews in Fisheries Science 14(4), 305-367. DOI: https://doi.org/10.1080/10641260600886455

Lieb, G.K., Kern, K., \& Seier, G. (2010) AlpinRiskGP - Abschätzung des derzeitigen und zukünftigen Gefährdungspotentials für Alpintouristen und Infrastruktur bedingt durch Gletscherrückgang und Permafrostveränderung im Großglockner-Pasterzengebiet (Hohe Tauern, Österreich). Endbericht von Start-Clim2009.F in StartClim2009: Anpassung an den Klimawandel: Beiträge zur Erstellung einer Anpassungsstrategie für Österreich. Online unter: http://www. startclim.at/fileadmin/user_upload/StartClim2009_reports/StC109F. pdf (letzter Zugriff: 25.05.2020).

Lippmann, H.C. (2016) Sommerfrische als Symbol- und Erlebnisraum bürgerlichen Lebensstils. Zur gesellschaftlichen Konstruktion touristischer ländlicher Räume. Dissertation, Technische Universität Berlin, Deutschland. Online unter: https://depositonce.tu-berlin.de/ bitstream/11303/5952/4/lippmann_hans_christian.pdf (letzter Zugriff: 25.05 .2020$)$.

Lise, W. \& Tol, R.S. (2002) Impact of climate on tourism demand. Climatic Change 55(4), 429-449. DOI: https://doi.org/ 10.1023/A:1020728021446

Loibl, W., Beck, A., Dorninger, M., Formayer, H., Gobiet, A. \& Schöner, W. (Hrsg.) (2007) reclip:more - research for climate protection: model run evaluation (Endbericht). ARC systems research $\mathrm{GmbH}$, Austrian Research Center (ARC), Wien, Österreich.

Löndahl, J., Massling, A., Pagels, J., Swietlicki, E., Vaclavik, E. \& Loft, S. (2007) Size-resolved respiratory-tract deposition of fine and ultrafine hydrophobix and hygroscopic aerosol particles during rest and exercise. Inhalation Toxicology 19(2), 109-116. DOI: https://doi. org/10.1080/08958370601051677

Lorenzo, S., Halliwill, J.R., Sawka, M.N. \& Minson, C.T. (2010) Heat acclimation improves exercise performance. Journal of Applied Physiology 109(4), 1140-1147. DOI: https://doi.org/10.1152/japplphysiol.00495.2010

Maddison, D. (2001) In search of warmer climates? The impact of climate change on flows of British tourists. Climatic Change 49(1-2), 193-208. DOI: https://doi.org/10.1023/A:1010742511380

Matzarakis, A. \& Amelung, B. (2008) Physiological equivalent temperature as indicator for impacts of climate change on thermal comfort of humans. In: Thomson, M.C., Garcia-Herrera, R. \& Beniston, M. (Hrsg.) Seasonal forecasts, climatic change and human health, S. 161-172. Springer, Dordrecht, Niederlande. DOI: https:// doi.org/10.1007/978-1-4020-6877-5 10

May, C. (2017) Tourismus auf dem Land: Sommerfrische 2.0. In: Eisenstein, B., Schmudde, R., Reif, J. \& Eilzer, C. (Hrsg.) Tourismusatlas Deutschland, S. 33-35. UVK, Konstanz, Deutschland.

Meili, M., Scheurer, K., Schipper, O. \& Holm, P. (2004) Dem Fischrückgang auf der Spur (Schlussbericht des Projektes Netzwerk Fischrückgang Schweiz - „Fischnetz“). Eidgenössische Anstalt für Wasserversorgung, Abwasserreinigung und Gewässerschutz (EAWAG), Dübendorf und Bundesamt für Umwelt, Wald und Landschaft (BUWAL), Bern, Schweiz. Online unter: http://www.fischnetz.ch/ 
content_d/publ/Publications/Kurz_Schlussbericht/schlussbericht_ deutsch.pdf (letzter Zugriff: 25.05.2020).

Melcher, A., Pletterbauer, F., Kremser, H. \& Schmutz, S. (2013) Temperaturansprüche und Auswirkungen des Klimawandels auf die Fischfauna in Flüssen und unterhalb von Seen. Österreichische Wasser- und Abfallwirtschaft 65(11-12), 408-417. DOI: https://doi. org/10.1007/s00506-013-0118-y

Miglbauer, E., Pfaffenbichler, P.C. \& Feilmayr, W. (2009) Kurzstudie Wirtschaftsfaktor Radfahren: die volkswirtschaftlichen Auswirkungen des Radverkehrs in Österreich. Bundesministerium für Landund Forstwirtschaft, Umwelt und Wasserwirtschaft (BMLFUW), Wien, Österreich. Online unter: https://www.bmlrt.gv.at/umwelt/ luft-laerm-verkehr/verkehr/radfahren/WirtschaftsfaktorRad.html (letzter Zugriff: 26.03.2020).

Moshammer, H., Prettenthaler, F., Damm, A., Hutter, H.P., Jiricka, A., Köberl, J., Neger, C., Pröbstl-Haider, U., Radlherr, M., Renoldner, K., Steiger, R., Wallner, P. \& Winkler, C. (2014) Gesundheit und Tourismus. In: APCC (2014) Österreichischer Sachstandsbericht Klimawandel 2014 (AAR14), S. 933-977. Austrian Panel on Climate Change (APCC), Verlag der Österreichischen Akademie der Wissenschaften (ÖAW), Wien, Österreich. Online unter: http://www.austriaca.at/APCC_AAR2014.pdf (letzter Zugriff: 25.05.2020).

Müller, H. \& Weber, F. (2008) 2030: Der Schweizer Tourismus im Klimawandel. Im Auftrag von Schweiz Tourismus. Forschungsinstitut für Freizeit und Tourismus der Universität Bern, Schweiz. Online unter: https://www.qualitaet-gr.ch/uploads/files/204_08a_01_bericht_klimaschutz_d.pdf (letzter Zugriff: 25.05.2020).

Müller, M. \& Job, H. (2009) Managing natural disturbance in protected areas: tourist's attitude towards the bark beetle in a German national park. Biological Conservation 142(2), 375-383. DOI: https://doi. org/10.1016/j.biocon.2008.10.037

Nationalparks Austria (2016) Neue Studie zum Urlaubsverhalten der Österreicher: Erholung in der Natur unangefochtene Nummer eins. Verein Nationalparks Austria, Hardegg, Österreich. Online unter: https://www.nationalparksaustria.at/fileadmin/neu/PM_NationalparksAustria_StudieErholung_April2016_final.pdf (letzter Zugriff: 23.01.2019).

Needham, M.D. \& Vaske, J.J. (2013) Activity substitutability and degree of specialization among deer and elk hunters in multiple states. Leisure Sciences 35(3), 235-255. DOI: https://doi.org/10.1080/014 90400.2013 .780513

Needham, M.D., Scott, D. \& Vaske, J.J. (2013) Recreation specialization and related concepts in leisure research. Leisure Sciences 35(3), 199202. DOI: https://doi.org/10.1080/01490400.2013.780457

Neururer, H. (2013) Aktuelle Hinweise für umweltschonende GolfplatzPflege im Jahre 2013. Erstellt von Univ. Prof. Dr. Hans Neururer auf Ersuchen des Österreichischen Golfverbandes und der Österreichischen Arbeitsgemeinschaft für integrierten Pflanzenschutz. Online unter: http://www.oeaip.at/fileadmin/user_upload/PDF_Dateien/ Pflanzenschutz_allg/Golfverband_Hinweise_2013.pdf (letzter Zugriff: 08.01.2020).

Niedermair, M., Lexer, M.J., Plattner, G., Formayer, H. \& Seidl, R. (2008) Klimawandel und Artenvielfalt: wie klimafit sind Österreichs Wälder, Flüsse und Alpenlandschaften? Österreichische Bundesforste AG (ÖBf), Purkersdorf, Österreich. Online unter: https://www. bundesforste.at/fileadmin/publikationen/studien/Klimastudie_WWF. pdf (letzter Zugriff: 25.05.2020).

O'Connor, M.C. (2015) The unholy alliance of climate change and paragliding in the Alps. Vice Media LLC, New York City, NY, USA. Online unter: https://www.vice.com/en_us/article/aemx35/ the-unholy-alliance-of-climate-change-and-paragliding-in-the-alps (letzter Zugriff: 22.10.2019).

ÖAMTC (2019) E-Mountainbikes voll im Trend. Österreichischer Automobil-, Motorrad- und Touringclub (ÖAMTC), Wien, Österreich. Online unter: https://www.oeamtc.at/thema/fahrrad/e-bikes-pe- delecs/e-mountainbikes-voll-im-trend-25326636 (letzter Zugriff: 23.01.2019).

ÖAV (2015) Hüttenbilanz: Rekordsommer und große Herausforderungen. Österreichischer Alpenverein (ÖAV), Innsbruck, Österreich. Online unter: https://www.alpenverein.at/portal/news/aktuelle_ news/2015/2015_09_30_alpenvereinshuetten-saisonbilanz.php̄ (letzter Zugriff: $2 \overline{3} .01 . \overline{2} 019$ ).

ÖAV (2017) Statistik: Mitgliederzahlen des Alpenvereins. Österreichischer Alpenverein (ÖAV), Innsbruck, Österreich. Online unter: https:// www.alpenverein.at/portal/news/aktuelle_news/2017/2017_02_09_ mitgliederstatistik-2016-begeisterung-fuer-den-alpenverein-haeltan.php (letzter Zugriff: 04.05.2019)

ORF (2018) Tierärzte warnen vor gefährlicher Blaualge (Artikel vom 31.07.2018). Österreichischer Rundfunk (ORF), Wien, Österreich. Online unter: https://salzburg.orf.at/news/stories/2927428/ (letzter Zugriff: 23.01.2019).

ÖROK Atlas (2015) Schutzgebiete in Österreich: Anteil der Schutzflächen an der Gesamtflächen. Geschäftsstelle der Österreichischen Raumordnungskonferenz (ÖROK), Wien. Online unter: https:// www.oerok-atlas.at/oerok/files/summaries/64.pdf (letzter Zugriff: 24.07.2019).

Österreich Werbung (2011) Jahresbericht 2011. Österreich Werbung, Wien, Österreich. Online unter: https://www.austriatourism.com/ fileadmin/user_upload/Media_Library/Downloads/Presse/Jahresberichte/oew_jahresbericht_2011.pdf (letzter Zugriff: 05.11.2019).

Österreich Werbung \& Fachverband Seilbahnen WKO (2018) Studie: Psychologie eines Sommerurlaubs in den Bergen. Österreich Werbung Tourismusforschung \& Data Analytics und Wirtschaftskammer Österreich (WKO), Fachverband Seilbahnen, Wien, Österreich. Online unter: https://www.wko.at/Content.Node/kampagnen/Sommerbergbahnen/studie-psychologie-sommerurlaub-in-den-bergen.pdf (letzter Zugriff: 23.01.2019).

Österreich Werbung (2018a) Sommeraussichten 2018. Österreich Werbung, Wien, Österreich. Online unter: https://www.austriatourism. com/tourismusforschung/studien-und-berichte/sommeraussichten-2018/ (letzter Zugriff: 23.01.2019).

Österreich Werbung (2018b) Sommersaison 2018: bestes Sommernächtigungsergebnis seit 1992 mit 76,7 Mio. Übernachtungen (+2,3\% NÄ); 24,67 Mio. Ankünfte (+3,1\% AN). Österreich Werbung, Wien, Österreich. Online unter: https://www.austriatourism. com/fileadmin/user_upload/Media_Library/Downloads/Tourismusforschung/2018G_Sommersaison_Naechtigungsstatistik_Hochrechnung_ZusFass.pdf (letzter Zugriff: 09.07.2019).

Österreich Werbung (2018c) Sommertourismus profitiert vom weltweiten Wirtschaftswachstum. Österreich Werbung, Wien, Österreich. Online unter: https://www.austriatourism.com/presse/sommertourismusprofitiert-vom-weltweiten-wirtschaftswachstum/ (letzter Zugriff: 06.11.2019).

Österreich Werbung (2018d) Ausgaben der Gäste in Österreich. T-MONA Urlauberbefragung 2018. Zur Verfügung gestellt von Österreich Werbung, Wien, Österreich.

Österreich Werbung (2019) Ausgaben der Gäste in Österreich. T-MONA Urlauberbefragung 2019. Zur Verfügung gestellt von Österreich Werbung, Wien, Österreich.

Patek, M. (2007) Klimawandel und Naturgefahren. Ländlicher Raum Jahrg. 2007, 1-29. Bundesministerium für Land- und Forstwirtschaft, Umwelt und Wasserwirtschaft (BMLFUW), Wien, Österreich. Online unter: https://www.bmnt.gv.at/dam/jcr:705978fd74ca-4bba-938b-79f704065978/Patek_pdf_END.pdf(letzter Zugriff: 26.05.2020).

Pechlaner, H., Demetz, M. \& Scuttari, A. (2015) Alpine biking tourism: the future of cycling tourism in the Alps. Eurac Research, Institute for Regional Development and Location Management, Bozen, Italien. Online unter: https://www.yumpu.com/en/document/ view/53712153/alpnet-eurac-cyclealps-finalpdf (letzter Zugriff: 26.05.2020). 
Perry, A. (2000) Impacts of climate change on tourism in the Mediterranean: adaptive responses. FEEM Working Paper, No. 35.00. DOI: https://doi.org/10.2139/ssrn.235082

Piskuta, A., Fiala, D., Laschewski, G., Jendritzky, G., Richards, M., Blazejczyk, K., Mekavič, I., Rintamäki, H., de Dear, R. \& Havenith, G. (2012) Validation of the Fiala multi-node thermophyiological model for utci application. International Journal of Biometeorology 56(3), 443-460. DOI: https://doi.org/10.1007/s00484-011-0450-5

Pröbstl, U. (2011) Tourismus, Natur und Klimawandel: Herausforderungen durch den Klimawandel für naturtouristische Angebote. Natur und Landschaft 86(12), 534-535. DOI: https://doi. org/10.17433/12.2011.50153132.534-538

Pröbstl, U. \& Damm, B. (2009) Wahrnehmung und Bewertung von Naturgefahren als Folge von Gletscherschwund und Permafrostdegradation in Tourismus-Destinationen am Beispiel des Tuxer Tals (Zillertaler Alpen/Österreich). Endbericht von Start-Clim2008.F in StartClim2008: Anpassung an den Klimawandel in Österreich. Online unter: http://www.startclim.at/fileadmin/user upload/reports/ StC108F.pdf (letzter Zugriff: 26.05.2020).

Pröbstl-Haider, U. \& Haider, W. (2013) Tools for measuring the intention for adapting to climate change by winter tourists: some thoughts on consumer behavior research and an empirical example. Tourism Review 68(2), 44-55. DOI: https://doi.org/10.1108/TR-04-2013-0015

Pröbstl-Haider, U. \& Haider, W. (2014) The role or protected areas in destination choice in the European Alps. Zeitschrift für Wirtschaftsgeographie 58(2), 144-163. DOI: https://doi.org/10.1515/ zfw.2014.0010

Pröbstl-Haider, U. \& Melzer, V. (2015) Witterungsunabhängige Tourismusangebote basierend auf Naturerlebnisangeboten - Bedeutung und innovative Entwicklungen. Endbericht von StartClim2014.E in StartClim2014: Beiträge zur Umsetzung der österreichischen Anpassungsstrategie. Online unter: http://www.startclim.at/fileadmin/ user_upload/StartClim2014_reports/StCl2014E_lang.pdf (letzter Zugriff: 26.05.2020).

Pröbstl, U. \& Müller, F. (2012) Hotel certification and its relevance for sustainable development: examples from the European Alps. In: Pineda, F.D. \& Brebbia, C.A. (Hrsg.) Sustainable Tourism V, S. 3-15. WIT Press, Ashurst, Vereinigtes Königreich. DOI: https:// doi.org/10.2495/ST120011

Pröbstl-Haider, U. \& Pütz, M. (2016) Large-scale protected areas and tourism in the Alps under climate change. Natur und Landschaft 91(1), 15-19. DOI: https://doi.org/10.17433/1.2016.50153375.15-19

Pröbstl, U., Jiricka, A., Schauppenlehner, T., Haider, W. \& Formayer, H. (2007) See-Vision: Einfluss von klimawandelbedingten Wasserschwankungen im Neusiedler See auf die Wahrnehmung und das Verhalten von Besucherinnen und Besuchern. Endbericht von StartClim2006.D3 in StartClim2006: Klimawandel und Gesundheit, Tourismus, Energie. Online unter: http://www.startclim.at/fileadmin/ user upload/reports/StCl06D3.pdf (letzter Zugriff: 26.05.2020).

Pröbstl, U., Haider, W., Hägeli, P. \& Rupf, R. (2011) Klimawandel und Bergtourismus. In: Bieger, T., Beritelli, P. \& Laesser, C. (Hrsg.) Wandel als Chance für den alpinen Tourismus: Schweizer Jahrbuch für Tourismus 2011, S. 83-92. ESV, Berlin, Deutschland.

Pröbstl, U., Greil, K. \& Wirth, V. (2012) Summer tourism and climate change in the Alpine region: is a viagra-effect likely to happen? An overview on research findings from Austria. In: Kozsk, M. \& Kozsk, N. (Hrsg.) 6th World conference for graduate research in tourism, hospitality and leisure: proceedings book, S. 843-849. Detay Anatolia Akademik Yayıncılık Danışmanlık Org. Turz. Ltd. Şti., Ankara, Türkei. Online unter: https://anatoliajournal.com/gradconference/ wp-content/uploads/2017/10/2012gradconf-book.pdf (letzter Zugriff: 26.05 .2020$)$

Pröbstl-Haider, U., Wirth, V. \& Haider, W. (2014) Wie viel „Natur“ suchen deutsche Urlauberinnen und Urlauber in den Alpen? Eine Quellgebietsstudie bezogen auf den Sommertourismus. Natur und Landschaft 1, 26-32. DOI: https://doi.org/10.17433/1.2014.50153252.26-32
Pröbstl-Haider, U., Kelemen-Finan, J., Haider, W., Schauppenlehner, T., Melzer, V. \& Mostegl, N. (2015) Will climate change influence the attractiveness of cultural landscapes in Austria? In: Pechlaner, H. \& Smeral, E. (Hrsg.) Tourism and leisure: current issues and perspectives of development, S. 355-370. Springer Gabler, Wiesbaden, Deutschland. DOI: https://doi.org/10.1007/978-3-658-06660-4_22

Pröbstl-Haider, U., Dabrowska, K. \& Haider, W. (2016) Risk perception and preferences of mountain tourists in light of glacial retreat and permafrost degradation in the Austrian Alps. Journal of Outdoor Recreation and Tourism 16, 66-78. DOI: https://doi.org/10.1016/j. jort.2016.02.002

Pröbstl-Haider, U., Lund-Durlacher, D., Antonschmidt, H. \& Hödl, C. (2017a) Mountain bike tourism in Austria and the Alpine region towards a sustainable model for multi-stakeholder product developmen. Journal of Sustainable Tourism 26(4), 567-582. DOI: https:// doi.org/10.1080/09669582.2017.1361428

Pröbstl-Haider, U., Haider, W. \& Mostegl, N. (2017b) Tourismus und Weinbau im Naturpark Südsteiermark in Österreich/Nature Park „Südsteiermark“, Austria: Tourism and Viniculture. In: Wagner, D., Mair, M., Stöckl, A. \& Dreyer, A. (Hrsg.) Kulinarischer Tourismus und Weintourismus, S. 145-156. Springer Gabler, Wiesbaden, Deutschland. DOI: https://doi.org/10.1007/978-3-658-13732-8_12

Pröbstl-Haider, U., Mostegl, N. \& Schlegel, A. (2018) Touristische Bedeutung des Wolfes. In: Hackländer, K. (Hrsg.) Der Wolf: im Spannungsfeld von Land- \& Forstwirtschaft, Jagd, Tourismus und Artenschutz. Leopold Stocker Verlag, Graz, Österreich.

Radlobby-Radtourismus (2016) 1. Österreichische Radreiseanalyse (Pilotprojekt). KondeorMarketinganalysenGmbH und Verein Radlobby Österreich, Wien, Österreich. Online unter: https://www.kondeor.at/fileadmin/berichte/PraesOeRRAITB.pdf (letzter Zugriff: 14.02.2019).

Rodriguez Diaz, J.A., Knox, J.W. \& Weatherhead, E.K. (2007) Competing demands for irrigation water: golf and agriculture in Spain. Irrigation and Drainage 56(5), 541-549. DOI: https://doi.org/10.1002/ ird. 317

Rösing, J. (2018) Gesundheitstouristisches Potenzial heilklimatischer Kurorte. Masterarbeit am Institut Gesundheits- und Tourismusmanagement, FH JOANNEUM, Bad Gleichenberg, Österreich.

Ross, M., Abbiss, C., Laursen, P., Martin, D. \& Burke, L. (2013) Precooling methods and their effects on athletic performance: a systematic review and practical applications. Sports Medicine 43(3), 207-225. DOI: https://doi.org/10.1007/s40279-012-0014-9

Rottenberg, T. (2016) Das neue Skifahren (Artikel vom 01.03.2016). STANDARD Verlagsgesellschaft m.b.H., Wien, Österreich. Online unter https://derstandard.at/2000031798426/Das-neue-Skifahren (letzter Zugriff: 04.05.2019).

Rudel, E., Matzarakis, A., Koch, E., Endler, C. \& Neumcke, R. (2007) Sommertourismus in Österreich unter den Aspekten des Klimawandels. Zentralanstalt für Meteorologie und Geodynamik, Wien, Österreich und Meteorologisches Institut, Universität Freiburg, Deutschland. Online unter: https://www.researchgate.net/publication/267692137_Sommertourismus_in_Osterreich_unter_den_Aspekten_des_Klimawandels (letzter Zugriff: 28.05.2020).

Schamel, J. \& Job, H. (2017) National parks and demographic change: modelling the effects of ageing hikers on mountain landscape intraarea accessibility. Landscape and Urban Planning 163, 32-43. DOI: https://doi.org/10.1016/j.landurbplan.2017.03.001

Schmutz, S., Melcher, A., Matulla, C., Gerersdorfer, T., Haas, P. \& Formayer, H. (2004) Beurteilung der Auswirkungen möglicher Klimaänderungen auf die Fischfauna anhand ausgewählter Fließgewässer (Endbericht). Im Auftrag des Bundesministeriums für Land- und Forstwirtschaft, Umwelt und Wasserwirtschaft (BMLFUW), Abteilung V/4 Immissions- und Klimaschutz, Wien, Österreich. Online unter: https://imp.boku.ac.at/klima/Literatur/FishClim_Endbericht. pdf (letzter Zugriff: 28.05.2020). 
Schneider, I., Arnberger, A., Cottrell, S. \& Ruschkowski, E. (2019) Modeling impacts of bark beetle infestations on forest visitor experiences and intended displacement. Forest Science 65(5), 614-625. DOI: https://doi.org/10.1093/forsci/fxz021

Schubert, A. (2010) Klimawandel contra Flugsport. DHV-info 163, 34-35. Online unter: https://www.dhv.de/medien/dhv-info/dhv-info-2010/dhv-info-163/ (letzter Zugriff: 28.05.2020).

Scott, D. \& Jones, B. (2007) A regional comparison of the implications of climate change for the golf industry in Canada. The Canadian Geographer/Le Géographe canadién 51(2), 219-232. DOI: https:// doi.org/10.1111/j.1541-0064.2007.00175.x

Scott, D. \& Lemieux, C. (2010) Weather and climate information for tourism. Procedia Environmental Sciences 1, 146-183. DOI: https:// doi.org/10.1016/j.proenv.2010.09.011

Scott, D. \& McBoyle, G. (2001) Using a "tourism climate index" to examine the implications of climate change for climate as a tourism resource. In: Matzarakis, A. \& de Freitas, C.R. (Hrsg.) Proceedings of the first international workshop on climate, tourism and recreation, 69-88. International Society of Biometeorology (ISB), Commission on Climate, Tourism and Recreation. Online unter: https:// www.yumpu.com/en/document/view/4998614/proceedings-of-thefirst-international-workshop-on-climate-tourism- (letzter Zugriff: 28.05.2020).

Scott, D., McBoyle, G. \& Schwartzentruber, M. (2004) Climate change and the distribution of climatic resources for tourism in North America. Climate Research 27(2), 105-117. DOI: https://doi.org/10.3354/ cr027105

Scott, D., Rutty, M. \& Peister, C. (2018) Climate variability and water use on golf courses: optimization opportunities for a warmer future. Journal of Sustainable Tourism 26(8), 1453-1467. DOI: https://doi. org/10.1080/09669582.2018.1459629

Seilbahnen Österreich (o.J.) Sommer-Bergbahnen. Wirtschaftskammer Österreich (WKO), Wien, Österreich. Online unter: https://www. wko.at/Content.Node/kampagnen/Sommerbergbahnen/index. html\#sommerbergbahnen (letzter Zugriff: 28.05.2020).

Sloan, P., Simons-Kaufmann, C. \& Legrand, W. (2012) Sustainable hospitality and tourism as motors for development: case studies from developing regions of the world. Routledge, London, Vereinigtes Königreich.

Statistik Austria (2018) Sommersaison 2018 - Mai bis September: +2,9\% mehr Ankünfte, +2,2\% mehr Übernachtungen. Österreich Werbung, Wien, Österreich. Online unter: https://www.austriatourism.com/fileadmin/user_upload/Media_Library/Downloads/ Tourismusforschung/2018G_September_Hochrechnung_ZusFass. pdf (letzter Zugriff: 23.01.2019).

Statistik Austria (2019) Tourismus. Bundesanstalt Statistik Österreich, Wien, Österreich. Online unter: https://www.statistik.at/ web_de/statistiken/wirtschaft/tourismus/index.html (letzter Zugriff: 24.10.2019).

Tussyadiah, I.P. (2013) Towards a theoretical foundation experience design in tourism. Journal of Travel Research 53(5), 543-564. DOI: https://doi.org/10.1177/0047287513513172

Veit, H. (2002) Die Alpen: Geoökologie und Landschaftsentwicklung. Ulmer, Stuttgart, Deutschland.

Voß, B. \& Thörner, G.W. (o.J.) Der Klimawandel und seine Auswirkungen auf unsere Golfplätze. Golf Club Hubbelrath/Land und Golf Club Düsseldorf e. V., Düsseldorf, Deutschland. Online unter: https://www.gc-hubbelrath.de/plaetze/greenkeepers-corner/der-klimawandel-und-seine-auswirkungen-auf-unsere-golfplaetze/ (letzter Zugriff: 23.01.2019).

Weber, F., Juschten, M., Fanninger, C., Brandenburg, C., Jiricka-Pürrer, A., Czachs, C. \& Unbehaun, W. (2018) "Sommerfrische" in times of climate change: a qualitative analysis of historical and recent perceptions of the term. In: Ohnmacht, T., Priskin, J. \& Stettler, J. (Hrsg.) Contemporary challenges of climate change, sustainable tourism consumption, and destination competitiveness, S. 7-23.
Emerald Publishing, Bingley, Vereinigtes Königreich. DOI: https:// doi.org/10.1108/S1871-317320180000015003

Wheeler, K. \& Nauright, J. (2006) A global perspective on the environmental impact of golf. Sport in Society 9(3), 427-443. DOI: https:// doi.org/10.1080/17430430600673449

WKO (2018) Tourismus und Freizeitwirtschaft in Zahlen: österreichische und internationale Tourismus- und Wirtschaftsdaten, 54. Ausgabe, Juni 2018. Wirtschaftskammer Österreich (WKO), Bundessparte Tourismus und Freizeitwirtschaft, Wien, Österreich. Online unter: https://www.wko.at/branchen/tourismus-freizeitwirtschaft/ tourismus-freizeitwirtschaft-in-zahlen-2018.pdf (letzter Zugriff: 28.05.2020).

ZAMG (o.J.a) Pflanzen- und Tierwelt. Zentralanstalt für Meteorologie und Geodynamik (ZAMG), Wien, Österreich. Online unter: https:// www.zamg.ac.at/cms/de/klima/informationsportal-klimawandel/ standpunkt/klimafolgen/pflanzen-und-tierwelt (letzter Zugriff: 23.01.2019).

ZAMG (o.J.b) Extremereignisse. Zentralanstalt für Meteorologie und Geodynamik (ZAMG), Wien, Österreich. Online unter: https://www. zamg.ac.at/cms/de/klima/informationsportal-klimawandel/klimazukunft/europa/extremereignisse (letzter Zugriff: 23.01.2019).

ZAMG (o.J.c) Zukunft. Zentralanstalt für Meteorologie und Geodynamik (ZAMG), Wien, Österreich. Online unter: https://www.zamg. ac.at/cms/de/klima/informationsportal-klimawandel/standpunkt/ klimafolgen/gebirgsgletscher/zukunft (letzter Zugriff: 23.01.2019).

Zebisch, M., Grothmann, T., Schröter, D., Hasse, C., Fritsch, U. \& Cramer, W. (2005) Klimawandel in Deutschland: Vulnerabilität und Anpassungsstrategien klimasensitiver Systeme. Umweltbundesamt, Dessau, Deutschland. Online unter: https://www.umweltbundesamt. de/sites/default/files/medien/publikation/long/2947.pdf (letzter Zugriff: 28.05.2020).

Zeilner, F. (2007) Kanusport: Wettkampf \& Freizeitsport. Freya-Verlag, Linz, Österreich. Online unter: https://www.dshs-koeln.de/fileadmin/ redaktion/Institute/ZBSport/E-Books/kanusport_wettkampf_und freizeitsport.pdf (letzter Zugriff: 28.05.2020).

Zukunftsinstitut (2011) Leisure travel: Tourismus der Zukunft. Zukunftsinstitut $\mathrm{GmbH}$, Frankfurt am Main, Deutschland. Online unter: https://www.zukunftsinstitut.de/artikel/tourismus/leisure-travel-tourismus-der-zukunft/ (letzter Zugriff: 23.01.2019). 
Open Access Dieses Buch wird unter der Creative Commons Namensnennung 4.0 International Lizenz (http://creativecommons.org/licenses/by/4.0/deed.de) veröffentlicht, welche die Nutzung, Vervielfältigung, Bearbeitung, Verbreitung und Wiedergabe in jeglichem Medium und Format erlaubt, sofern Sie den/die ursprünglichen Autor(en) und die Quelle ordnungsgemäß nennen, einen Link zur Creative Commons Lizenz beifügen und angeben, ob Änderungen vorgenommen wurden.

Die in diesem Buch enthaltenen Bilder und sonstiges Drittmaterial unterliegen ebenfalls der genannten Creative Commons Lizenz, sofern sich aus der Abbildungslegende nichts anderes ergibt. Sofern das betreffende Material nicht unter der genannten Creative Commons Lizenz steht und die betreffende Handlung nicht nach gesetzlichen Vorschriften erlaubt ist, ist für die oben aufgeführten Weiterverwendungen des Materials die Einwilligung des jeweiligen Rechteinhabers einzuholen. 